\title{
Detection of subsurface anomalies in composite bridge decks using infrared thermography
}

\author{
Hasan Moh'd Alqennah \\ West Virginia University
}

Follow this and additional works at: https://researchrepository.wvu.edu/etd

\section{Recommended Citation}

Alqennah, Hasan Moh'd, "Detection of subsurface anomalies in composite bridge decks using infrared thermography" (2000). Graduate Theses, Dissertations, and Problem Reports. 1100.

https://researchrepository.wvu.edu/etd/1100

This Thesis is protected by copyright and/or related rights. It has been brought to you by the The Research Repository @ WVU with permission from the rights-holder(s). You are free to use this Thesis in any way that is permitted by the copyright and related rights legislation that applies to your use. For other uses you must obtain permission from the rights-holder(s) directly, unless additional rights are indicated by a Creative Commons license in the record and/ or on the work itself. This Thesis has been accepted for inclusion in WVU Graduate Theses, Dissertations, and Problem Reports collection by an authorized administrator of The Research Repository @ WVU. For more information, please contact researchrepository@mail.wvu.edu. 


\title{
DETECTION OF SUBSURFACE ANOMALIES IN \\ COMPOSITE BRIDGE DECKS USING INFRARED THERMOGRAPHY
}

\author{
By \\ Hasan Alqennah \\ A THESIS \\ Submitted to \\ West Virginia University \\ In partial fulfillment of the requirements \\ for the degree of \\ Master of Science in Civil Engineering
}

\author{
Udaya Halabe, Ph.D., P.E., Chair \\ Hota GangaRao, Ph.D., P.E. \\ Hema Siriwardane, Ph.D., P.E.
}

Department of Civil and Environmental Engineering

\author{
Morgantown, West Virginia
}

2000

Keywords: Anomalies, Delamination, Debond, Infrared Thermography, Temperature differences 


\title{
ABSTRACT \\ DETECTION OF SUBSURFACE ANOMALIES IN COMPOSITE BRIDGE DECKS USING INFRARED THERMOGRAPHY
}

\author{
Hasan Alqennah
}

This document presents the findings of an experimental study on the use of Infrared Thermography for nondestructive evaluation of subsurface anomalies in composite bridge decks.

Composite bridge deck specimens were constructed in the laboratory with varying subsurface delamination conditions such as sizes, thicknesses and filler materials. These simulated delaminations were placed between the $3 / 8$ " thick wearing surface and the top of the fiber reinforced polymer (FRP) deck. The laboratory specimens were tested using the infrared imaging system. The infrared images from the delaminated specimens were compared with solid (undamaged) specimens to study the effect of subsurface anomalies (delaminations) on the infrared images under controlled laboratory conditions. In addition, several field tests were conducted using infrared thermography on the composite decks of two bridges (Wickwire Run and Laurel Lick) located in West Virginia. The field tests were used to detect subsurface delaminations and study the effect of environmental parameters on the infrared images. As an additional example, infrared testing was conducted to evaluate FRP wrapping and detect debonding between the FRP wrap and concrete columns on the Pond Creek Bridge in West Virginia.

This study shows that the infrared thermography technique can be used effectively for rapid evaluation of subsurface condition of composite bridge decks. The study also shows how the environmental conditions (e.g., shadow, oil spill, and angle of reflection of solar rays) can affect the output infrared images. 


\section{ACKNOWLEDGEMENT}

The author wishes to express his sincere gratitude to his research advisor and committee chairman, Dr. Udaya B. Halabe for his constant encouragement, guidance, and motivation during the course of this research. The author is also grateful to Dr. Hota V. S. GangaRao and Dr. Hema Siriwardane for serving on his thesis committee and providing valuable help in the completion of this research.

The author would like to thank Dr. Powsiri Klinkhachorn for his valuable support

in the completion of this research. Appreciation is also extended to everybody that I worked with or have known throughout my years of schooling at WVU.

I also would like to thank the Constructed Facilities Center at West Virginia University for funding this research as a part of a research grant from West Virginia Division of Highways (WVDOH). 


\section{Table of Contents}

$\underline{\text { Description }}$

Page No.

Chapter 1 Introduction...............................................1

1.1 Background.......................................................

1.2 Research Objectives................................................... 3

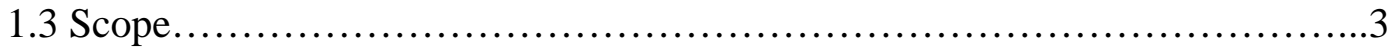

1.4 Organization.......................................................4

\section{Chapter 2- Review of Infrared Applications for Condition}

\section{Assessment of Composite Members .....................5}

2.1 Enhanced Thermographic Detection of Delamination with

Computational Pulse Shaping ..........................................5

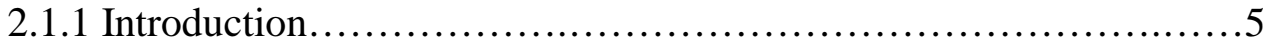

2.1.2 Specimen Description and Defects............................6

2.1.3 Type of Technique.......................................6

2.1.4 Results....................................................

2.1.5 Conclusion..................................................

2.2 Delamination Detection in Reinforced Concrete Using Thermal Inertia.........9

2.2.1 Introduction.............................................

2.2.2 Thermal Inertia Mapping.....................................11

2.2.3 Feasibility Study Using Surrogate Bridge Decks..................11

2.2.3.1 Type of Technique..................................11

2.2.3.2 Type and Size of Defect..............................12

2.2.3.3 Results.......................................... 12

2.2.4 Grass Valley Creek Bridge Inspections........................13

2.2.4.1 Type of Technique...................................13 
2.2.4.2 Type and Size of Defect................................13

2.2.4.3 Results.................................................... 14

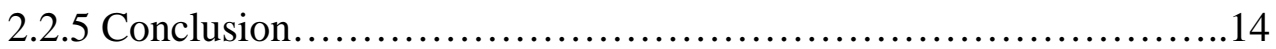

2.3 Thermal Nondestructive testing (TNDT) of Adhesively Bonded

Composite Reinforcements Applied to Concrete Civil Structure................16

2.3.1 Introduction.................................................. 16

2.3.2 TNDT Testing of a Concrete Column...............................18

2.3.2.1 Type of Technique.....................................18

2.3.2.2 Specimen.............................................. 18

2.3.2.3 Results................................................ 19

2.3.3 TNDT of a Naval Pier............................................. 20

2.3.3.1 Type of Technique....................................20

2.3.3.2 Tested Materials..........................................21

2.3.3.3 Results............................................. 21

2.3.3.3.1 Pultruded Graphite Fiber Rods.....................21

2.3.3.3.2 Pultruded Fiberglass I-Beams......................22

2.3.3.3.3 Pultruded Graphite Fiber Strips..................22

2.3.3.3.4 Laminated Graphic. Epoxy Fabric.................23

2.3.3.3.5 Laminated Vinyl Ester/ Fiberglass.................23

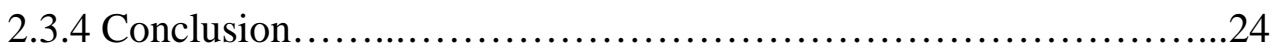

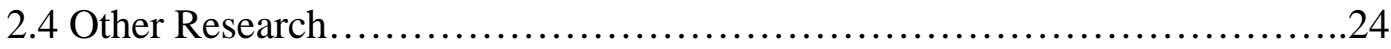

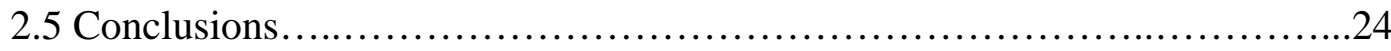

Chapter 3- Infrared Basics........................................26

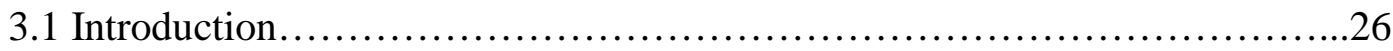

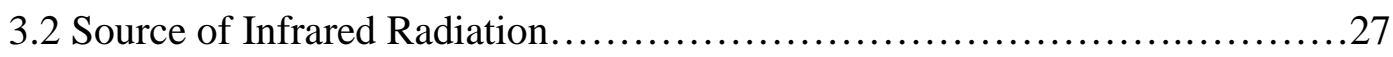

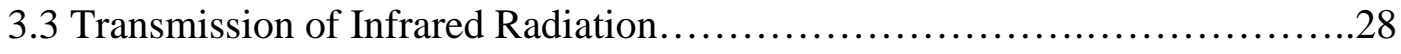

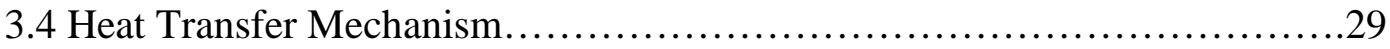

3.4.1 Radiation........................................................ 30

3.4.2 Conduction......................................................... 30 


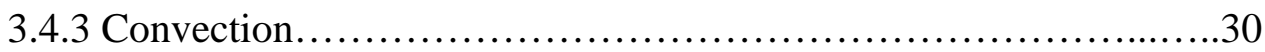

3.5 Detection of Infrared Radiation...............................................31

3.6 Application of Infrared Thermography to a Bridge Deck.......................32

Chapter 4- Laboratory Experiments.............................36

4.1 Experiment Set-Up.................................................. 36

4.1.1 Equipment Set-Up........................................... 36

4.1.2 Specimen Set-Up............................................. 38

4.1.2.1 Sample 1.............................................. 38

4.1.2.2 Sample 2................................................ 38

4.1.2.3 Sample 3 ...........................................39

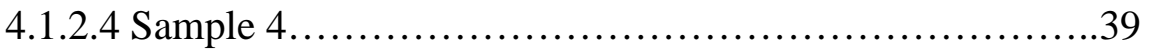

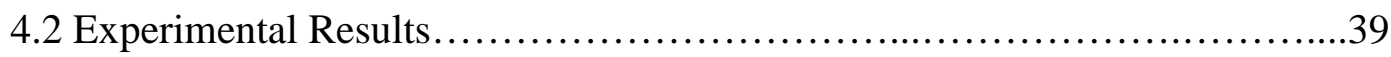

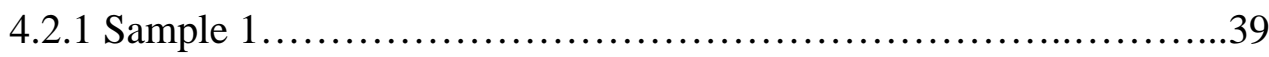

4.2.2 Sample 2 ....................................................... 40

4.2 .3 Sample 3 ....................................................... 41

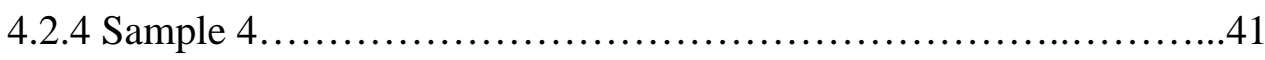

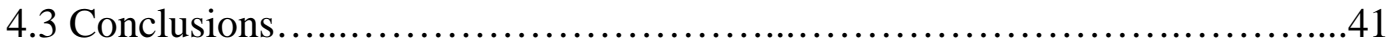

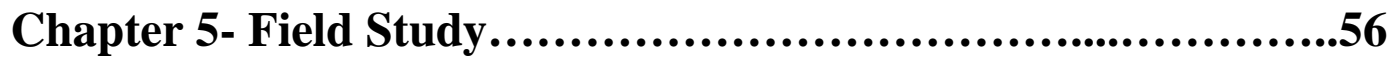

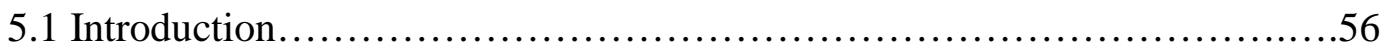

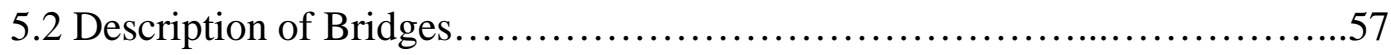

5.2.1 Laurel Lick Bridge ..............................................57

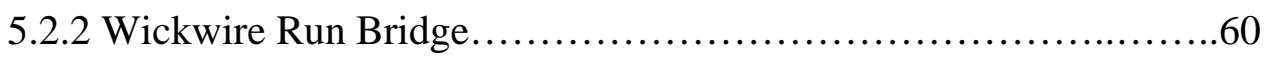

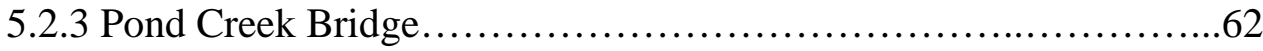

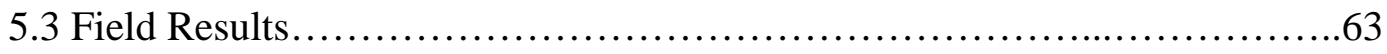

5.3.1 Equipment Set-up........................................63

5.3.2 Laurel Lick Bridge Deck........................................63

5.3.3 Wickwire Run Bridge deck......................................65 
5.3.4 Pond Creek Bridge Column....................................65

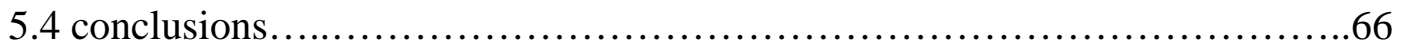

Chapter 6- Conclusions and Recommendations..................78

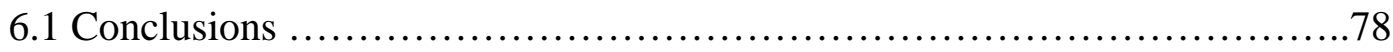

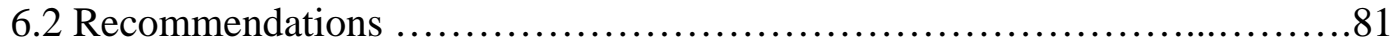

References.........................................................................83 


\section{List of Figures}

$\underline{\text { Description }}$

Page No.

2.1.1 Comparison of measured response and pulse shaped response

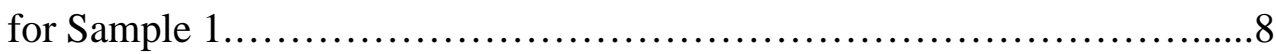

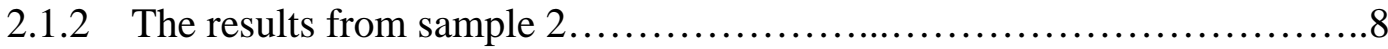

2.1.3 Comparison of measured response and pulse shaped response

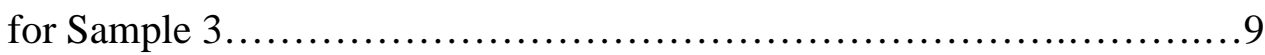

2.2.1 Grass Valley Greek bridge deck photo, LW temperature map, SW temperature map, and LW - SW clutter mask.....................15

2.2.2 Processed clutter mask, delamination site map, and damage size.............................................................

2.2.3 Bridge deck delamination map (3-D) and damaged bridge deck photo..........................................................

2.3.1 Column confinement configuration for the specimen...................19

2.3.2 Thermal image of a disbond in $1 / 2$ " thick fiber glass adhesively bonded to a concrete column.............................20

2.3.3 Thermal images of pultruded Graphite fiber strips....................22

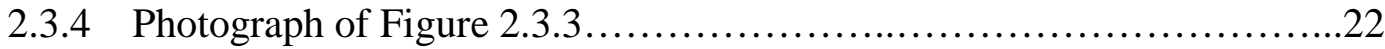

2.3.5 Thermal image of two disponds on the edges of pultruded Graphite fiber strips.........................................23

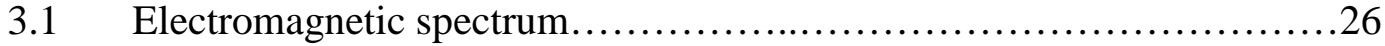

3.2 Variation of energy per interval of wavelength........................28

3.3 Atmospheric transmission of infrared radiation over one mile............29

3.4 Field data for temperature differences between solid and delaminated area in a bridge deck................................ 33

3.5 Effect of crack filler material on surface temperature differentials.........34

3.6 Effect of crack width on surface temperature differentials...................35

3.7 Effect of concrete cover thickness on surface temperature differentials....................................... 35

4.1 Photographs for the experimental set-up..........................43 
4.2 Specimen cross-section............................................ 44

4.3 Composite deck with built-in debonding (Sample 1)......................44

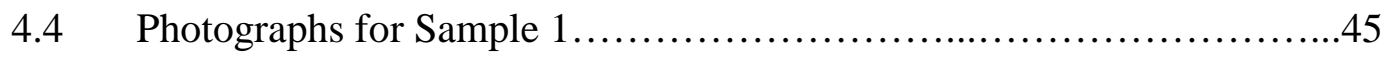

4.5 Composite deck with built-in delamination (Sample 2)...................46

4.6 Photograph for Sample 2 ............................................. 47

4.7 Composite deck with 11" x 7.5" x 0.05 " built-in delamination

(Sample 3) ......................................................... 48

4.8 Composite deck with two subsurface delaminations (Sample 4),..........49

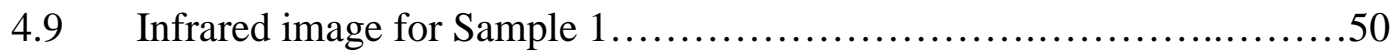

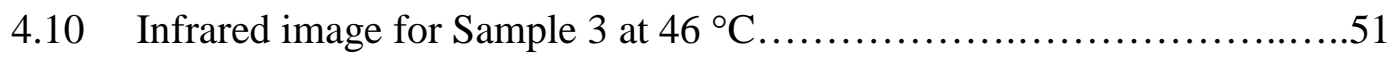

4.11 Infrared image for Sample 3 at $73{ }^{\circ} \mathrm{C}$ (viewed from

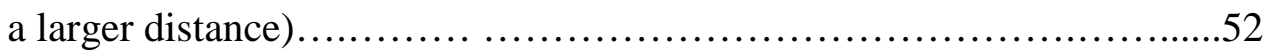

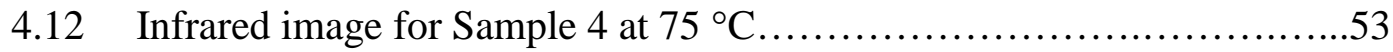

4.13 Infrared image for sample 4 at $71^{\circ} \mathrm{C}$ with more contrast

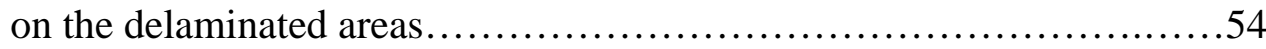

4.14 Infrared image for Sample 4 at $82{ }^{\circ} \mathrm{C}$ with the highest contrast

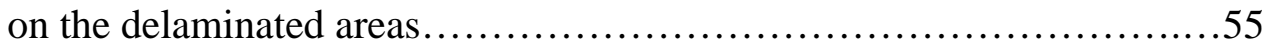

$5.1 \quad$ H-Deck pultruded components....................................57

5.2 Laurel Lick Bridge: Deck Cross-Section..................................58

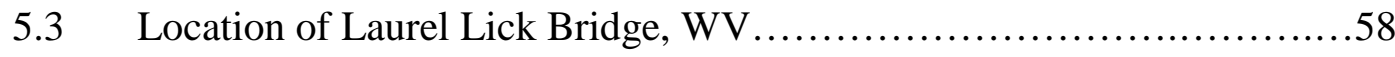

5.4 Photographs for Laurel Lick Bridge....................................59

5.5 Location of Wickwire Run Bridge, WV ...............................60

5.6 Photographs for Wickwire Run Bridge with the field test equipment set-up....................................................

$5.7 \quad$ Wickwire Run Bridge: Deck Cross-Section...........................62

5.8 Thermal image for Laurel Lick bridge deck..........................67

5.9 Photograph for Laurel Lick bridge guardrail............................68

5.10 Photograph for Laurel Lick bridge guardrail with the

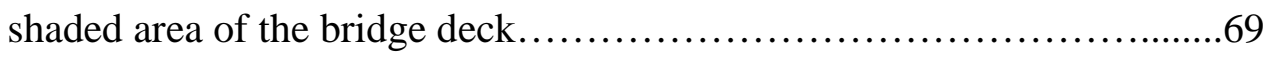

5.11 Thermal image for the shaded area of Laurel Lick bridge deck............70 
5.12 Thermal image for Laurel Lick bridge deck with surface irregularity...................................................... 71

5.13 Photograph and thermal image for Wickwire Run bridge deck - Surface Crack 1 .............................................72

5.14 Photograph and thermal image for Wickwire Run bridge deck - Surface Crack 2 ............................................73

5.15 Photograph and thermal image for Wickwire Run bridge deck - Surface Crack 3 .......................................... 74

5.16 Thermal image for Pond Creek bridge column - Location 1...............75

5.17 Thermal image for Pond Creek bridge column - Location 2 ...............76

5.18 Thermal image for Pond Creek bridge column - Location 3...............77 


\section{CHAPTER 1}

\section{INTRODUCTION}

\subsection{Background}

Transportation is an essential element for the economic well-being of our society. Transportation accounts for 17 percent of the gross national product and employs over 10 percent of the workforce (Garber and Hoel 1997). It is the responsibility of transportation engineers to develop high-quality transportation systems commensurate with the available funds and social policies.

According to USDOT, over $40 \%$ of the total number of bridges in the USA are classified as structurally deficient or functionally obsolete, with the estimated cost of repairs running into billions of dollars. One of the major reasons of deficient bridges is the deck deterioration (Dunker and Rabbat 1990). A conventional concrete deck has a high-rate of deterioration. Therefore, there is a need for a new material with lower deterioration rate.

Composite materials have proven to be very useful in rehabilitation of old structures. Some of their advantages over conventional materials are: (1) high strength and stiffness to weight ratio, (2) good fatigue resistance, and (3) low-rate of deterioration. For example, by replacing a concrete deck of an old bridge with a composite deck, the dead load of the bridge will be reduced by up to $80 \%$. Thus, the live load (the total weight 
of vehicles on the bridge) that can be carried by the same bridge can be increased, i.e., load rating can be enhanced greatly, without upgrading the columns and foundation.

Use of innovative bridge deck materials, like fiber reinforced polymer (FRP) composites, require new types of field testing and evaluation methods. Many nondestructive evaluation (NDE) techniques are being investigated to monitor composite structural members and study their behavior. Infrared thermography and ground penetrating radar (GPR) have been emerging as the more promising techniques.

The infrared technique uses an infrared camera to generate a temperature profile of the surface of the deck in the form of a color or black-and-white visual image. The subsurface defects affect the surface temperature because of their thermal conductivity differences, resulting in changes in the infrared picture or image. The GPR technique transmits electromagnetic waves through the thickness of the bridge deck, and the subsurface defects affect the echo signals. Both Infrared and GPR techniques can test (scan) large portions of a bridge deck in a relatively short time. However, GPR has a disadvantage in that the interpretation of radar signals is difficult. On the other hand, infrared thermography has an advantage of producing a real-time image that can be interpreted easily to evaluate the integrity of the structure.

While infrared thermography has been applied to concrete decks, its use for evaluation of composite structural members is relatively new, and very little information is available on the evaluation of composite decks with the infrared technique. Therefore, 
this research focuses on laboratory and field evaluation of composite decks using infrared thermography.

\subsection{Research Objectives}

The objectives for this research are to:

1. Conduct a literature review on the application of infrared thermography for monitoring composite structural members. The review includes an evaluation of the infrared thermography technique in terms of parameters of interest (type and size of defect), advantages and disadvantages, and application to field environment.

2. Study the effect of sub-surface anomalies (e.g., cracks, delaminations) on the infrared images by conducting experiments on composite bridge deck specimens under controlled laboratory conditions and compare the images from undamaged and delaminated areas in these specimens. The various composite deck specimens include different delamination sizes, thicknesses, and filler material.

3. Conduct infrared testing of two composite bridges in the field to detect subsurface delaminations and demonstrate the applicability of the infrared technique to field evaluation of composite structural members.

\subsection{Scope}

The scope of this research includes utilization of infrared thermal images generated for isolated anomalies under controlled laboratory conditions to study the capabilities and limitation of using infrared thermography for composite bridge deck 
condition assessment. The scope also includes field testing of two composite bridge decks in West Virginia, which are, Laurel Lick and Wickwire Run Bridges. The field testing was conducted to demonstrate the applicability of infrared thermography to evaluate composite bridge decks. Some field test results from FRP wrapped concrete columns of the Pond Creek Bridge have also been included as added example.

\subsection{Organization}

This document consists of six chapters. The first chapter gives a description of the problem and outlines the objectives and scope of this research. Chapter 2 presents a literature review on the application of infrared thermography to condition assessment of composite structural members. The chapter also includes concrete decks, where infrared technique has been applied in the past. The basic theory of infrared thermography is discussed in Chapter 3. This chapter also describes the features of an infrared scanner (camera) and its application to testing of composite bridge decks. Chapter 4 describes the experimental set-up including the infrared equipment and the laboratory specimens as well as the results obtained. Chapter 5 presents the field study including descriptions of the bridges and field results. The conclusions and recommendations for future research are presented in Chapter 6. 


\section{CHAPTER 2}

\section{REVIEW OF INFRARED APPLICATIONS FOR CONDITION ASSESMENT OF COMPOSITE MEMBERS}

This chapter presents a literature review on the application of infrared thermography to condition assessment of composite structural members. The chapter also includes concrete decks, where infrared technique has been applied in the past. The review includes an evaluation of the infrared thermography technique in terms of parameters of interest (type and size of defect), advantages and disadvantages, and application to field environment.

\subsection{Enhanced Thermographic Detection of Delamination with Computational Pulse Shaping (Winfree 1998)}

\subsubsection{Introduction}

In Thermal Nondestructive Testing (TNDT), radiative heaters such as flash or quartz lamps are used to heat the specimen. Then infrared images are collected from the specimen. This technique, also known as infrared thermography, has advantages over conventional contact temperature measurement technique. It can inspect a relatively large area in minutes. It can also inspect curved surfaces. The disadvantage of this technique is 
the lack of sensitivity to delaminations at depths greater than half the thickness of the specimen.

The sensitivity of the technique can be enhanced by tailoring the shape of the radiative heating (Winfree 1998). It is not possible to control the shape of the heat pulse by using the flash lamps. However, with quartz lamps, it is possible to change the duration of radiation heat, but difficult to vary its amplitude. However, controlling the heat amplitude can be achieved by applying negative heat (cooling the specimen).

\subsubsection{Specimen Description and Defects}

Three different composite samples were made with delaminations of different sizes and shapes. All the samples were $1 / 8 "(0.3 \mathrm{~cm})$ thick square plates, $12 "(30.5 \mathrm{~cm})$ on a side. Infrared images from both sides were taken before performing the test. Sample 1 had the largest delamination and Sample 3 had the smallest delamination.

\subsubsection{Type of Technique}

Two flash lamps were used to radiatively heat the surface. An infrared imager with a single scanned $\mathrm{HgCdTe}$ detector was used to acquire image of the surface radiation profile in the 8-12 $\mu \mathrm{m}$ range. The imager produced full field measurements at $30 \mathrm{~Hz}$. The output was video conforming to RS170 format. The image processor performed an 8 bit digitization of the video signal and real time averaging of the digitized data into 16 bit images. A computer synchronized the acquisition of the digitized data and the application of heat by the flash lamp (Winfree 1998). 
Since the thermal response of the composite is relatively slow, a $10 \mathrm{~Hz}$ sampling rate was achieved by averaging 2 images from the imager with additional 1/30 second needed for the recording. The average images were 256 by 256 pixel. A total of 64 images were recorded. The first stored imaged was the averaged input from the infrared imager immediately preceding the flash heating. This image served as the base line (background) for all subsequent measurements. The subsequent 63 stored images were the averaged output of the infrared imager following the flash heating. The resulting time record was approximately 6.4 seconds long. Before any processing, the base line image was subtracted from all the other images (Winfree 1998).

\subsubsection{Results}

For Sample 1, the images for both the measured response (i.e., before subtraction of the base line) and the pulse shaded response (i.e., after base line subtraction) were able to detect all delaminations as shown in Figure 2.1.1. For Sample 2 (see images shown in Figure 2.1.2), the pulse shaded response image was able to show all delaminations while the measured response image failed to show any delamination. Since the delaminations in

Sample 3 were very small, even the pulse shaded response image was able to show only some of the delaminations (see Figure 2.1.3).

\subsubsection{Conclusion}

Computational pulse shaping is an effective technique for increasing the contrast between flawed and unflawed regions in a specimen (Winfree 1998). The results show 
that subtraction of the base line measurement enhances the ability of the technique to detect flaws.

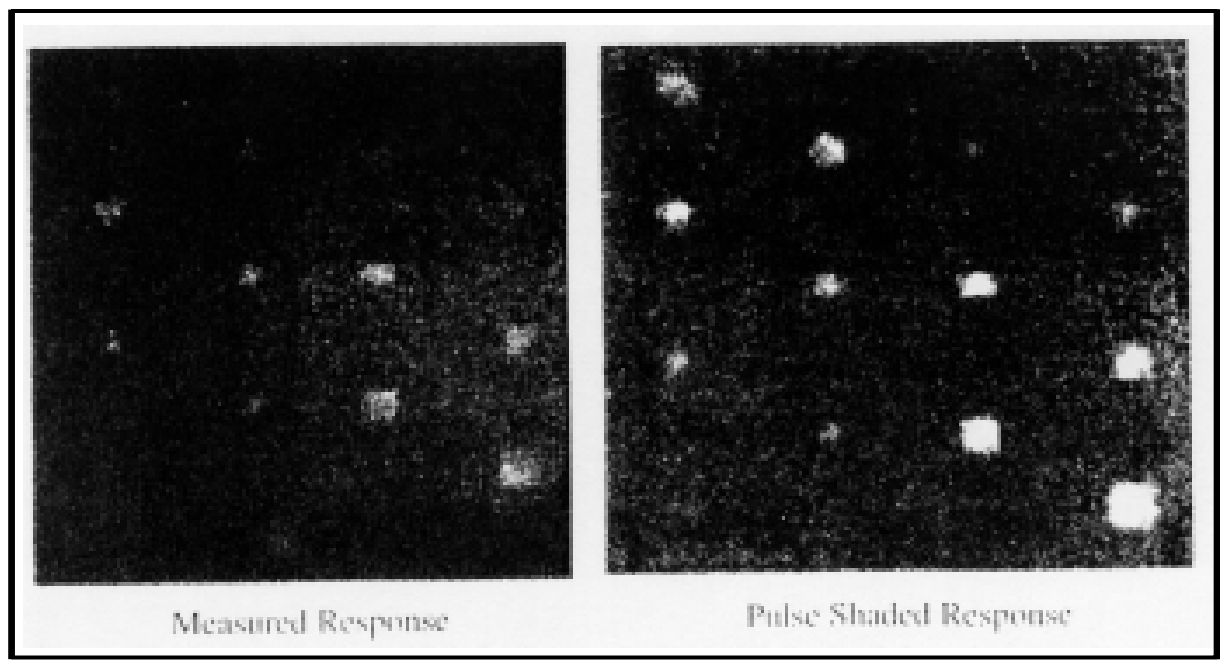

Figure 2.1.1: Comparison of measured response and pulse shaped response for Sample 1. Both images correspond to times with maximum contrast (Winfree 1998).

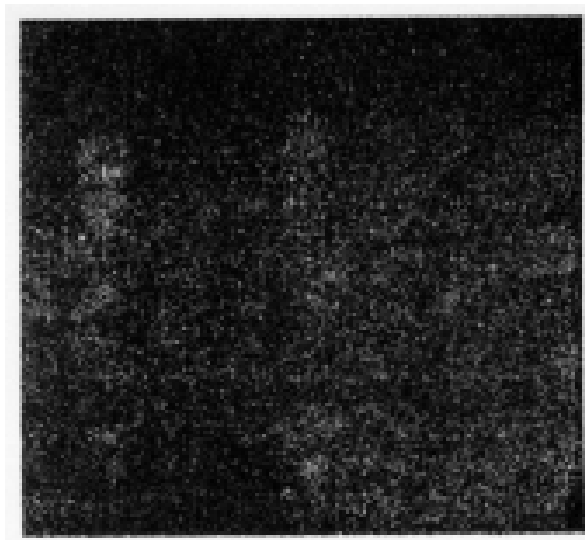

Measured Response

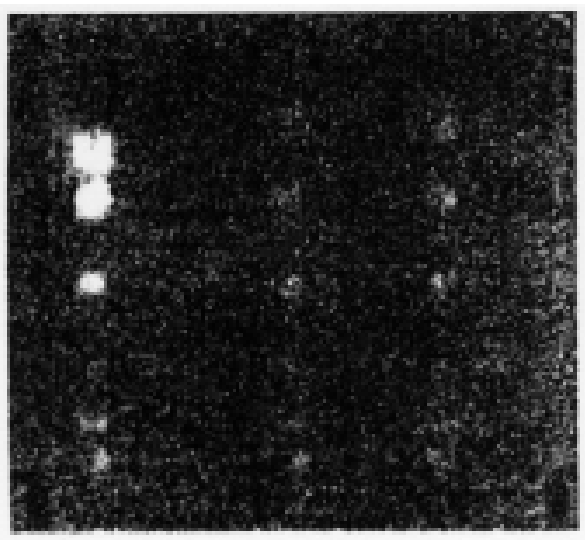

Pulse Shaded Response

Figure 2.1.2: The results from Sample 2. Both the images shown have the maximum contrast (Winfree 1998). 


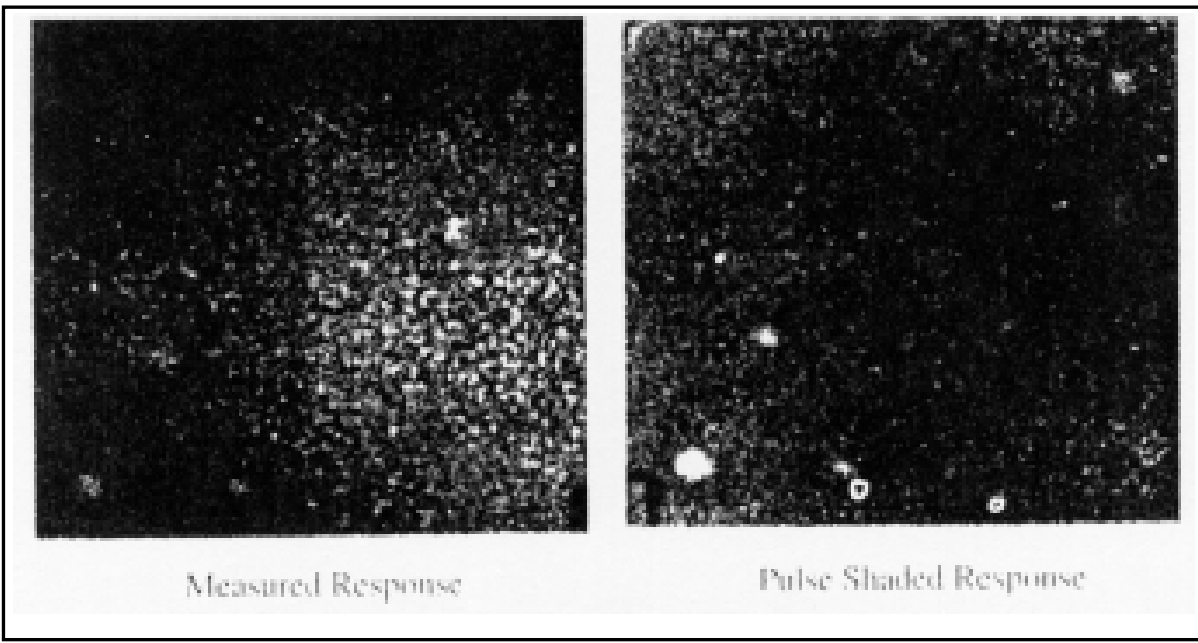

Figure 2.1.3: Comparison of measured response and pulse shaped response for Sample 3. Both images correspond to times with maximum contrast (Winfree 1998).

\subsection{Delamination Detection in Reinforced Concrete Using Thermal}

\section{Inertia (Del Grande and Durbin 1999)}

\subsubsection{Introduction}

Physically, thermal inertia is a measure of the resistance of the bridge deck to temperature change. Experimentally, it is determined from the inverse slope of the surface temperature versus the inverse square root of time. Mathematically, thermal inertia is computed as the square root of the product of thermal conductivity, density, and heat capacity (Del Grande and Durbin 1999). In order to locate and identify surface delaminations, it is necessary to remove the surface clutter or unwanted details on the infrared (IR) images. Foreign materials on the roadway, shadows, and reflected IR background often introduce clutter. Unlike the thermal signals produced by subsurface 
delamination, the clutter signals vary with IR wavelength. To take advantage of this phenomenon, a dual-band infrared (DBIR) thermal and thermal inertia imaging system can be used to acquire bridge deck data. By removing spatially varying emissivity noise, DBIR methods improve temperature accuracy and precision by an order of magnitude compared to single-band infrared (SBIR) methods. Also, DBIR methods provide emissivity-noise maps, which clarify interpretation of heat flow anomalies from subsurface features (e.g., under ground objects and structural deficiencies). Past applications of the DBIR imaging method has resulted in successful identification of (Del Grande and Durbin 1999):

- Geothermal Aquifers under 20' to 200' (6 to $60 \mathrm{~m}$ ) of dry soil

- Cemetery walls, trenches and a building foundation under $2^{\prime}-7 \frac{1}{2} 2^{\prime \prime}(80 \mathrm{~cm})$ of asphalt and debris

- Buried mines, rocks and objects under $3 / 8$ " to $8 "(1$ to $20 \mathrm{~cm})$ of disturbed sand, soil, or sod

- Airframe material loss from corrosion under $1 / 32 "(1 \mathrm{~mm})$ or $1 / 16 "(2 \mathrm{~mm})$ of exposed aluminum skin

- Synthetic bridge-deck delaminations, 2" $(5 \mathrm{~cm})$ and 4" $(10 \mathrm{~cm})$ deep, in concrete and asphalt-concrete slabs

- Bridge delaminations recorded from a mobile inspection laboratory and later confirmed by pavement removal 


\subsubsection{Thermal Inertia Mapping}

The rationale for thermal inertia mapping is based on the solution to the heat transfer equation for a thick target with an instantaneous surface heat flux, which is (Del Grande and Durbin 1999):

$$
T(x, t)=\frac{q}{\sqrt{4 \pi k \rho c t}} \exp \left(-\mathrm{x}^{2} / 4 \alpha t\right) \quad . . . . . .
$$

where $T$ is temperature, $x$ is depth beneath the surface, $k$ is thermal conductivity, $\rho$ is density, $c$ is heat capacity, $\alpha$ is thermal diffusivity, $t$ is time and $q$ is the surface heat flux. For a semi-infinite solid approximation, the surface temperature is inversely proportional to the square root of time and also inversely proportional to the thermal inertia, $\mathrm{P}$, which varies as $(k \rho c)^{1 / 2}$.

\subsubsection{Feasibility Study Using Surrogate Bridge Decks}

\subsubsection{Type of Technique}

Concrete and asphalt-concrete slabs, 6' $(1.8 \mathrm{~m})$ square by $7 \frac{1}{2} "$ " $(19 \mathrm{~cm})$ thick, were constructed. One of the slabs was paved with a 2" $(5 \mathrm{~cm})$ thick layer of asphalt. These slabs were used to compare solar-heated thermal maps with flash-heated thermal inertia maps to characterize surrogate delaminations in concrete and asphalt-concrete slabs. Different foreign objects were placed on the slabs, which produced surface clutter. Image-processing methods were developed to unmask synthetic delaminations and remove surface clutter. The temperature images were processed using the VIEW computer code developed at the Lawrence Livermore National Laboratory (LLNL). 
Emissivity-corrected surface temperature maps were developed to depict heat flow anomalies produced by surface delaminations and remove surface clutter. Clutter may occur from unseen chemical differences in concrete which respond differently at two IR wavelengths measured with the dual-scanner system. By mapping the DBIR image differences at 3-5 $\mu \mathrm{m}(\mathrm{SW})$, and 8-10 $\mu \mathrm{m}(\mathrm{LW})$, the foreign material clutter was identified and removed.

\subsubsection{Type and Size of Defect}

The synthetic delaminations consisted of 2" $(5 \mathrm{~cm})$ deep embedded pieces of Styrofoam cut to various square sizes and thicknesses. These pieces were placed at a depth of 2" $(5 \mathrm{~cm})$ in the unpaved concrete slab and 4" $(10 \mathrm{~cm})$ in the paved concrete slab. Objects were placed on the slab to produce surface scatter.

\subsubsection{Results}

A strong relationship between the defect volume and the temperature signal was discovered. The daytime (above-ambient) minus nighttime (below-ambient) IR temperature-difference signals varied linearly with the volume of the embedded Styrofoam pieces that resulted in the temperature differences (Del Grande and Durbin 1999). Bridges with large delamination volumes are expected to produce large daytime and nighttime temperature excursions. 


\subsubsection{Grass Valley Creek Bridge Inspections}

\subsubsection{Type of Technique}

For field inspections, a mobile DBIR thermal imaging laboratory was built. The unit consisted of Agema 900 dual scanners with $40^{\circ}$ lenses, and were mounted on a telescoping mast about 13' (4 m) above the roadway. The system controls, 12-bit digital image processor, and high-speed recording hard drives were housed inside the modified $27^{\prime}(8.2 \mathrm{~m})$ motor home. The mobile laboratory was driven at $25 \mathrm{mph}$ to acquire bridgedeck thermal images. Using thermal image analysis, the delaminations (concrete gaps) were distinguished from surface materials and clutter.

To distinguish delaminated decks from normal decks, decks with surface material differences, and clutter, the following parameters were determined: (1) size, shape, relative volume and location for the delamination sites; (2) thermal inertia (or daytime minus nighttime temperature differences) relative to ambient deck sites; (3) daytime and nighttime temperatures, relative to ambient deck sites; and (4) spectral (or LW - SW) image differences, relative to deck sites with surface material differences and clutter (Del Grande and Durbin 1999).

\subsubsection{Type and Size of Defect}

This test was conducted on Grass Valley Greek Bridge to detect and measure delaminations (concrete gaps) on the bridge deck and to distinguish these delaminations from shaded areas. 


\subsubsection{Results}

The delaminated site chosen for the analysis had an area of $8.2 \mathrm{ft}^{2}\left(0.76 \mathrm{~m}^{2}\right)$. Figure 2.2.1 compares a digital photo of the delamination site with short-wave (SW) and long-wave (LW) thermal images taken simultaneously with the video photo and a coregistered SW minus LW spectral difference image. Figure 2.2.2 shows the spectral difference image processed on the SGI work station as a mask to remove the nonthermal surface clutter in order to clarify the subsurface delamination sites. Figure 2.2.3 compares the predicted delamination site with "bridge truth" photography of the actual delamination site subsequent to pavement removal.

\subsubsection{Conclusion}

The distinction between defective deck sites and normal but cluttered deck sites (with foreign surface materials, shaded areas, etc.) could be made based on their respective spatial, spectral thermal, thermal inertia, emissivity, and temporal response (Del Grande and Durbin 1999). The DBIR method replaces human speculation about bridge deck emissivity behavior with spectral measurement. The method can determine the fractional area of the bridge deck that is delaminated, and can also locate and characterize the damaged regions. Flash-heated stationary system plays a big role in clarifying suspected delaminations by ruling out clutter from deck sites. 


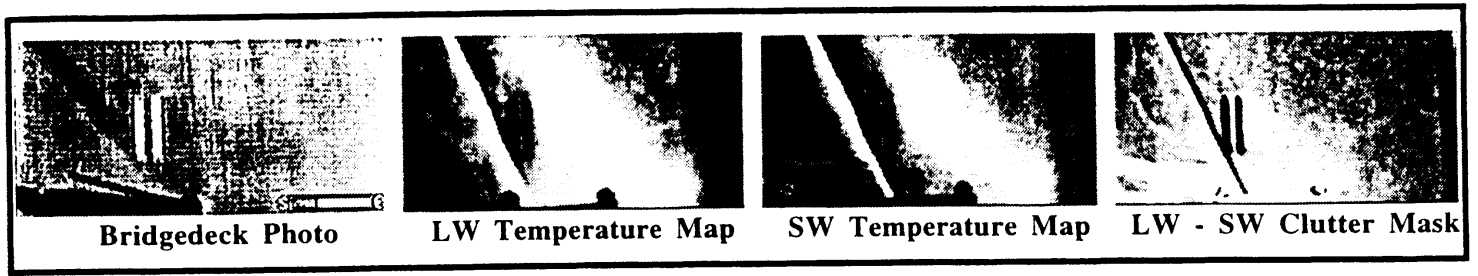

Figure 2.2.1: The digitized Grass Valley Greek bridgedeck photo (far left), unlike the daytime LW - SW clutter mask (far right) is not coregistered with the longwave (LW) and shortwave (SW) IR daytime temperature maps shown left and right of center (Del Grande and Durbin 1999).

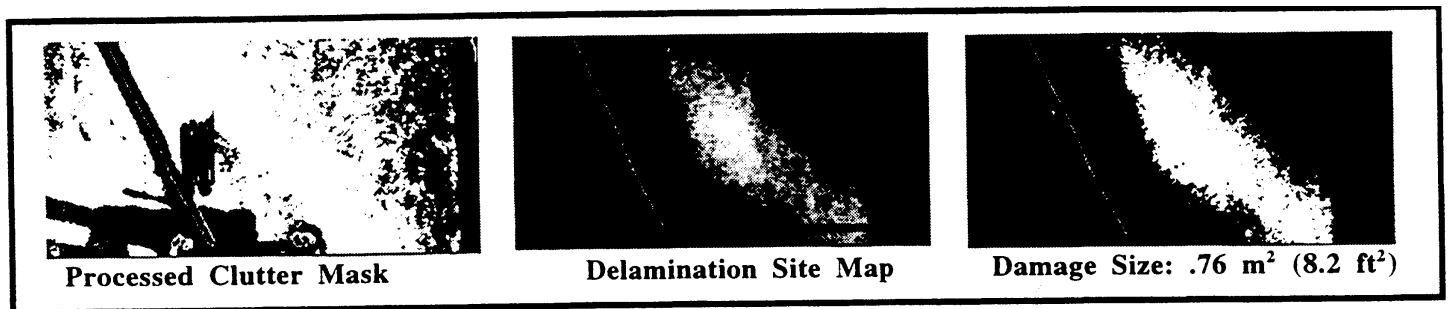

Figure 2.2.2: The processed clutter mask (left) removes clutter from the shortwave IR temperature map to depict the sub surface delamination site (center). The delamination size (right) is determined using a computer program which counts the number of the warmer-than- ambient pixels (picture elements) within the delamination site relative to the number of pixels for a known area (Del Grande and Durbin 1999). 


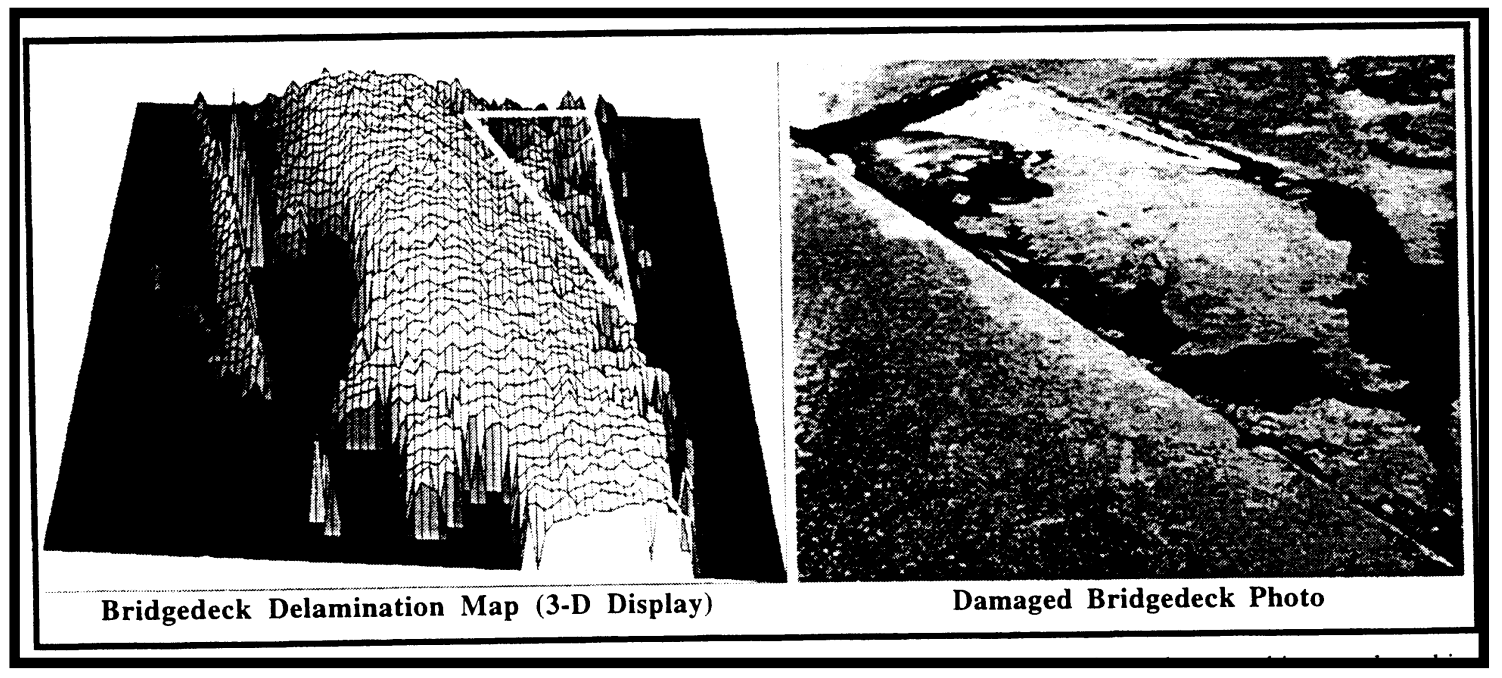

Figure 2.2.3: The bridgedeck delamination map (left) uses the $\mathrm{z}$ coordinate to display daytime above-ambient and ambient temperatures, respectively for delaminated and normal deck areas, such as shown within the white triangle. After removing the pavement above the "predicted" delamination, we discovered 0.12 cubic meters (4.2) cubic feet) of damaged concrete. The white triangle on the "bridge-truth" photo (right) coincided with the predicted undamaged deck site. Also, the scalloped edge of the damaged bridgedeck on the photo confirmed the predicted shape of damaged concrete on the bridge deck delamination map (Del Grande and Durbin 1999).

\title{
2.3 Thermal Nondestructive Testing (TNDT) of Adhesively Bonded
}

\section{Composite Reinforcements Applied to Concrete Civil Structure}

\author{
(Burleigh et al. 1999)
}

\subsubsection{Introduction}

Thermography or TNDT is a process of mapping the distribution of temperature on the surface (Burleigh et al. 1999). The infrared scanner provides a video image of the temperature distribution. The image is constructed of many thousands of pixels that represent the level of infrared energy radiating from a point on the surface. 
TNDT is generally conducted by applying a uniform heat pulse to the surface of the test material and thermographically monitoring the temperature distribution of that surface for a short time. The temperature distribution will change as the surface heats and cools. At a given instant, the surface temperature will remain uniform where the structure is free of delaminations. Surfaces with underlying disbonds or delaminations will warm up relative to the adjacent bonded areas since they lack contact with underlying material which acts as heat sinks in well-bonded material. Therefore, disbonds and delaminations appear in a thermographic image as a light area in a darker field.

There are many choices of test parameters and configurations for TNDT. The selection of a technique depends on the dimension of the part to be tested, the size (critical flow size) and type of defect sought, the thermal properties (specific heat, thermal conductivity, thermal diffusivity, thermal effusivity, density, etc.) and optical properties of the material to be inspected, whether one-sided or two-sided access is available, the type of thermographic camera used, and the heating options to be employed (Burleigh et al. 1999). The selection of a heating source depends on the requirements for the energy and duration of the heat pulse, the surface properties (e.g., emissivity) of the object, portability, power consumption, safety, cost, and availability. Some examples are hot air guns, Quartz lamps, Xenon flash lamps, hot or cold water, vortex tubes, liquid nitrogen, etc. The selection of the camera is based on requirements for spatial resolution, thermal resolution, speed (frame rate-measured in $\mathrm{Hz}$ ), wavelength sensitivity, selection of appropriate lenses, portability, cost, and availability. 


\subsubsection{TNDT Testing of A Concrete Column}

\subsubsection{Type of Technique}

An 18" x 24" rectangular reinforced concrete column was clad with adhesivelybonded fiberglass shells. The column was heated by an industrial heat gun (1500 Watt Master or equivalent) and a 1000 Watt quartz lamp. TNDT images were taken to locate the disbonded areas and to establish some testing standards.

\subsubsection{Specimen}

A steel reinforced concrete column that has rectangular cross section of 18 " x 24 " was fabricated. Layers of fiberglass shells were adhesively bonded to the concrete column to simulate a $40 \%$ scale seismic retrofit of a typical rectangular shear column. The composite jacket system comprised of eight "L" shaped shell components which were epoxy bonded in place around the concrete column creating an overlapping configuration. This provided a minimum of 2 shell thickness, or 0.30 ”, at any location. In areas where corner angles overlapped, the total thickness including bond line was approximately 0.60 " as shown in Figure 2.3.1. 


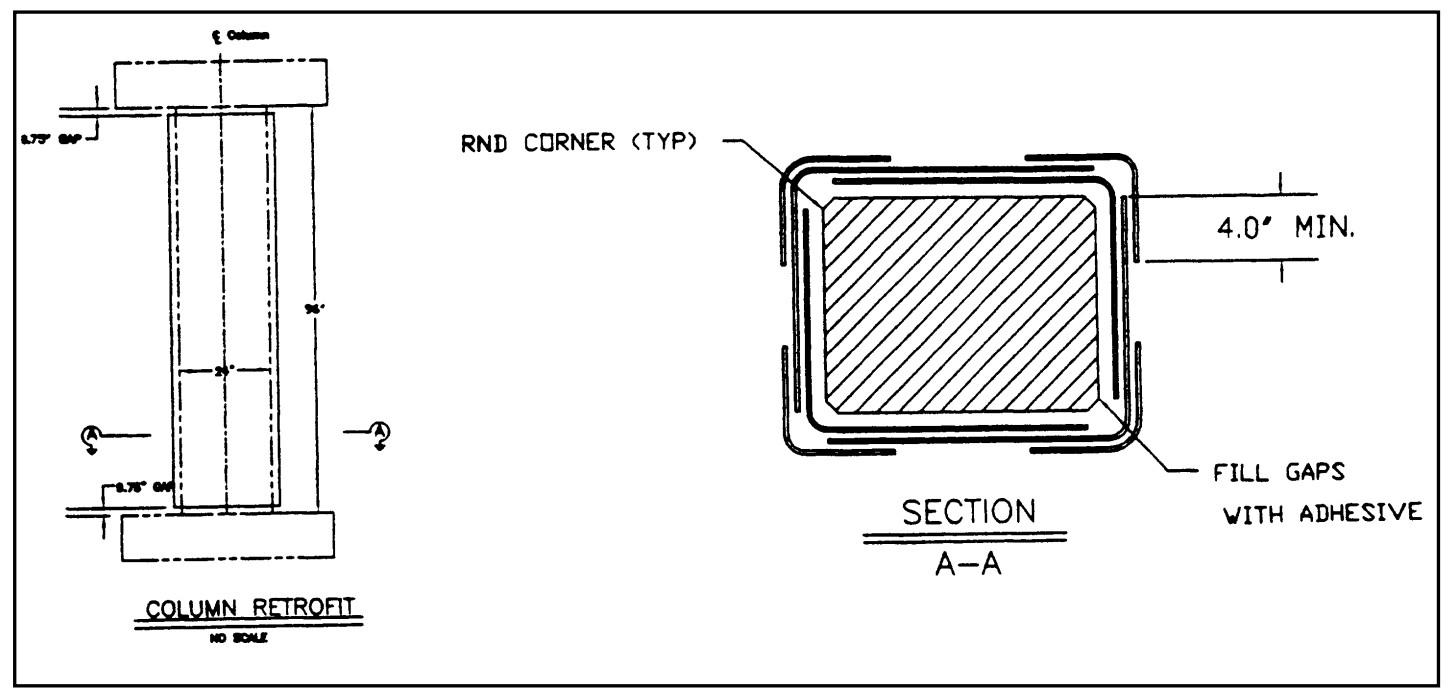

Figure 2.3.1: Column confinement configuration (Burleigh et al. 1999)

\subsubsection{Results}

While the heat gun method was found to be successful, its use was questionable specially for thick fiberglass plates that required deligence and control by the operator to provide a uniform heat input. The quartz lamp was successful as well. It was, however, accompanied by several safety constraints which make their use less attractive than the use of a heat gun.

Voids in adhesive layers were detected through two and three layers of $1 / 8$ " thick fiberglass with a layer of adhesive between each. The defective areas were tapped using a special hammer. This secondary test was consistent with the TNDT. Figure 2.3.2 shows the thermal image of a disbond approximately 6" long under the $1 / 2$ " thick fiberglass which was adhesively bonded to the column (Burleigh et al. 1999). The central vertical line identifies the free edge of the corner shell, and does not indicate a disbond. In all areas examined, the marked outlines showing the disbonds were accurate to $\pm 1 / 4$ ". 


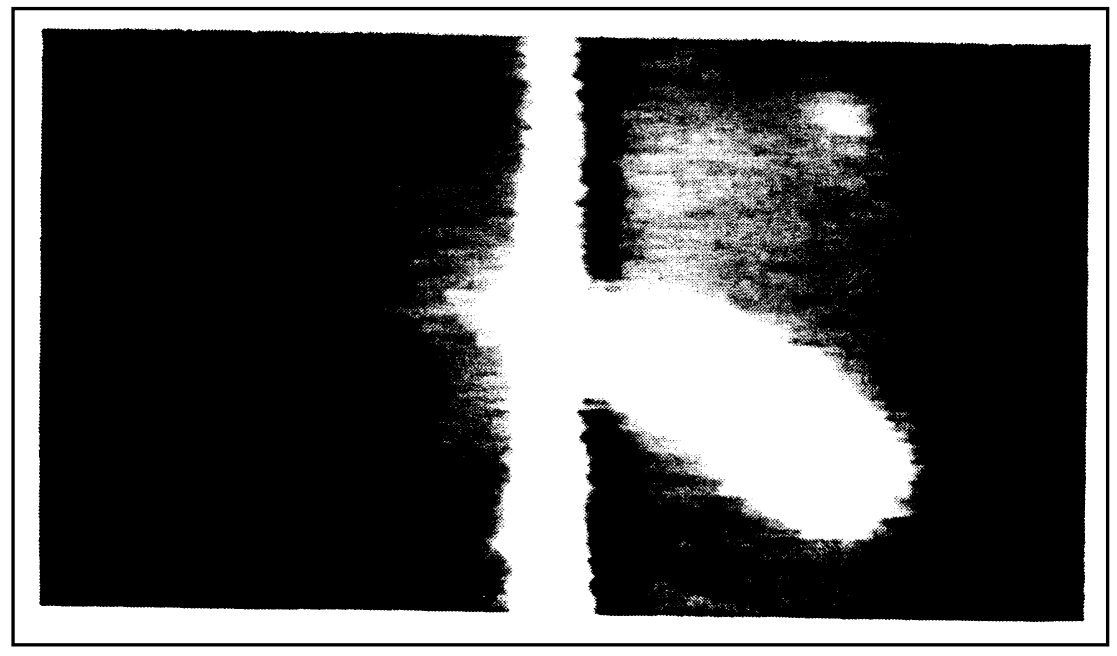

Figure 2.3.2: Thermal image of a disbond in $1 / 2$ " thick fiberglass adhesively bonded to a concrete column (Burleigh et al. 1999)

\subsubsection{TNDT of A Naval Pier}

One of the active piers in the heart of the Navy's San Diego Naval Base was limited by low deck loading capacity. The goal for this rehabilitation project was to increase the capacity of the crane positions from 30 to 50 tons.

\subsubsection{Type of Technique}

This test was challenging because of many difficulties such as accessibility problems, and fairly constant and cold wind $\left(10-15 \mathrm{mph}, \sim 50^{\circ} \mathrm{F}\right)$ which interfered with the process of heating the inspected surface. Prior to field testing, some standards were developed by creating simulated defects generated by inserting 0.05 " to 0.10 " thick closed cell foam pieces into the bondline between the composite and the cement. 


\subsubsection{Tested Materials}

The increase in the loading capacity was achieved by the addition of five structural reinforcement systems fabricated with five different composite materials described below:

1. Pultruded Graphite fiber rods embedded into slots saw cut into the top deck to increase negative moment capacity.

2. Pultruded fiberglass I-beams bolted and epoxy bonded to the underside deck surface deck to increase shear strength and positive moment capacity.

3. Pultruded Graphite fiber strips epoxy bonded to the underside deck surface deck to increase positive moment capacity.

4. Laminated Graphite/epoxy fiber adhesively bonded to the underside deck surface deck to increase positive moment capacity.

5. Laminated vinyl ester/fiberglass shells installed on selected vertical piles to provide improved ductility and side load capacity.

\subsubsection{Results}

\subsection{Pultruded Graphite Fiber Rods:}

This system was not considered to be a reasonable candidate for TNDT, and was not tested. 


\subsection{Pultruded Fiberglass I-Beams:}

These materials are 0.50 " thick and relatively dense. An NDE standard was constructed with defects ranging from 0.25 to1.0 square inches. Infrared testing of this material was not successful in detecting simulated disbonds.

\subsection{Pultruded Graphite Fiber Strips:}

One strip was applied to the concrete as an NDT standard. Figures 2.3.3 to 2.3.5 show how TNDT was very effective in detecting the disbonds, especially at places where the material was relatively thin.

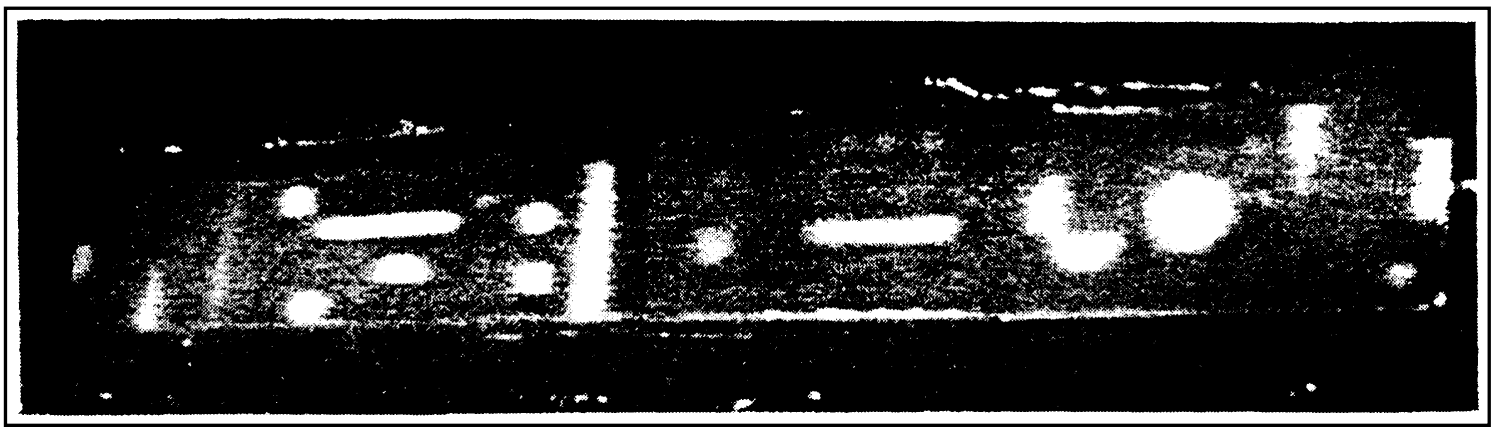

Figure 2.3.3: Composite of two thermal images of simulated defects in an NDT standard of pultruded Graphite fiber strips (Burleigh et al. 1999)

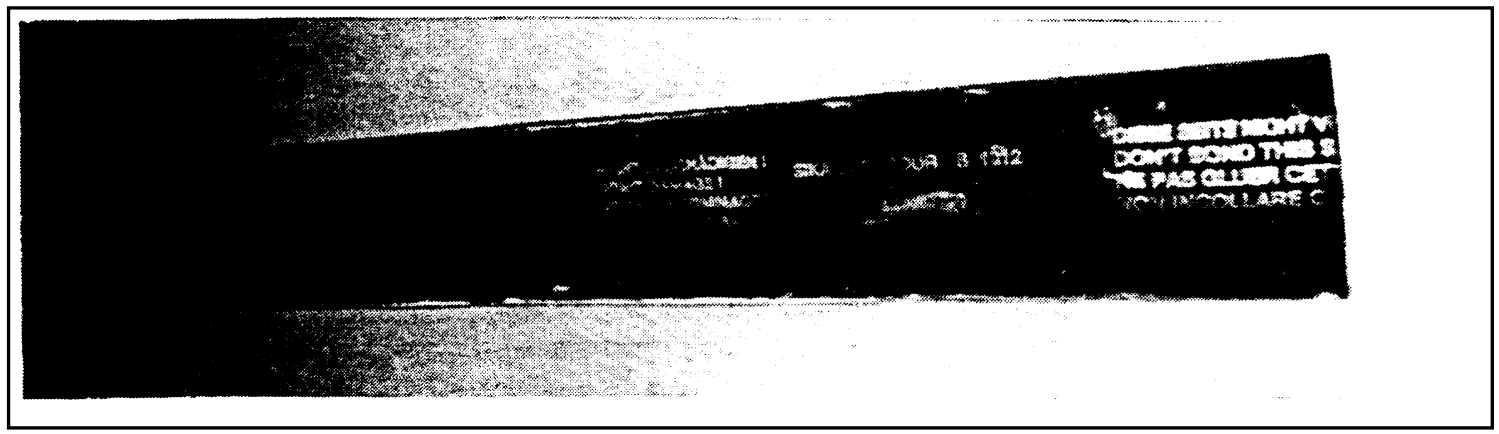

Figure 2.3.4: Photograph of the NDT standard in Figure 2.3.3 (Burleigh et al. 1999). 


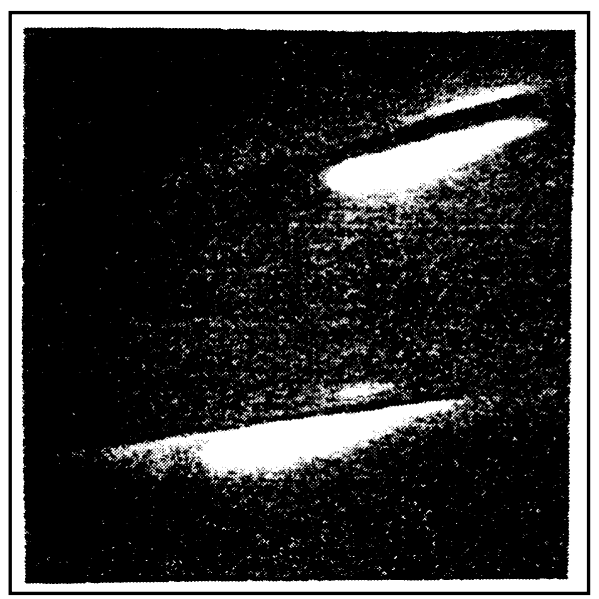

Figure 2.3.5: Thermal image of two disbonds on the edges of pultruded Graphite fiber strips (Burleigh et al. 1999).

\subsection{Laminated Graphite/Epoxy Fabric:}

Testing of the standard showed that defects larger than 1 square inch could be detected.

\subsection{Laminated Vinyl Ester/Fiberglass:}

The TNDT was reliabile in finding disbonds in the " $\mathrm{H}$ " connector at the adhesive bondline closest to the surface. Disbonds at the second bondline could be detected, but not with good reliability, as this required thermal energy to pass through the first bondline (Burleigh et al. 1999). 


\subsubsection{Conclusion}

As thickness of the composite increases, the minimum detectable disbond size increases. Information on the types of defects which occur in these structures and their locations has led to process improvements in the application of adhesively bonded laminated composites to steel reinforced concrete structures (Burleigh et al. 1999). Further development of TNDT would be required to enhance this technique.

\subsection{Other Research}

While most previous literature on infrared applications to highway condition monitoring has been limited to concrete decks/pavements with or without asphalt overlays (e.g., Maser and Roddis 1990), recent reseach has extended the use of infrared technique to composite bridge decks and FRP wrapped concrete columns. A very recent publication by Jackson et al. (2000) reports the successful application of infrared thermography in detecting disbonds and voids between FRP wrap and concrete columns. This indicates that infrared thermography is a promising NDE technique for evaluation of composite members, and its use is bound to increase in coming years.

\subsection{Conclusions}

Based on the literature review, it can be concluded that infrared thermography is a promising technique for evaluation of composite structural members for the following reasons: 
1. Infrared thermography does not require the use of external sensors and wires, and enables remote surface temperature measurements.

2. The technique has a great potential for rapid survey of subsurface condition of composite bridge decks, and leads to labor and time saving.

3. Compared to other NDE monitoring systems (e.g., ground penetrating radar), infrared data can be interpreted with relative ease.

4. The application of infrared technique by other researchers for detection of flaws (e.g., delaminations and debonding) in composite structures has been fairly successful. 


\section{CHAPTER 3}

\section{INFRARED BASICS}

\subsection{Introduction}

Infrared radiation is physically of the same form as visible radiation (light), but it behaves rather differently in many of its interactions with matter. The wavelength of infrared radiation is longer than that of radiation in the visible region, causing it to lie 'beyond the red' when a spectrum is formed by a prism from an incandescent source (Morten 1971).

The essential property, which distinguishes infrared from visible light, is its wavelength (see Figure 3.1). Unlike visible spectra images (wavelength spectrum: 0.35$0.75 \mu \mathrm{m})$ which are produced by reflection and reflectivity differences, infrared images (wavelength spectrum: $0.75-100 \mu \mathrm{m}$, if taken in a broad sense) are produced by a selfemission phenomenon and also by variation of emissivity (Maldague 1993).

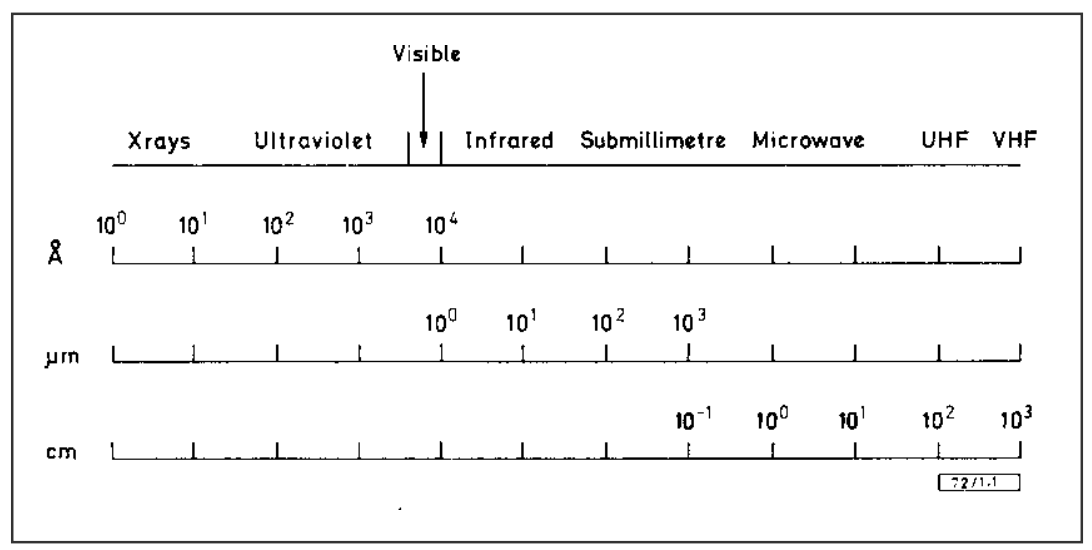

Figure 3.1: Electromagnetic spectrum (Morten 1971) 


\subsection{Source of Infrared Radiation}

All objects radiate electromagnetic waves at any temperature above absolute zero $\left(-273{ }^{\circ} \mathrm{C}\right)$, but the amount emitted and its distribution with wavelength depend on the temperature and emissivity of the body. The emissivity of any object is defined as the ratio of the actual emission from the object to that from a hypothetical source called a "black body" at the same temperature. The emissivity generally varies with wavelength. The properties of a "black body" radiator may be calculated theoretically. Three points about the black body are of a particular importance (Morten 1971):

1. The total energy radiated $\left(\mathrm{W}_{\text {tot }}\right)$ is proportional to the fourth power of the absolute temperature $\mathrm{T}\left({ }^{\circ} \mathrm{C}+273\right)$ :

$$
\mathrm{W}_{\mathrm{tot}}=\sigma \mathrm{T}^{4} \quad \text {. } . . . \quad . \quad . \quad . \quad . \quad . \quad . \quad . \quad . \quad .
$$

Where $\sigma$ is Stefan's constant, which is approximately equal to $5.67 \times 10^{-12}\left(\mathrm{Wcm}^{-2}\right.$ $\left.\mathrm{K}^{-4}\right)$

2. The curve of variation of energy per interval of wavelength $\left(W_{\lambda} d \lambda\right)$ is always of the same shape, following Planck's law:

$$
\mathrm{W}_{\lambda} \mathrm{d} \lambda=\frac{C_{1} \lambda^{-5} d \lambda}{\exp \left(C_{2} / \lambda T\right)-1} \quad \text {. . . . . . . . . . }
$$

where $\mathrm{C}_{1}$ and $\mathrm{C}_{2}$ are constants given by

$$
\begin{aligned}
& \mathrm{C}_{1}=3.7 \times 10^{-12} \mathrm{Wcm}^{2} \\
& \mathrm{C}_{2}=1.44 \mathrm{~cm} \mathrm{~K}
\end{aligned}
$$

Figure 3.2 shows the variation of energy for some typical source temperatures. 
3. The wavelength of the peak emission is a simple function of the absolute temperature (Wien's displacement law). The wavelength in $\mu \mathrm{m}$ is:

$$
\lambda_{\mathrm{pk}} \cong 2900 / \mathrm{T} \quad \text {. . . . . . . . . . . . . . . }
$$

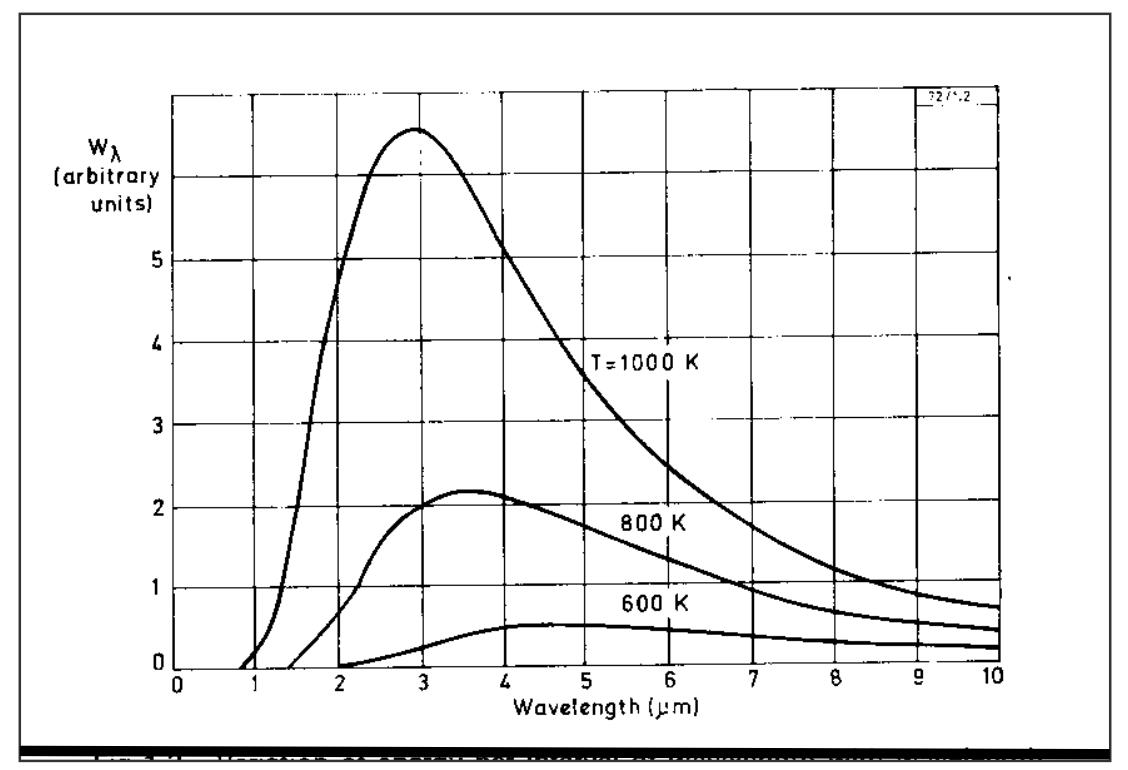

Figure 3.2: variation of energy per interval of wavelength with wavelength (Morten 1971)

\subsection{Transmission of Infrared Radiation}

In spite of the similarity between infrared radiation and visible light, it is important to note that an object that is transparent or opaque in the visible region may not necessarily exhibit the same behavior (transparent or opaque) in the infrared region. For example, ordinary clear glass is transparent up to only about $2.5 \mu \mathrm{m}$ in the infrared region. On the other hand, semiconductor materials such as germanium and silicon, opaque in the visible region, are transparent in the infrared region beyond 1.8 and $1 \mu \mathrm{m}$, 
respectively. The atmosphere is also an important factor in transmission of infrared radiation. Figure 3.3 shows typical transmission percentage over a path of one mile. The "transparent" regions in this figure (for example, 8 to $13 \mu \mathrm{m}$ ) are referred to as “windows" (Morten 1971).

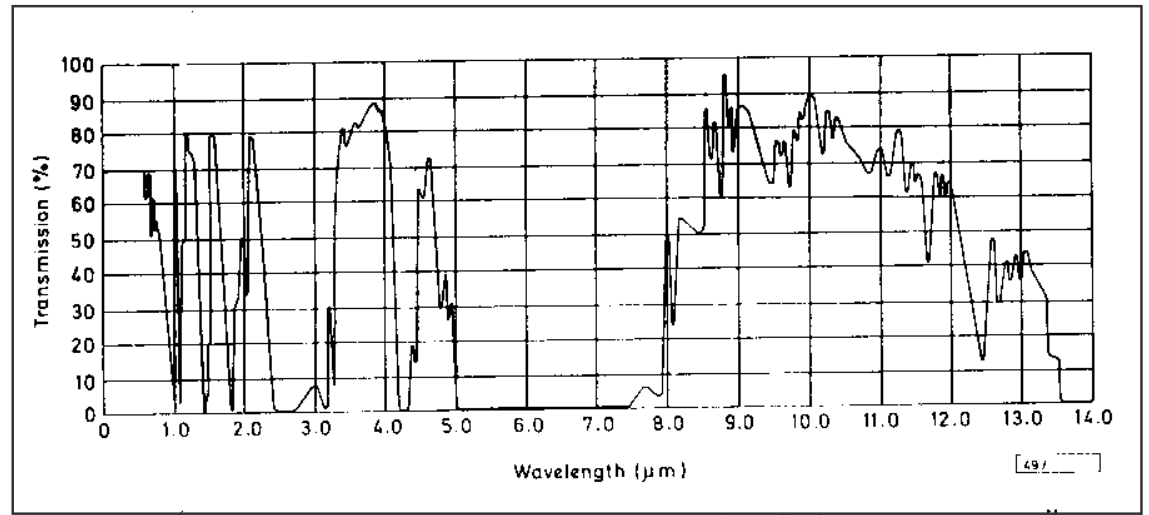

Figure 3.3: Atmospheric transmission of infrared radiation over one mile (Morten 1971)

\subsection{Heat Transfer Mechanism}

The temperature of a bridge deck is a function of the heat flow between the deck and the surrounding environment. The heat transfer mechanism in a bridge deck takes place in three ways:

\section{- Radiation}

- Conduction

- Convection 


\subsubsection{Radiation}

Thermography measures the differences in the surface temperature of the top of the deck by measuring the radiant emission. All surfaces not only radiate heat to the atmosphere but also simultaneously receive radiation back from the atmosphere. The ambient temperature determines the amount of radiation received by the top and the bottom of the deck surfaces from the atmosphere. Solar radiation is the major heat source for the top of the bridge deck.

\subsubsection{Conduction}

Conduction is defined as the type of heat flow that takes place through a material from a hotter region to a cooler region (Halabe 1999). Thermal conductivity is defined as the ratio of the heat flux to the temperature gradient and is measured in heat flow per unit area for a unit temperature difference across a unit thickness (Neville 1973). The heat flow through a thermally conductive medium is directly proportional to the temperature difference across the medium. Therefore, as the temperature difference increases, the heat flow increases and vise versa.

\subsubsection{Convection}

Convection takes place between the surrounding air and the bridge deck by transfer of heat through fluid (air) movement and mixing. The temperature at the top and the bottom surfaces, the ambient temperature, and the wind speed determine the amount of heat flow by convection. 
The major heat source for the bridge deck among the three mechanisms is the solar radiation. The amount of solar radiation depends on the time of the day and year.

\subsection{Detection of Infrared Radiation}

Since infrared is a form of electromagnetic energy, it is possible to detect it by absorbing it and hence converting the energy to heat. This was the basis of the early experiments using a blackened thermometer bulb. However this method was slow, insensitive, and inconvenient; therefore, an electrical output device, such as an infrared scanner, became more desirable.

Infrared Scanner: The difference between the infrared scanner (camera) and the regular video camera is that the infrared camera's optical system is only transparent to infrared radiation and is insensitive to visible spectrum of light. The infrared camera converts radiated heat (passing through the optics) into an electronic signal, which is converted into a thermal image that can be displayed on a regular monitor. The energy detector in the scanner is highly sensitive to background noise and must therefore be cooled (Halabe 1999). Different infrared cameras use different methods of cooling such as fan, electronic cooling or liquid nitrogen.

Liquid nitrogen cools the detector to $-196{ }^{\circ} \mathrm{C}$, which allows detection of temperature variations within $0.01^{\circ} \mathrm{C}$ (Weil 1989). Infrared thermography is useful in detecting defects in structures with surface temperatures ranging from $-20{ }^{\circ} \mathrm{C}$ to +2000 
${ }^{\circ} \mathrm{C}$ (Halabe 1999). Currently available infrared cameras provide a temperature resolution of $0.1{ }^{\circ} \mathrm{C}$, which is adequate for most civil engineering applications.

\subsection{Application of Infrared Thermography to A Bridge Deck}

The net heat flow through the bridge deck depends on the ambient conditions such as solar radiation (time of the day and year), atmospheric temperature, wind velocity, deck thickness, and thermal properties of the different layers in the deck. Anomalies in the deck such as delaminations cause thermal discontinuities, which affect the conductive heat transfer through the delamination region and result in surface temperature differences when compared to solid (undamaged) portion of the deck. A similar difference is seen in Figure 3.4 for concrete deck field data collected by Manning and Holt (1980). This figure shows that the maximum temperature difference between solid and delaminated areas occur around noon, when the thermal gradient through the thickness of the deck is at its peak.

A delamination in a deck may be filled with air, which acts as a thermal insulator. Surface temperature differences between solid and delaminated areas are caused by the differences in thermal behavior due to different properties of heat conduction and/or heat capacity. If the delaminated areas were filled with water, a clear thermal difference may not occur since the thermal conductivity of water is not substantially lower than that of concrete. To illustrate this phenomenon, Kazzi (1988) and Maser and Roddis (1990) have conducted theoretical studies on a 7.5 inch thick concrete deck using finite element heat 
transfer model to assess the effect of crack filler material, crack width and cover thickness on the detectability of subsurface cracks with a depth of 1.5 " from the top of the deck.

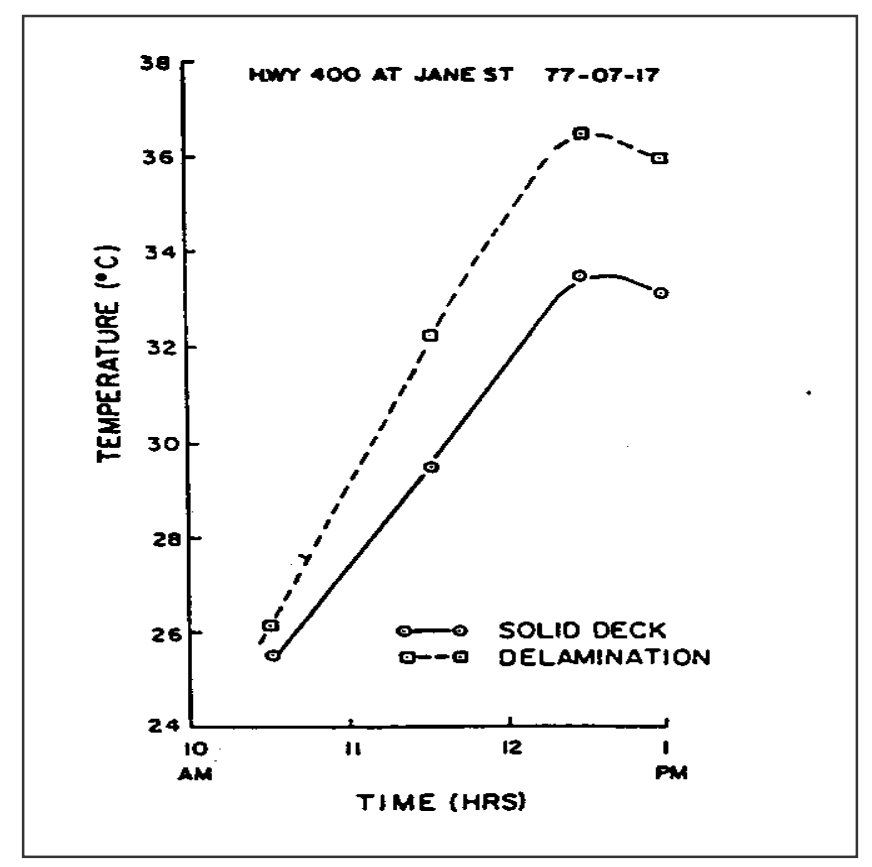

Figure 3.4: Field data for temperature differences between solid and delaminated area in bridge deck (Manning and Holt 1980)

Figure 3.5 shows the effect of crack filler material on the surface temperature differences. This figure shows that the water-filled crack result in much lower surface temperature differentials compared to an air-filled crack. Figure 3.6 shows the effect of air-filled crack width on the surface temperature differential. The larger the crack width, the higher is the surface temperature differential. Figure 3.7 shows the relation between the concrete cover thickness (above the subsurface crack) and the surface temperature differential. It is also apparent from Figures 3.5, 3.6, and 3.7 that the maximum surface temperature differentials occur either during midday, that is, 10 A.M. to 2 P.M. (peak heating cycle) or at night around 10 P.M. to 2 A.M. (peak cooling cycle). Also, air filled 
cracked area, which acts as a thermal insulator, results in a lower surface temperature compared to solid areas during nighttime when the deck is radiating heat to the surrounding. On the other hand, during a sunny day, when the deck is receiving heat from solar and atmospheric radiation, the air-filled cracked areas show higher surface temperature compared to surrounding solid areas. Other external factors which influence heat flow include cloud cover, amount of solar radiation, ambient temperature, wind velocity, and moisture content.

It is apparent from the above discussions that infrared measurements are affected by the delamination's thickness and filler material, and the environmental effect. The effect of these parameters on composite bridge decks have been investigated in the current research using controlled laboratory and field tests, which are described in the next two chapters.

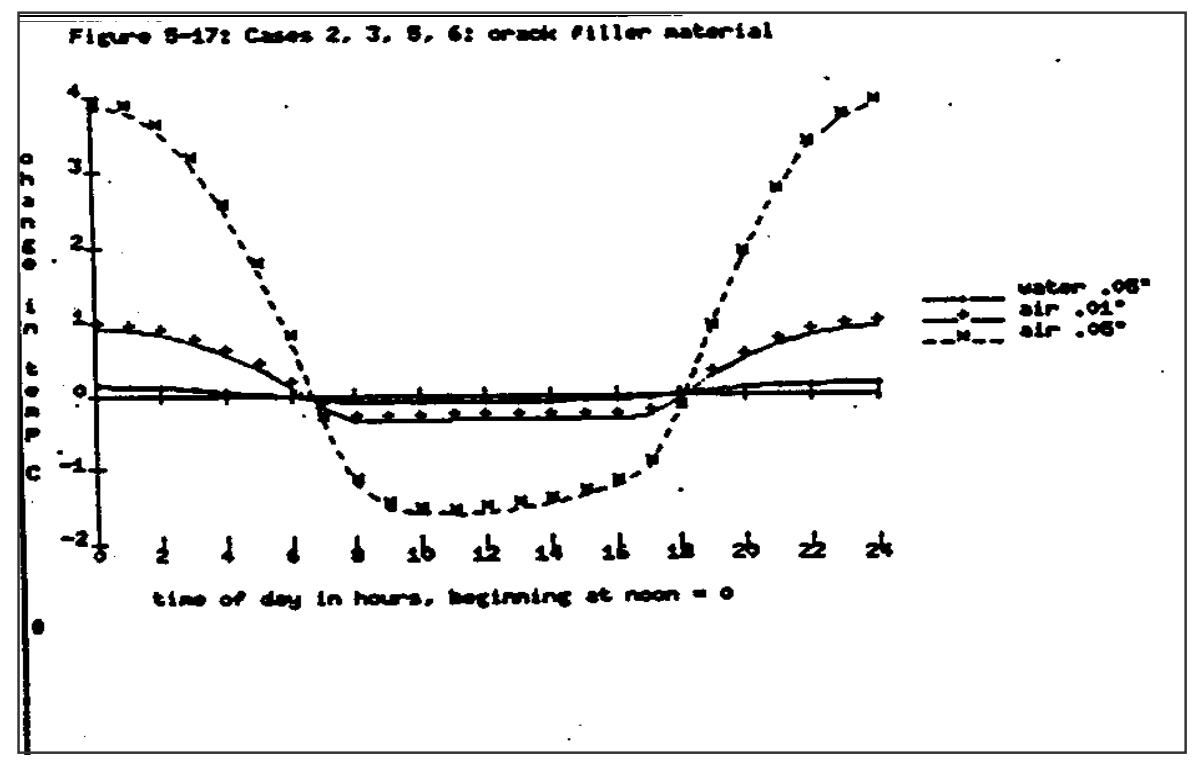

Figure 3.5: Effect of crack filler material on surface temperature differentials (Kazzi 1988) 


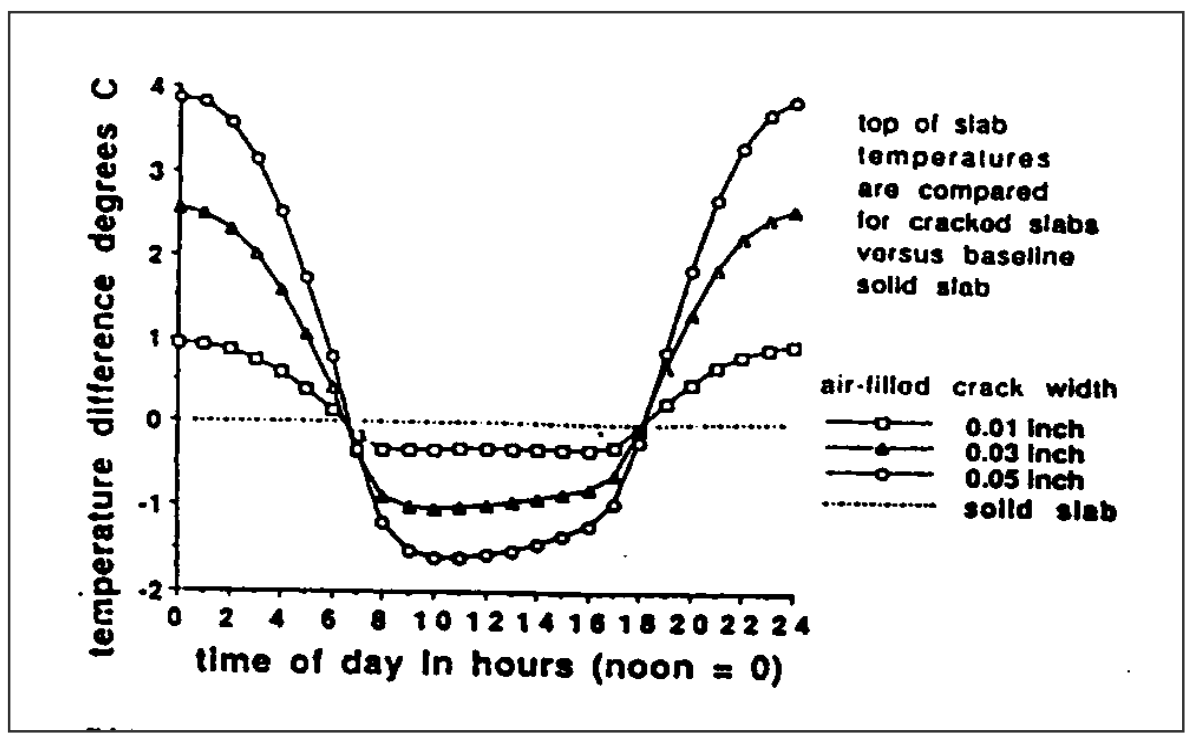

Figure 3.6: Effect of crack width on surface temperature differentials (Maser and Roddis 1990)

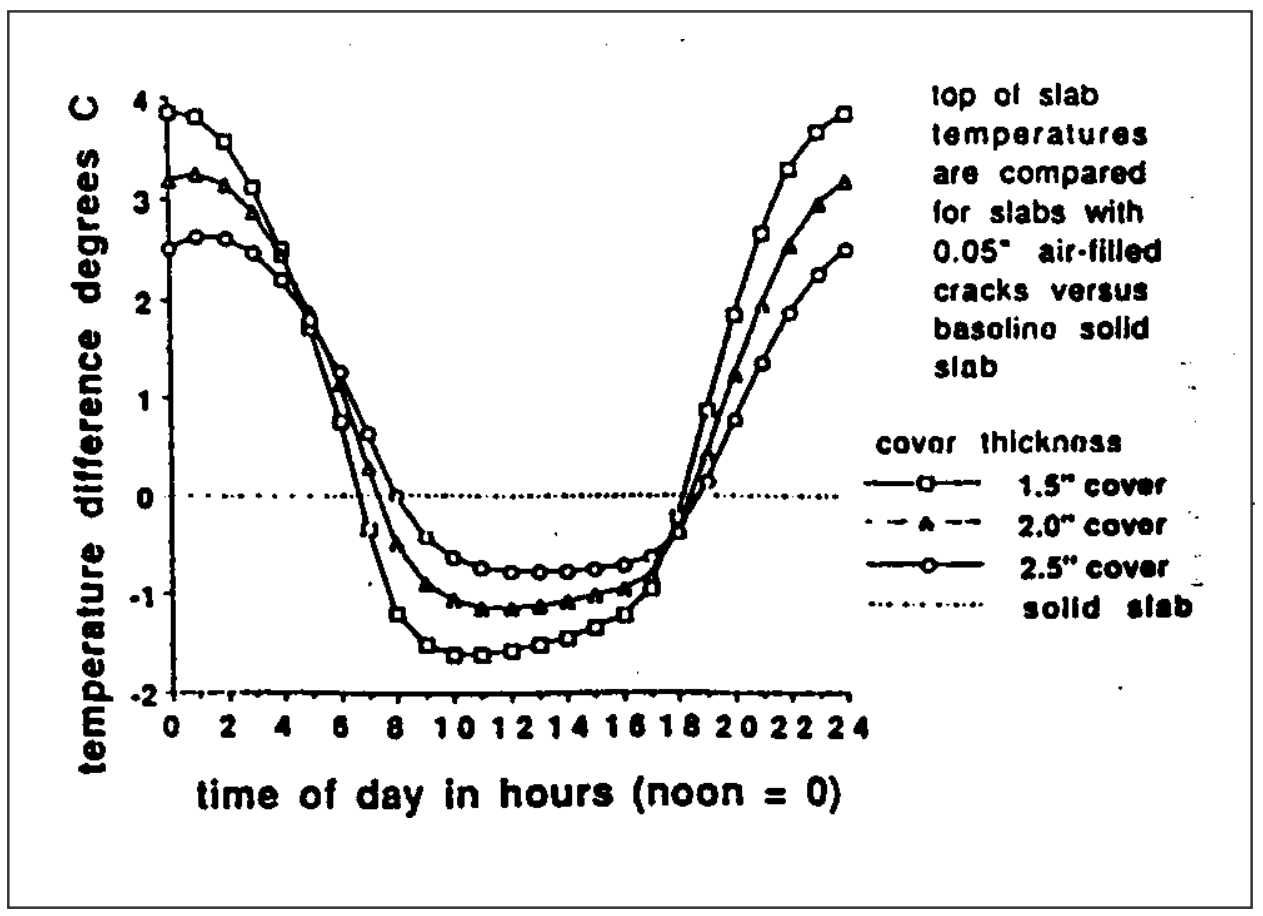

Figure 3.7: Effect of concrete cover thickness on surface temperature differentials (Maser and Roddis 1990) 


\section{CHAPTER 4}

\section{LABORATORY EXPERIMENTS}

This chapter presents the equipment set-up in the laboratory, specimen configurations, and the results of infrared testing conducted on the laboratory specimens.

\subsection{Experiment Set-up}

\subsubsection{Equipment Set-up}

Two infrared cameras, Insight 80 Series and FLIR Prism Single Point, with a resolution of 0.1 and $0.2{ }^{\circ} \mathrm{C}$, respectively, were used to measure the temperature differences on the specimens' surface during the heating or cooling cycles. The thermal imager on both infrared cameras has two modes, black and white and color. The black and white mode is a gray scale, ranging from white, which is hot, to black, which is cold. The color mode gives different colors (white, pink, green, blue and black) with different intensities. As the surface temperature of the specimen increases, the color intensity increases.

In addition, the IR cameras provides two control buttons, black level and gain control buttons. The black level control allows the operator to select the particular temperature at which the viewed object becomes visible on the display screen. The gain control allows the operator to select the width of the temperature spread to be viewed. 
The main difference between the two infrared cameras is the spectral range. The spectral range for the Insight 80 Series camera is $8-11 \mu \mathrm{m}$ while the Prism Single Point camera has a spectral range of $3-5 \mu \mathrm{m}$. As the spectral ranges get closer to the visible wavelength, the infrared camera becomes more sensitive to the environment. Therefore, a black room was constructed to eliminate the environmental effects.

The Thermal Imager is connected to an 8-inch monitor that has a built-in VCR. The monitor and the VCR are used to capture and record the thermal images that are produced from the specimen during the heating (or cooling) cycles. The thermal imager is mounted on a tripod to control the distance between the thermal imager and the heated samples as well as the angle of imaging. Figure 4.1 shows photographs for the experimental set-up.

Quartz tower heater, heat gun, and solar radiation were different heat sources used to heat the specimens. The quartz heater with two temperatures settings, 750 and 1500 watts, was mounted on a cart. By using the cart to control the distance between the heater and the specimen, and using the two temperature settings, the specimen could be uniformly heated to the desired temperature. However, the heat gun can be hand-held by the operator and should be moved continuously to achieve the desired uniform temperature. The disadvantage of the heat gun is that it requires diligence and control ("art") by the operator to achieve a uniformly heated specimen.

Use of negative heat source (cooling) using liquid Carbon Dioxide $\left(\mathrm{CO}_{2}\right)$ at -40 ${ }^{\circ} \mathrm{C}$ was also explored. 


\subsubsection{Specimen Set-up}

Four composite deck specimens with built-in delaminations between the wearing surface and the FRP deck were made by Transpo Industries, NY. The delaminations were made with different sizes, filler material and varying locations from the edges to study the effects of these variables on the infrared nondestructive testing technique.

The wearing surface is $3 / 8$ inches thick and made of a mixture of T-48 Epoxy, Basalt aggregate, sand and silicon. The cross-section of the bridge deck composite specimen is shown in Figure 4.2.

\subsubsection{Sample 1}

A 12" x 16" FRP composite deck specimen was constructed. A 2" x 2" debonding was created between the wearing surface and the FRP deck by using a duct tape. The debonding was located at distances of 3" and 5" from the adjacent edges as shown in Figures 4.3 and 4.4 .

\subsubsection{Sample 2}

Sample 2 is a 12" x 24" composite deck as shown in Figures 4.5 and 4.6. Six different delaminations with varying sizes and shapes were constructed between the composite deck and the wearing surface.

The delaminations consisted of two plastic sheet layers attached to each other to simulate small air gaps. Five of them were of 0.01 " thickness and the sixth one was 0.02 " 
thick. Different sizes and shapes (see Figure 4.5) were chosen to evaluate the capability of the infrared technique to detect these delaminations.

\subsubsection{Sample 3}

A 12" x 16" FRP composite deck was constructed, which has an 11" x 7.5" air gap with 0.05 " thickness to simulate subsurface delamination as shown in Figure 4.7. A larger area and thicker air gap was chosen to evaluate the capability of the infrared camera (Prism Single Point) for detecting subsurface delamination under 3/8 inches wearing surface.

\subsubsection{Sample 4}

A 12" x 16" FRP composite deck with two subsurface delaminations (0.05" thickness air gaps) were constructed as shown in Figure 4.8. The two air gaps were made with smaller areas to evaluate the minimum delamination size that can be detected by the infrared camera (Prism Single Point).

\subsection{Experimental Results}

\subsubsection{Sample 1}

Sample 1 was tested by the two infrared cameras and neither were able to detect the simulated debonding. The duct tape was not adequate to create any thermal differential on the specimen surface. 
Figure 4.9 was taken by the Insight 80 Series camera. This figure shows the heat distribution on the surface of the specimen (note that the Insight 80 Series infrared camera has a circular view). As one moves from the center of the specimen towards the edges, the color changes from white to red to blue, which indicates that the center of the specimen is hotter than the edges. This phenomenon is normal since the edges have more heat dissipation to the surrounding and thus become colder.

\subsubsection{Sample 2}

Sample 2 was tested (scanned) using Prism Single Point infrared camera. The sample was heated to different temperatures ranging from $20^{\circ} \mathrm{C}\left(68^{\circ} \mathrm{F}\right)$ up to $80^{\circ} \mathrm{C}(176$ ${ }^{\circ} \mathrm{F}$ ) and by different heating methods including quartz tower heater, heat gun and solar radiation. In addition, negative heat (cooling the specimen using $\mathrm{CO}_{2}$ liquid) was applied to the specimen to enhance the heat flow through the sound area, making it colder on the surface compared to the delaminated area, resulting in higher surface temperature differentials.

Many infrared images were taken for this specimen but none were able to show any delamination, even with the application of negative heat (cooling). Use of the heat gun was not found to be very useful since it did not result in uniform heating. The specimen was also tested inside the black room to eliminate the environmental effects and still no results were achieved. 


\subsubsection{Sample 3}

Sample 3 was tested using the Prism Single Point infrared camera. It was heated up to a temperature range between 45 and $75^{\circ} \mathrm{C}$ using quartz tower heater to achieve the best possible uniform heat. The surface temperature differential between the delaminated area and the sound area was about $7^{\circ} \mathrm{C}$. Figures 4.10 and 4.11 show clearly the delaminated area, which has brighter color than the solid areas (red is hot and blue is cold).

\subsubsection{Sample 4}

Sample 4 was tested using the Prism Single Point infrared imager. It was heated up to $82{ }^{\circ} \mathrm{C}$ using quartz tower heater to achieve the best possible uniform heat. Figures 4.12 to 4.14 show the delaminated areas. More contrast can be achieved in the infrared images by setting the infrared camera (gain/level control button) to different temperature spans to be viewed. Figure 4.12 has the least contrast and Figure 4.14 has the maximum contrast.

From these figures, it is clear that the Prism Single Point infrared camera is able to detect a small delamination of $1 " \mathrm{x} 1$ " size with 0.05 " thickness.

\subsection{Conclusions}

The laboratory experiments on the FRP composite bridge deck specimens have proven that the infrared thermography technique is able to detect subsurface delaminations under a typical wearing surface. The minimum delaminated area that can 
be detected is 1 square inch. Any other delamination with area less than 1 square inch might be detectable if more advanced camera is used or if a sustained negative heat is applied to the specimen to enhance the temperature differential on the surface. In addition, increasing the delamination thickness or decreasing its depth will also enhance the surface temperature differentials. This study has shown that a delamination of 0.05 " thickness under $3 / 8$ " wearing surface is detectable using the infrared technique. 

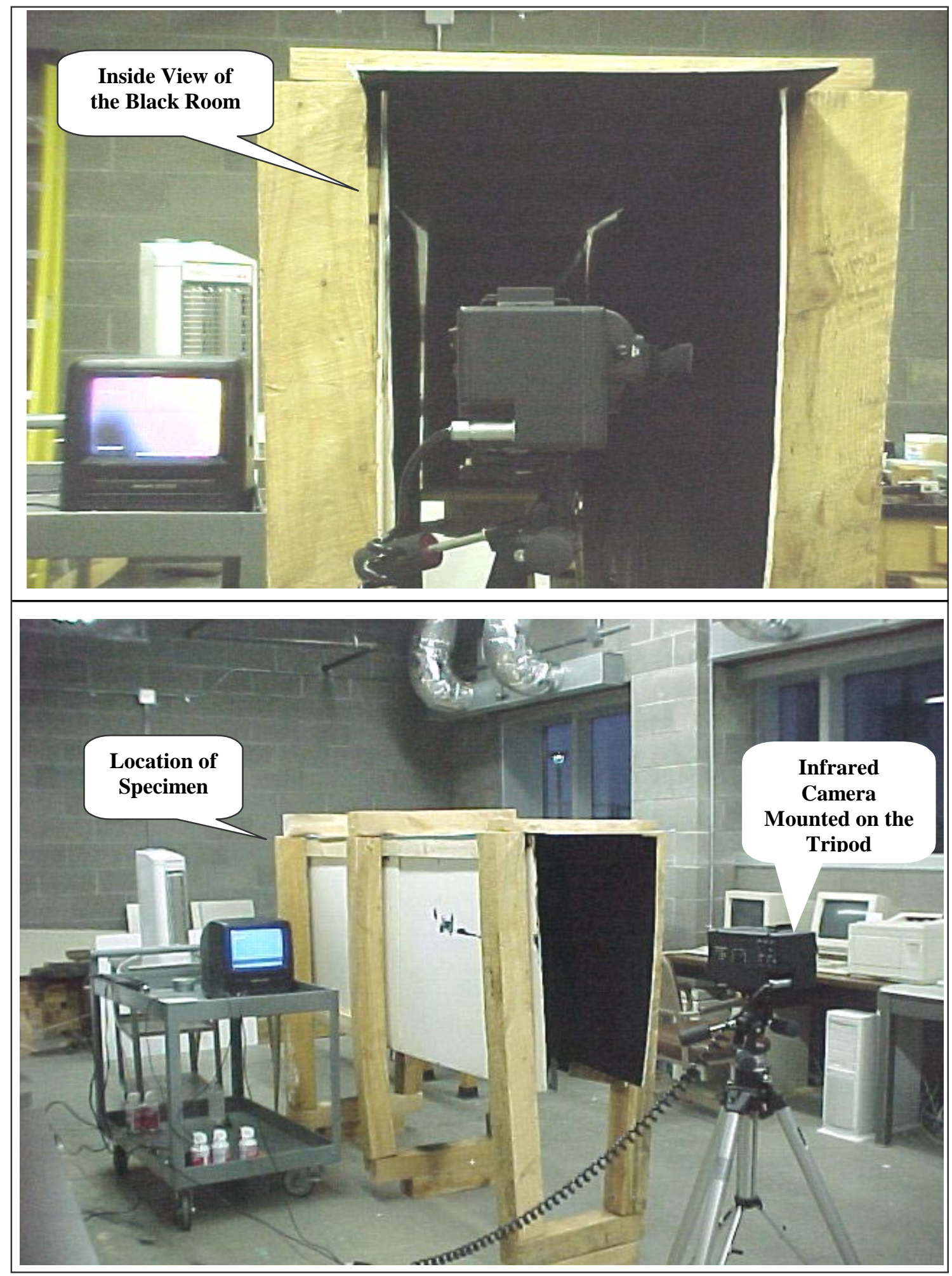

Figure 4.1: Photographs for the experimental set-up 


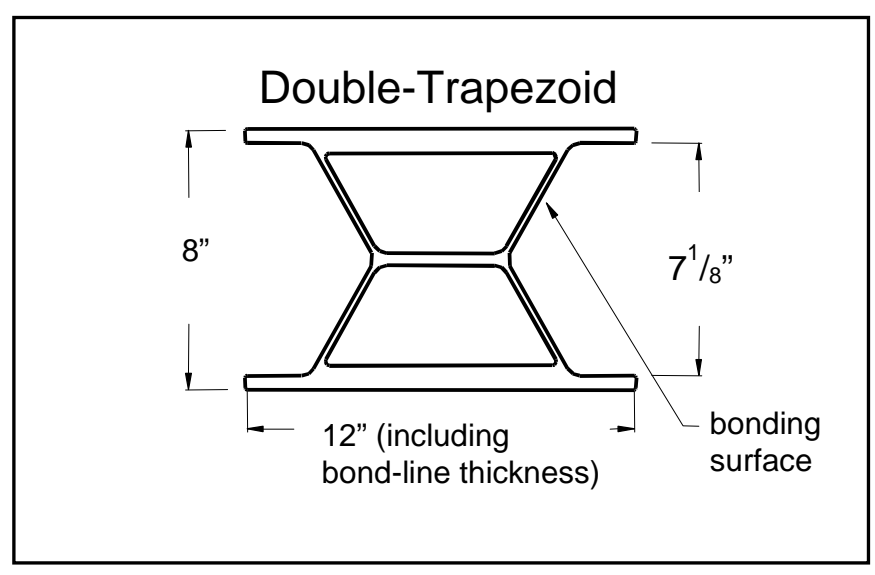

Figure 4.2: Specimen cross-section

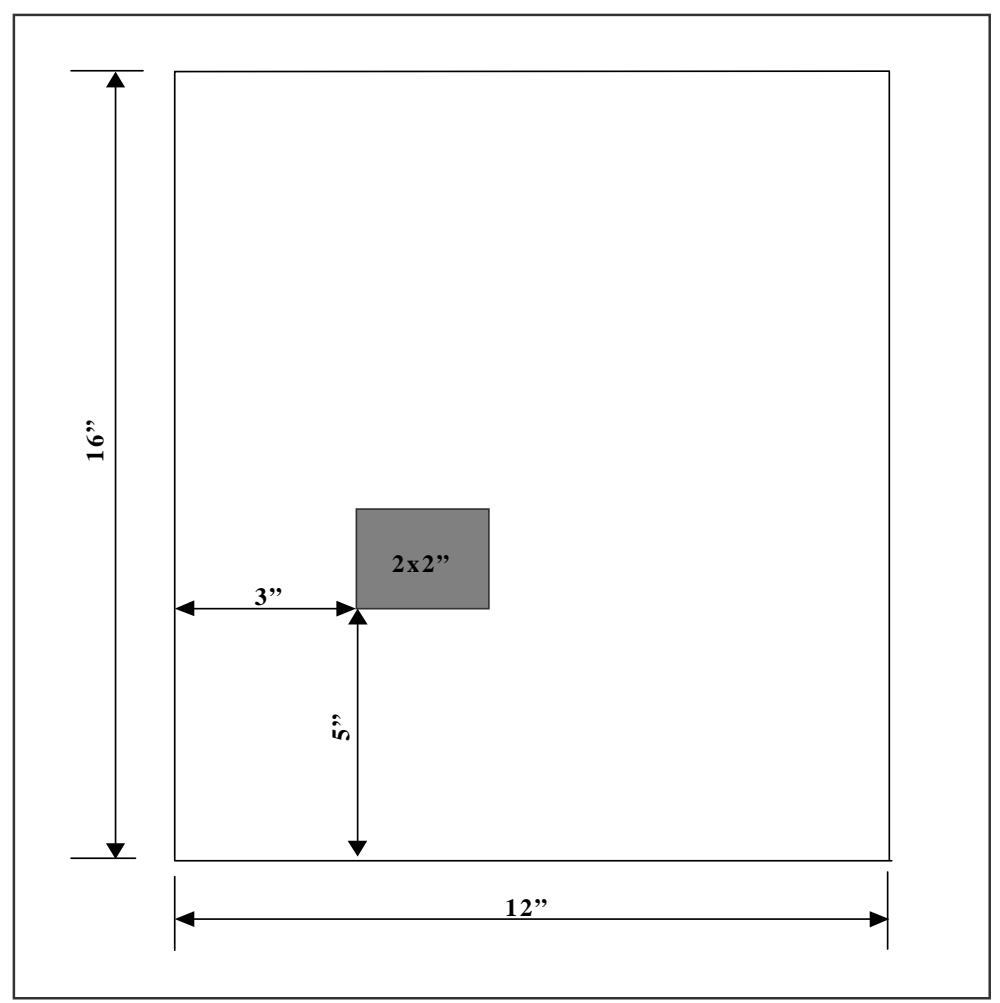

Figure 4.3: Composite deck with built-in debonding (Sample 1) 


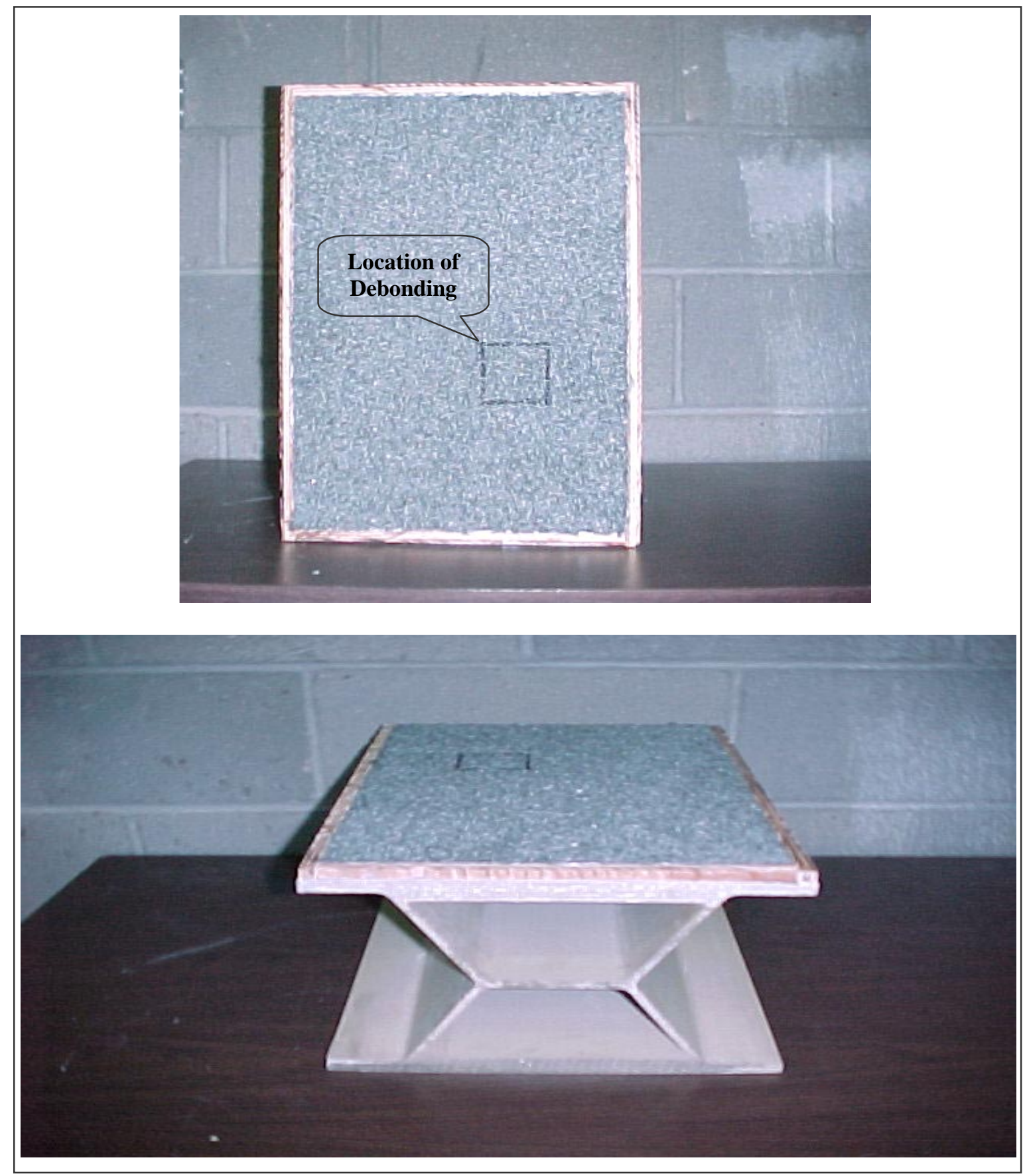

Figure 4.4: Photographs for Sample 1 


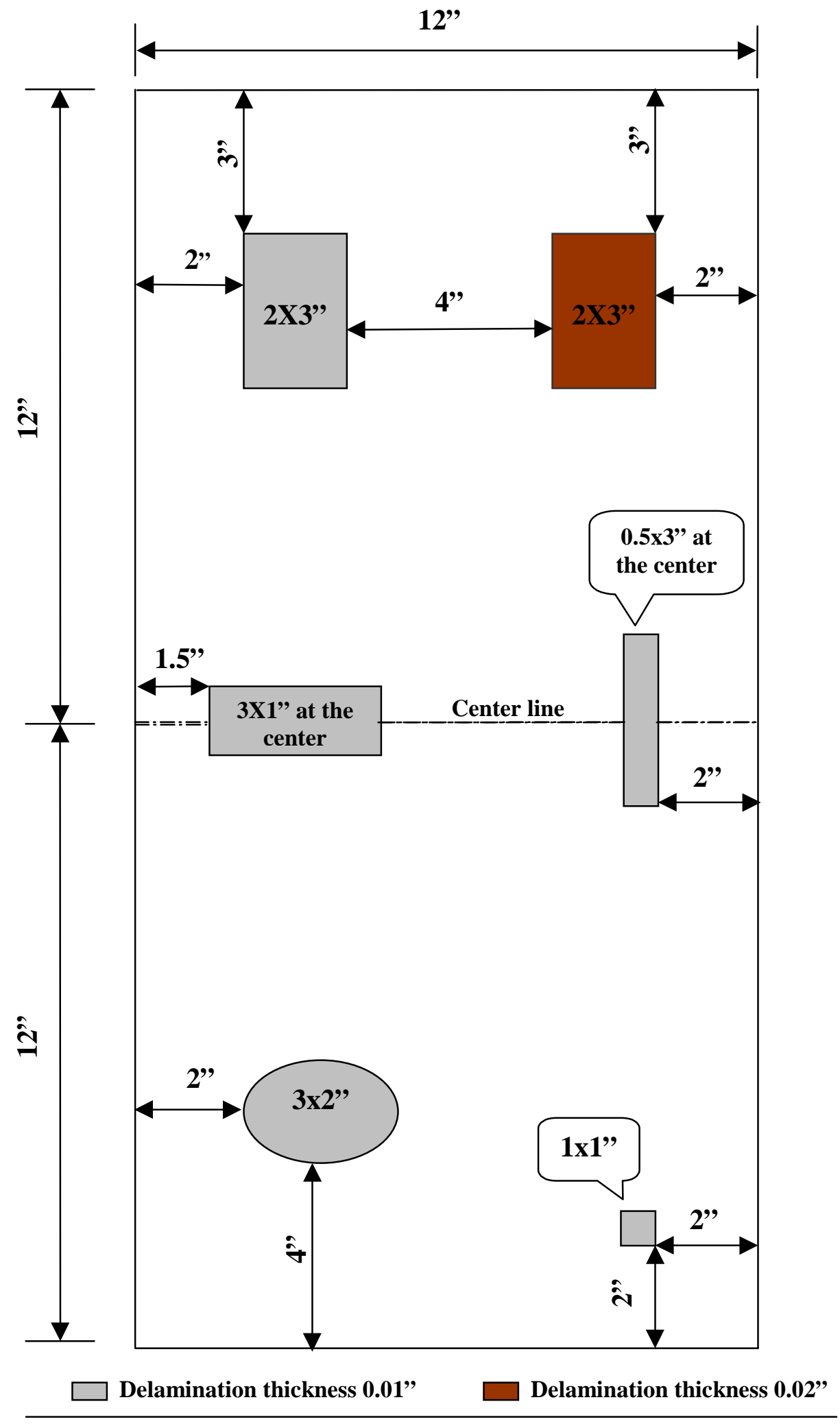

Figure 4.5: Composite deck with built-in delamination (Sample 2) 


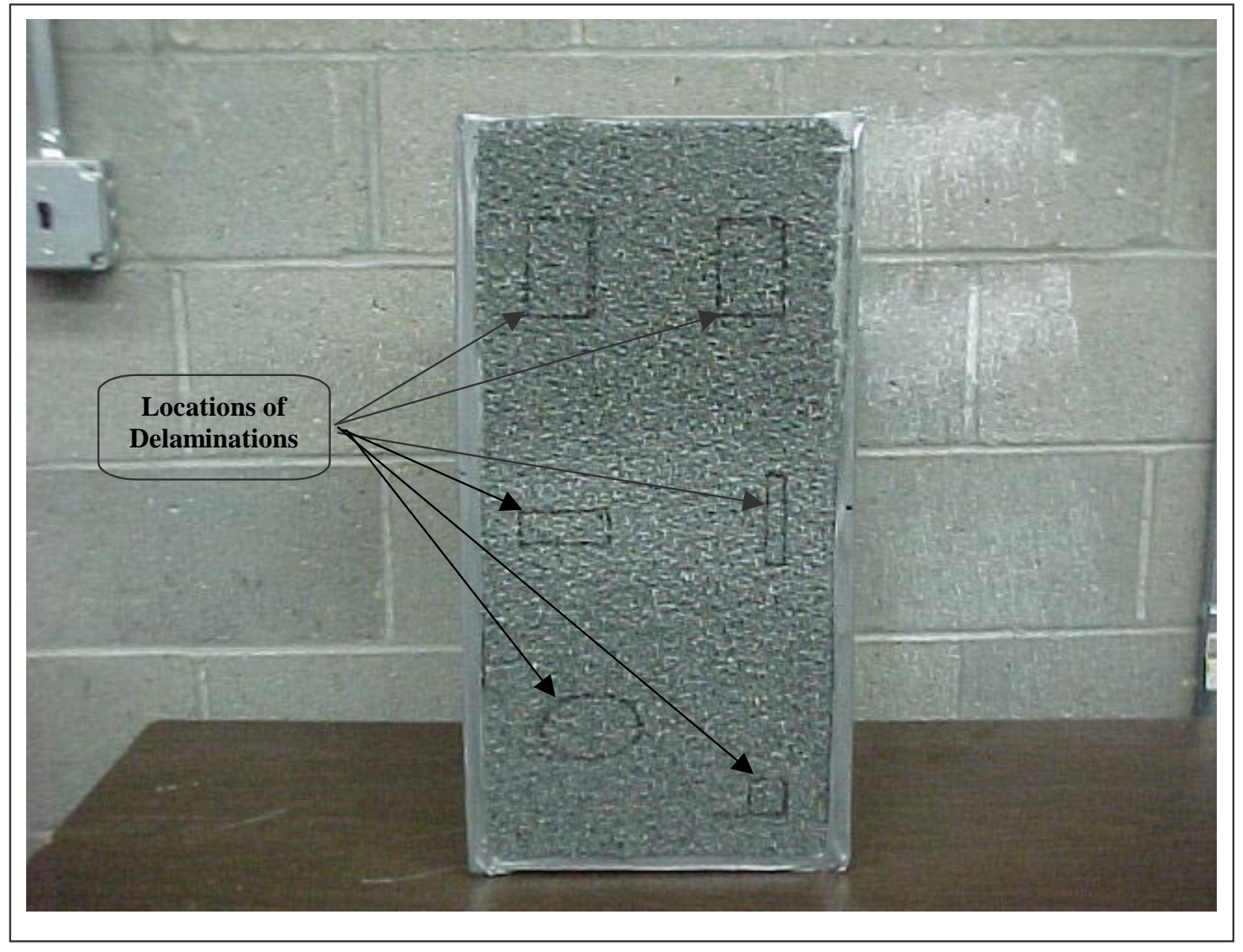

Figure 4.6: Photograph for Sample 2 


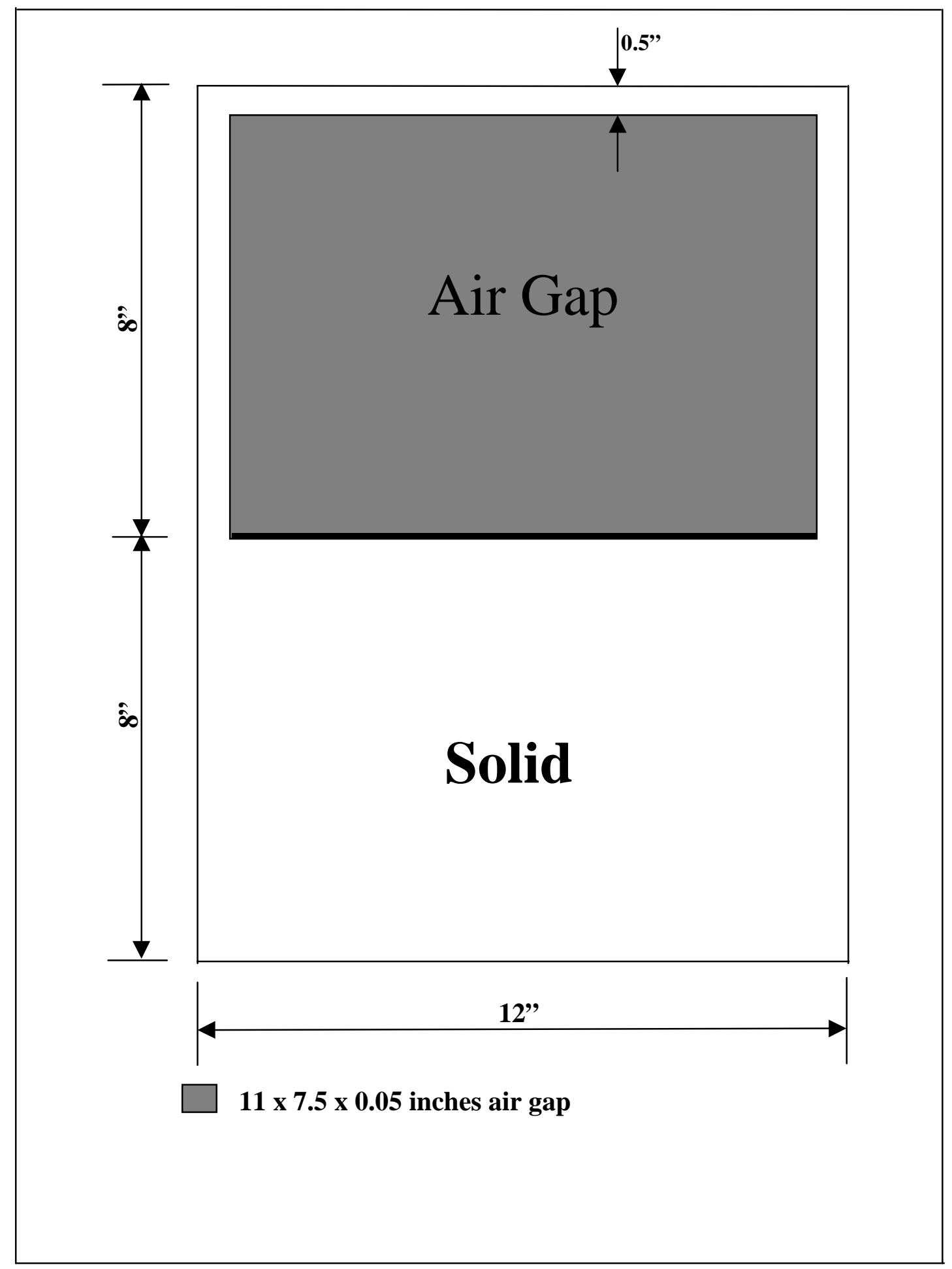

Figure 4.7: Composite deck with 11" x 7.5" x 0.05" built-in delamination (Sample 3) 


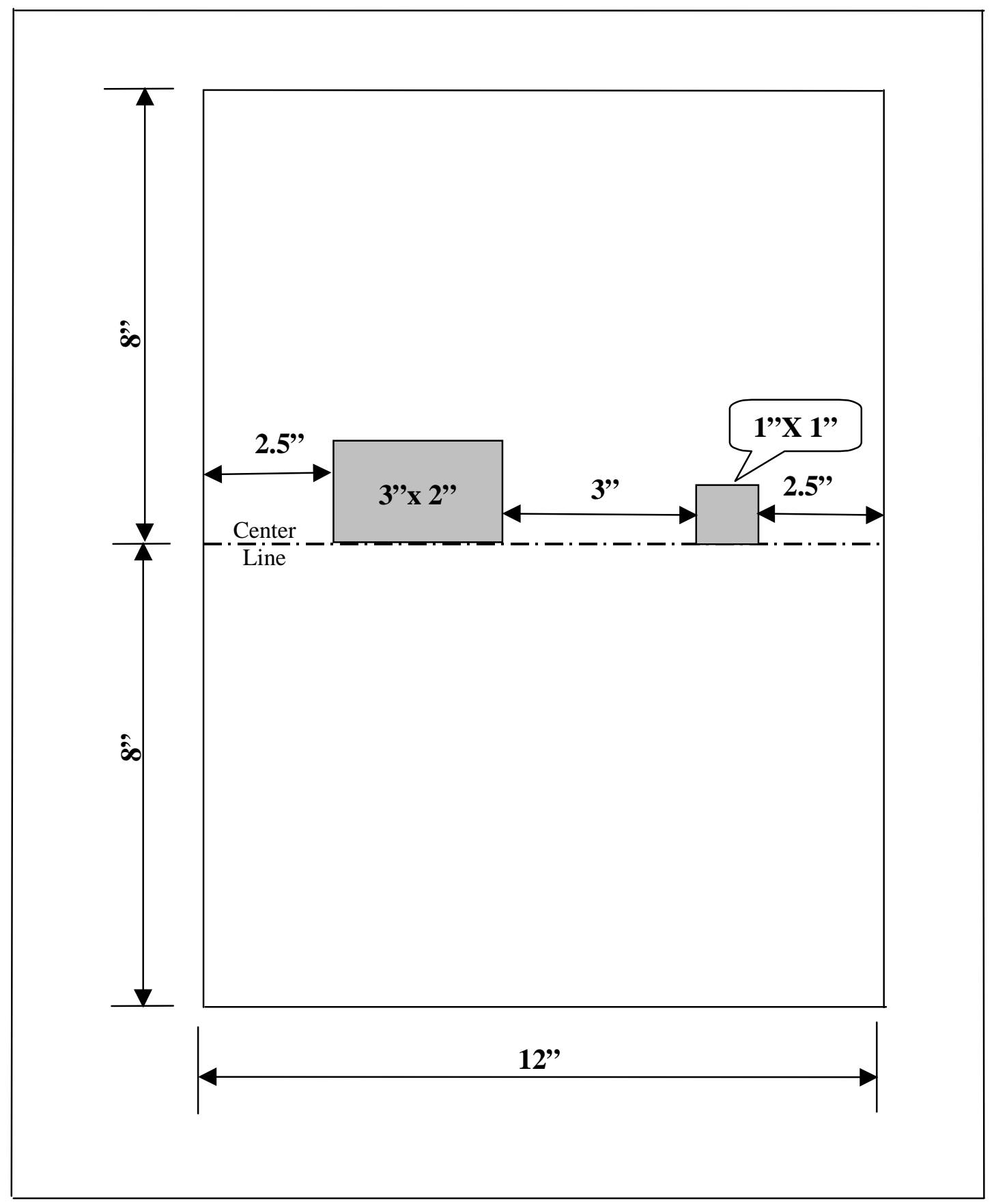

Figure 4.8: Composite deck with two subsurface delaminations (Sample 4) 


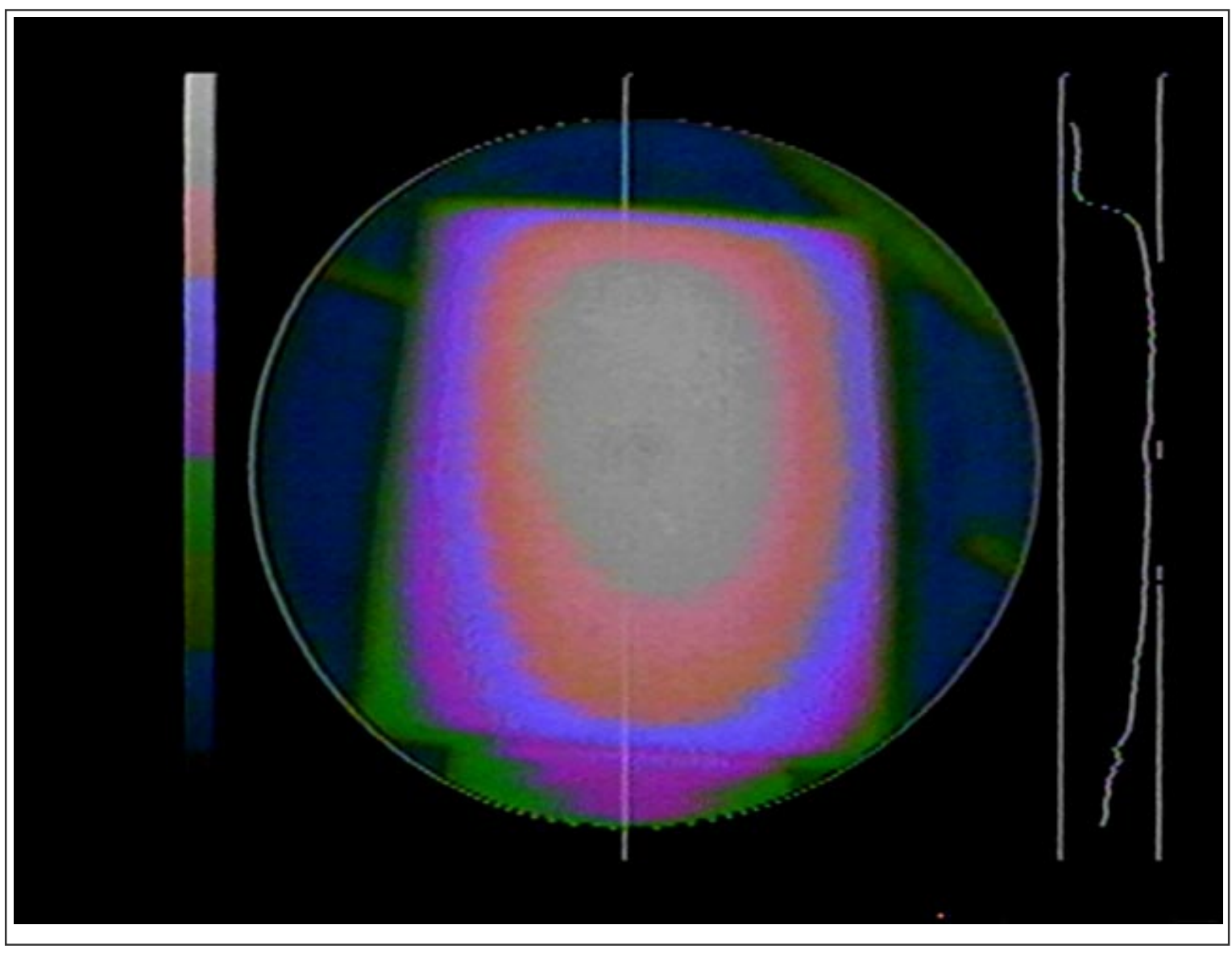

Figure 4.9: Infrared image for Sample 1 


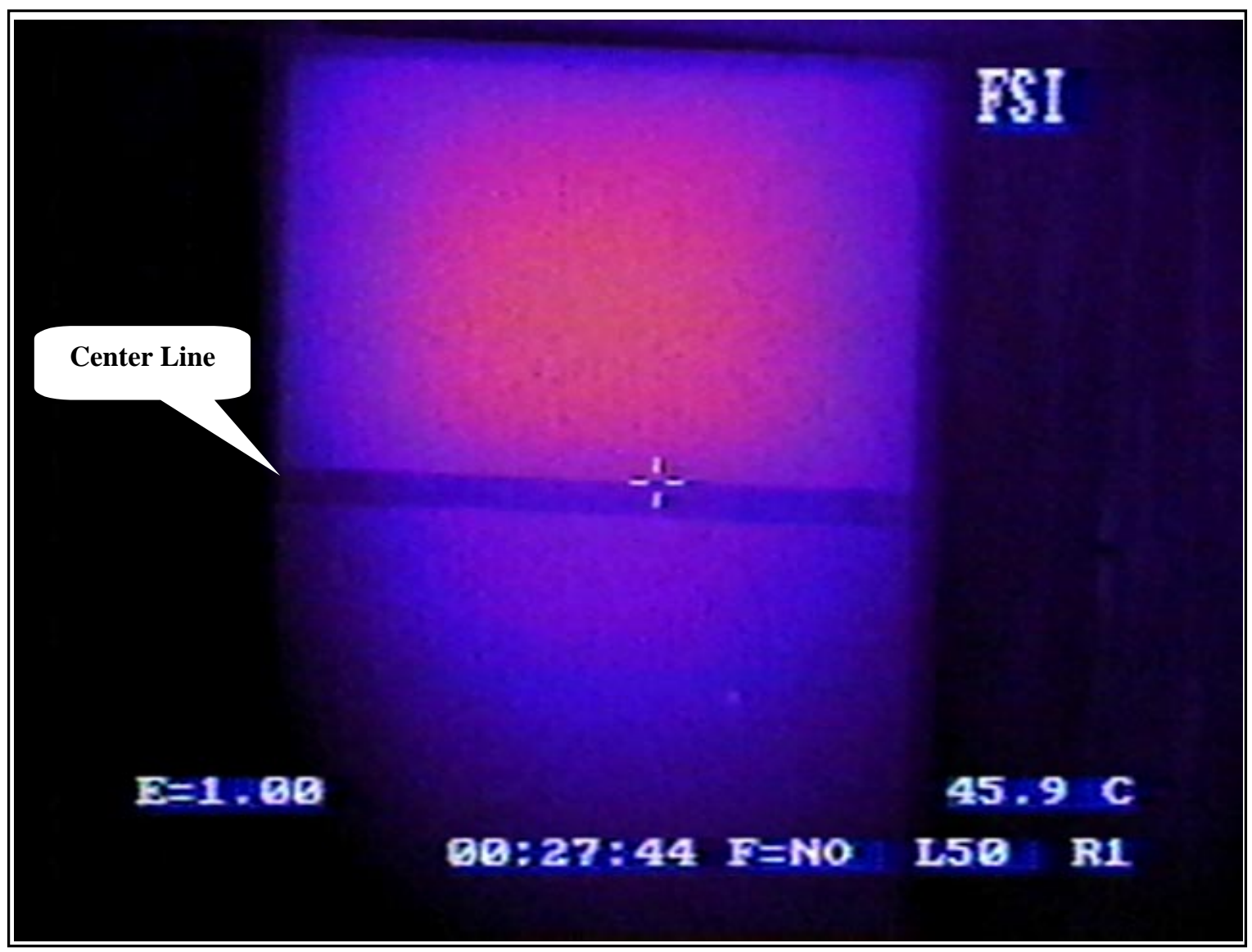

Figure 4.10: Infrared image for Sample 3 at $46^{\circ} \mathrm{C}$ 


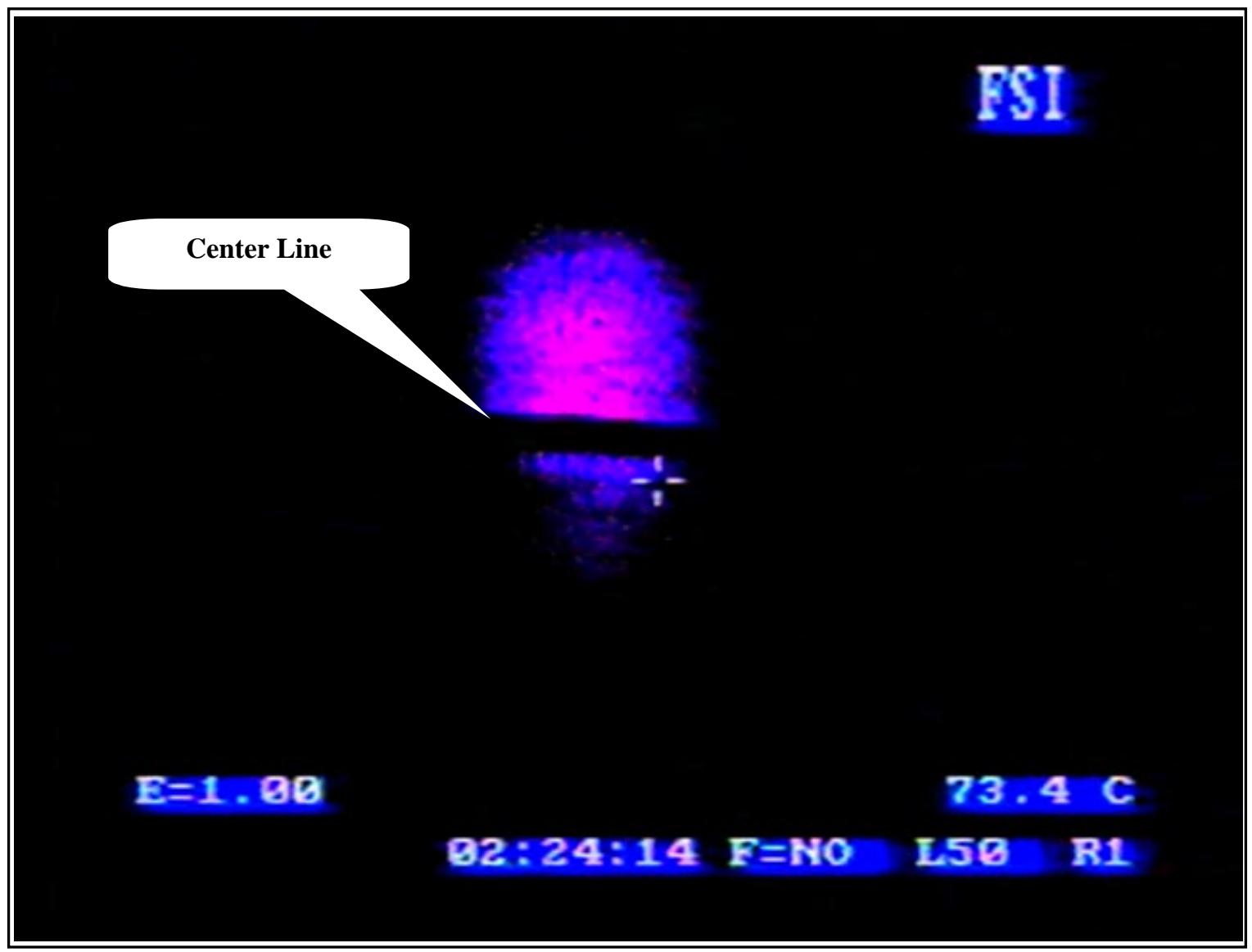

Figure 4.11: Infrared image for Sample 3 at $73{ }^{\circ} \mathrm{C}$ with more contrast on the delaminated area (viewed from a larger distance) 


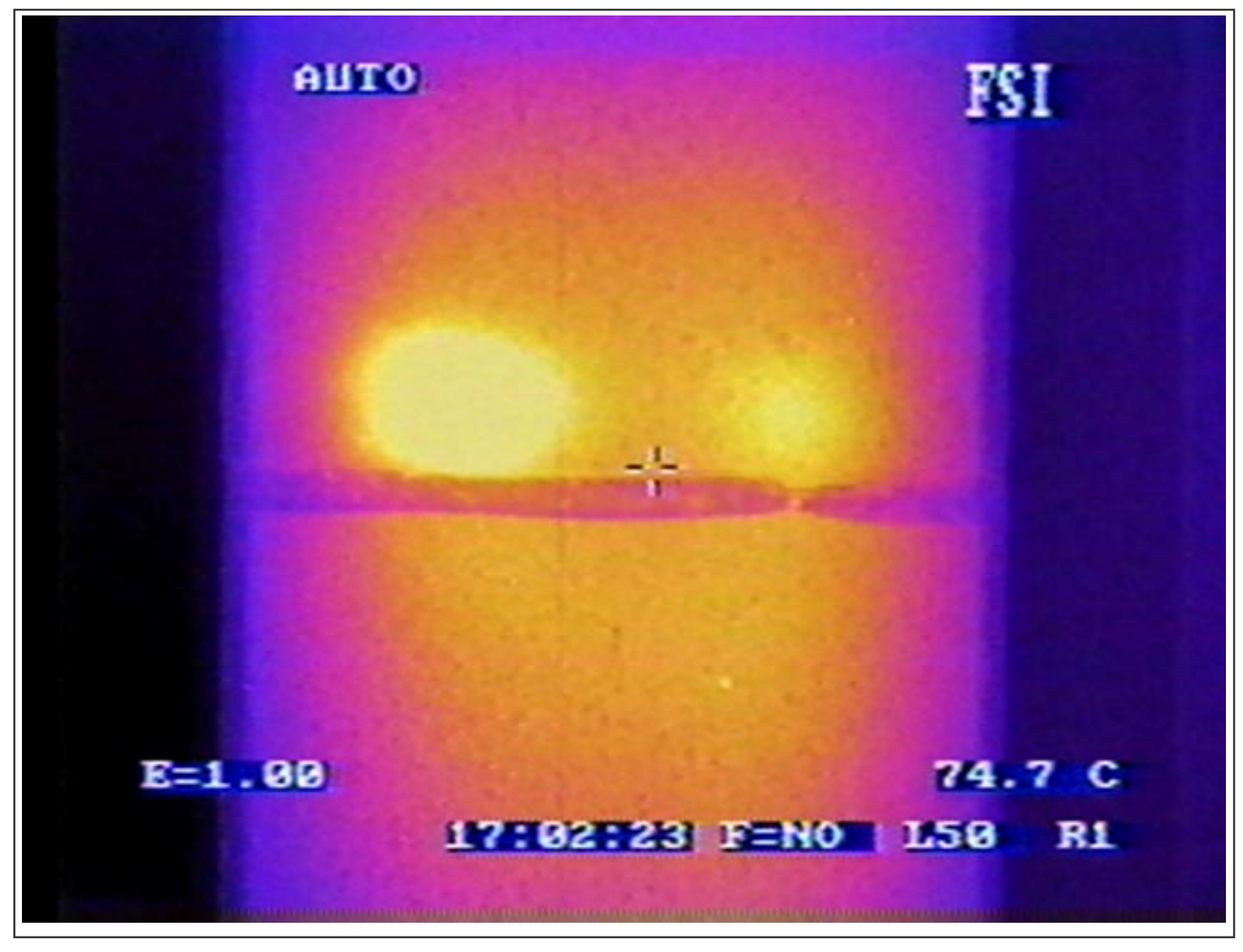

Figure 4.12: Infrared image for Sample 4 at $75^{\circ} \mathrm{C}$ 


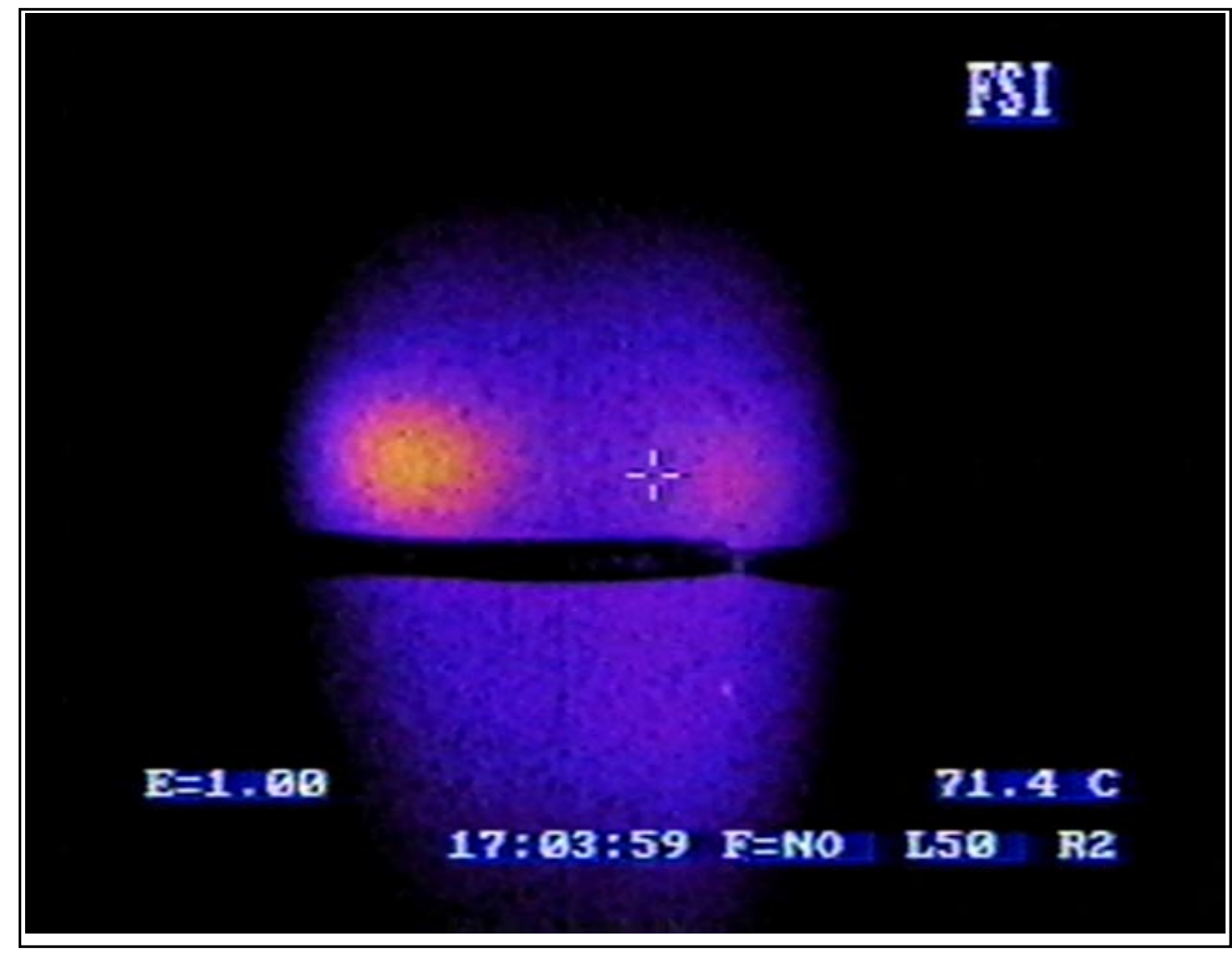

Figure 4.13: Infrared image for Sample 4 at $71^{\circ} \mathrm{C}$ with more contrast on the delaminated areas 


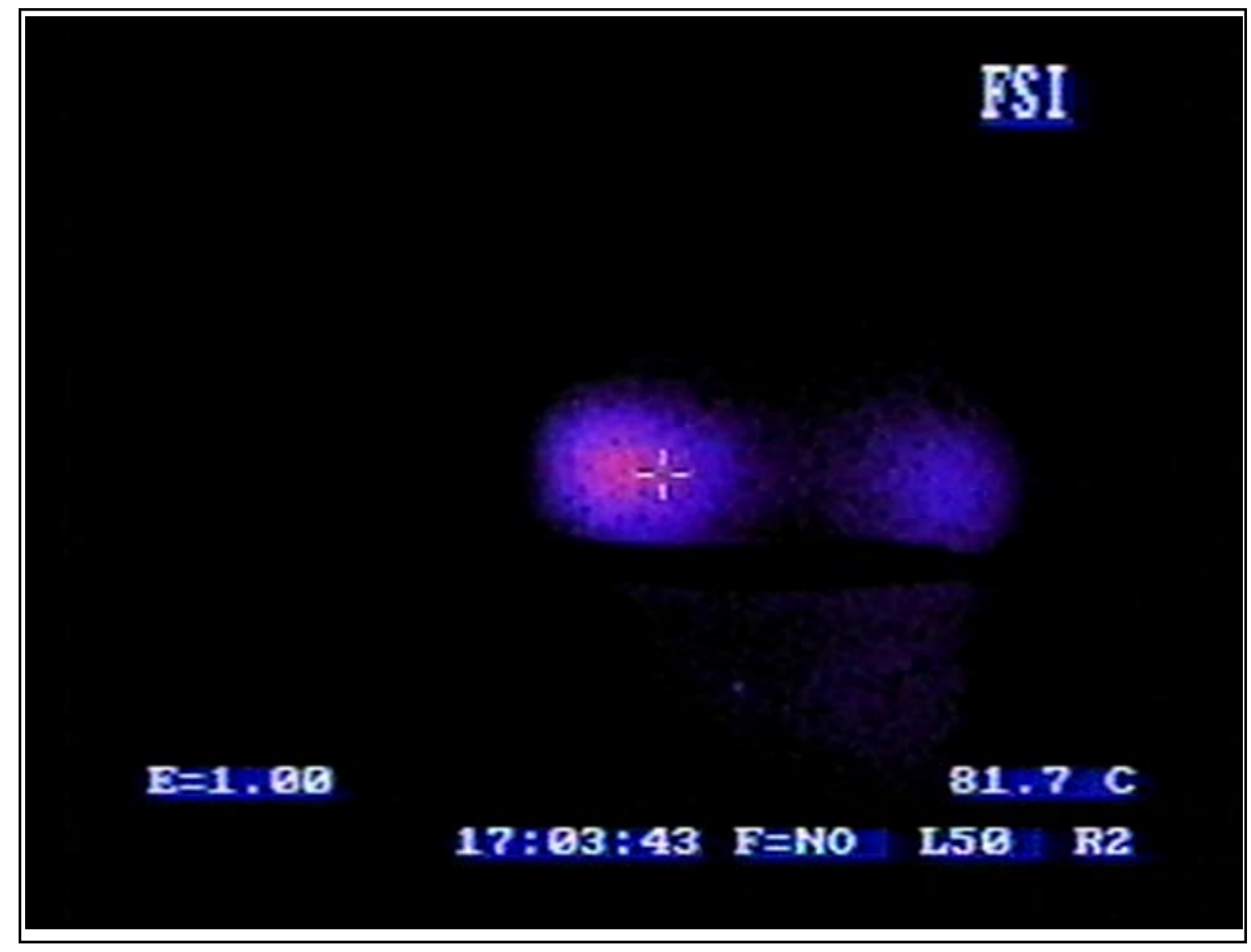

Figure 4.14: Infrared image for Sample 4 at $82{ }^{\circ} \mathrm{C}$ with the highest contrast on the delaminated areas 


\section{CHAPTER 5}

\section{FIELD STUDY}

\subsection{Introduction}

This chapter presents the description of two bridges in West Virginia, which are, Laurel Lick and Wickwire Run. The results of infrared testing conducted on the composite decks of these bridges are also presented in this chapter. In addition, test results from Pond Creek Bridge columns are presented.

The Federal Highway Administration and West Virginia Department of Transportation, Division of Highways (WVDOH) have sponsored the development of the composite deck system for concrete bridge deck replacement. Laurel Lick and Wickwire Run bridge decks were constructed using fiber reinforced polymer (FRP) composites. Non-corrosive FRP composite materials were used to develop a modular bridge deck that has high strength and stiffness to weight ratio, with good fatigue resistance. The FRP composite deck cross-section (made of full- depth hexagons and half-depth trapezoids) and the glass fiber architecture (fabrics) were manufactured using the pultrusion process and designed to provide optimal structural performance for highway bridge loads. The resulting product is called a "H-deck" as shown in Figure 5.1.

The FRP composite deck modules are placed transversely to the traffic direction and are supported by longitudinal beams. The deck depth was constrained to 8" (203 mm) in order to utilize the FRP deck system as a replacement to conventional concrete decks. 


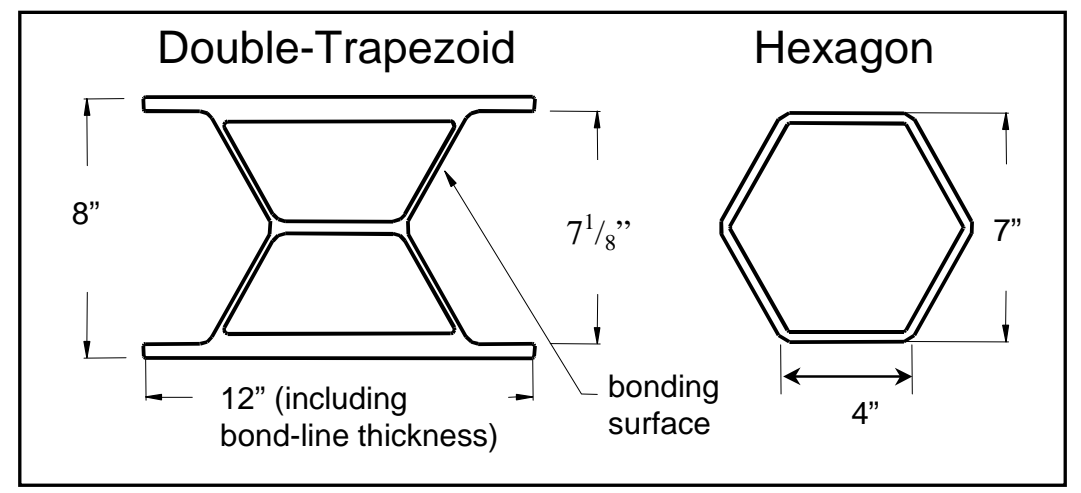

Figure 5.1: H-Deck pultruded components

In the field, a thin polymer concrete overlay or wearing surface was applied on the FRP deck. After sand blasting the deck surface, urethane-based primer was applied to enhance adhesion of the polymer concrete to the FRP deck. Then, the polymer concrete was applied by the "broom and seed" method. The thickness of the polymer concrete overlay is approximately $3 / 8 "(10 \mathrm{~mm})$. The polymer concrete binder is isophthalic unsaturated polyester resin.

\subsection{Description of Bridges}

\subsubsection{Laurel Lick Bridge}

Construction of the Laurel Lick Bridge was completed in May 1997. The bridge was constructed with a modular FRP deck supported by wide-flange pultruded stringers. The length of the bridge deck is $20^{\prime}(6.10 \mathrm{~m})$ and the width is $16^{\prime}(4.88 \mathrm{~m})$. The crosssection of the bridge deck is shown in Figure 5.2. Figure 5.3 shows the location of the bridge and Figure 5.4 shows two photographs of the bridge. 


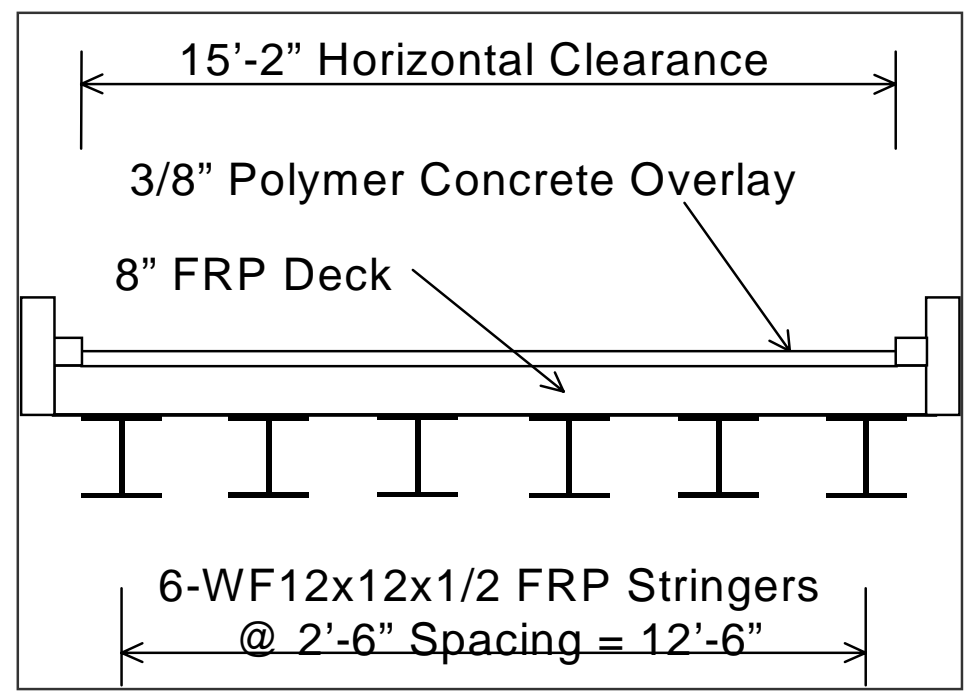

Figure 5.2: Laurel Lick Bridge: Deck Cross-Section

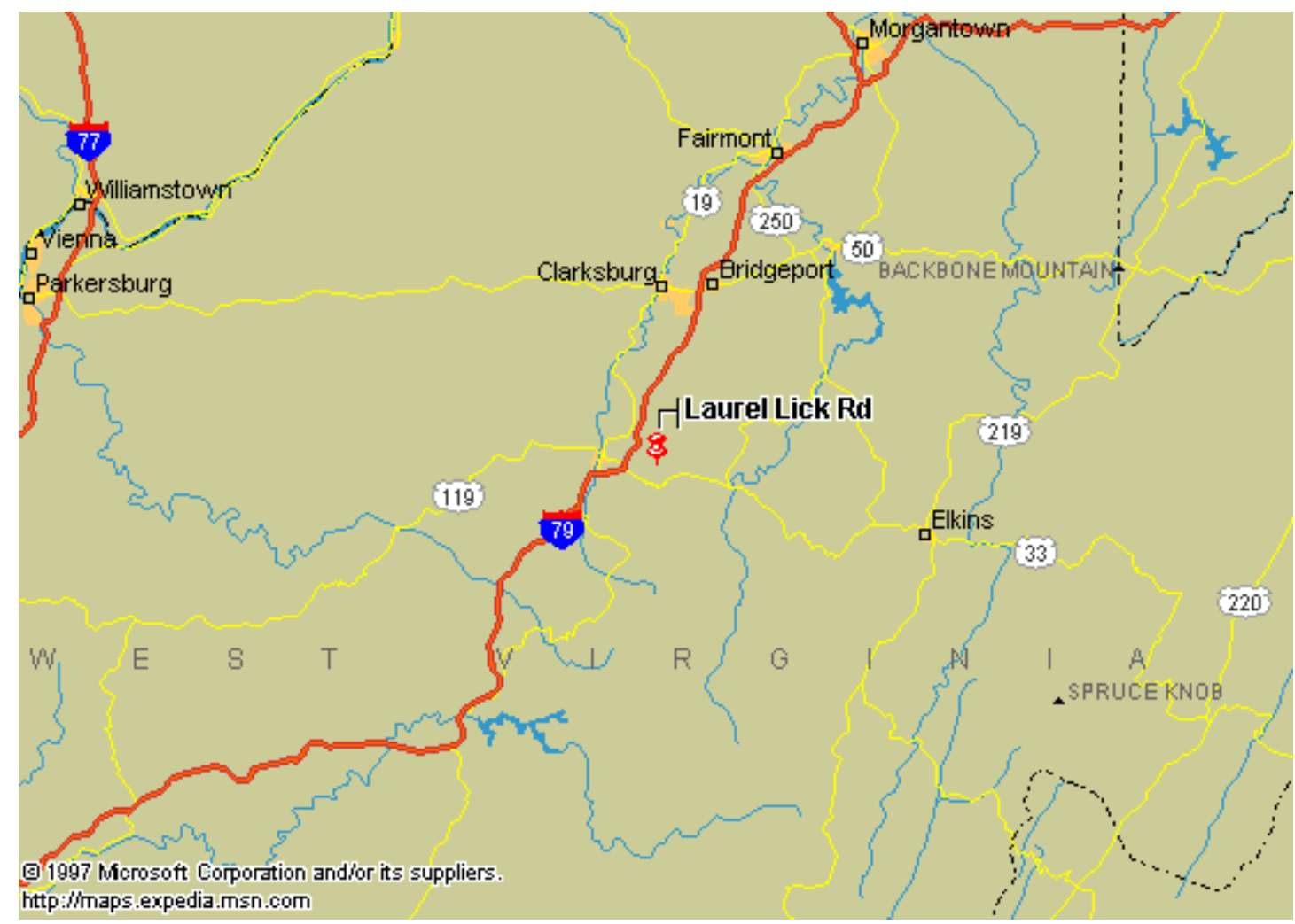

Figure 5.3: Location of Laurel Lick Bridge, WV 

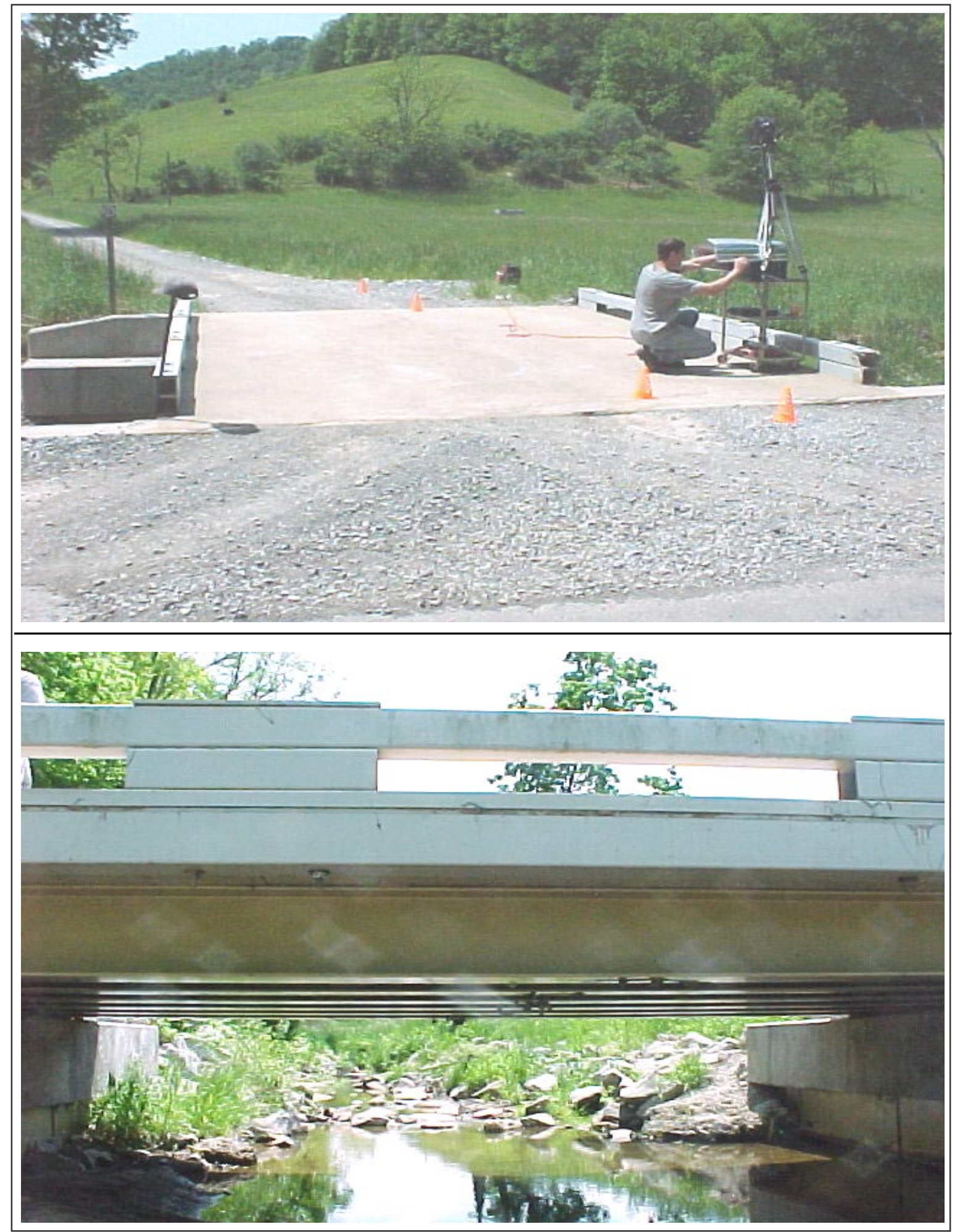

Figure 5.4: Photographs for Laurel Lick Bridge 


\subsubsection{Wickwire Run Bridge}

Construction of the Wickwire Run Bridge was completed in October 1997. This bridge is located off US Route 119 in Taylor County, WV as shown in Figure 5.5. The bridge was constructed with a composite H-deck supported by four longitudinal steel beams spaced 6' $(1.83 \mathrm{~m})$ apart. The length of the bridge deck is $30^{\prime}(9.14 \mathrm{~m})$ and the width is $21.7^{\prime}(6.60 \mathrm{~m})$. Two photographs of the bridge are shown in Figure 5.6. The cross-section of the bridge deck is shown in Figure 5.7.

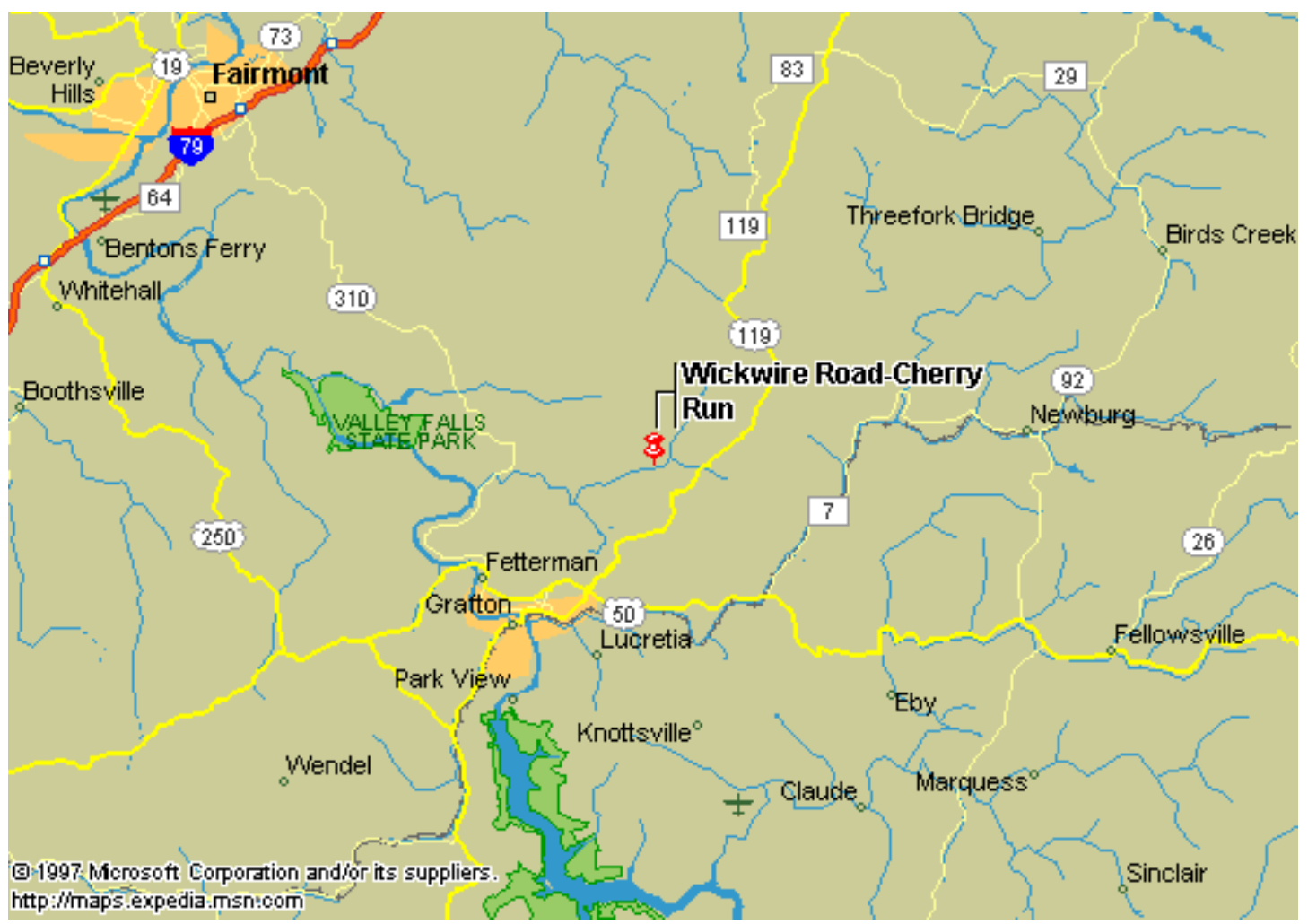

Figure 5.5: Location of Wickwire Run Bridge, WV 


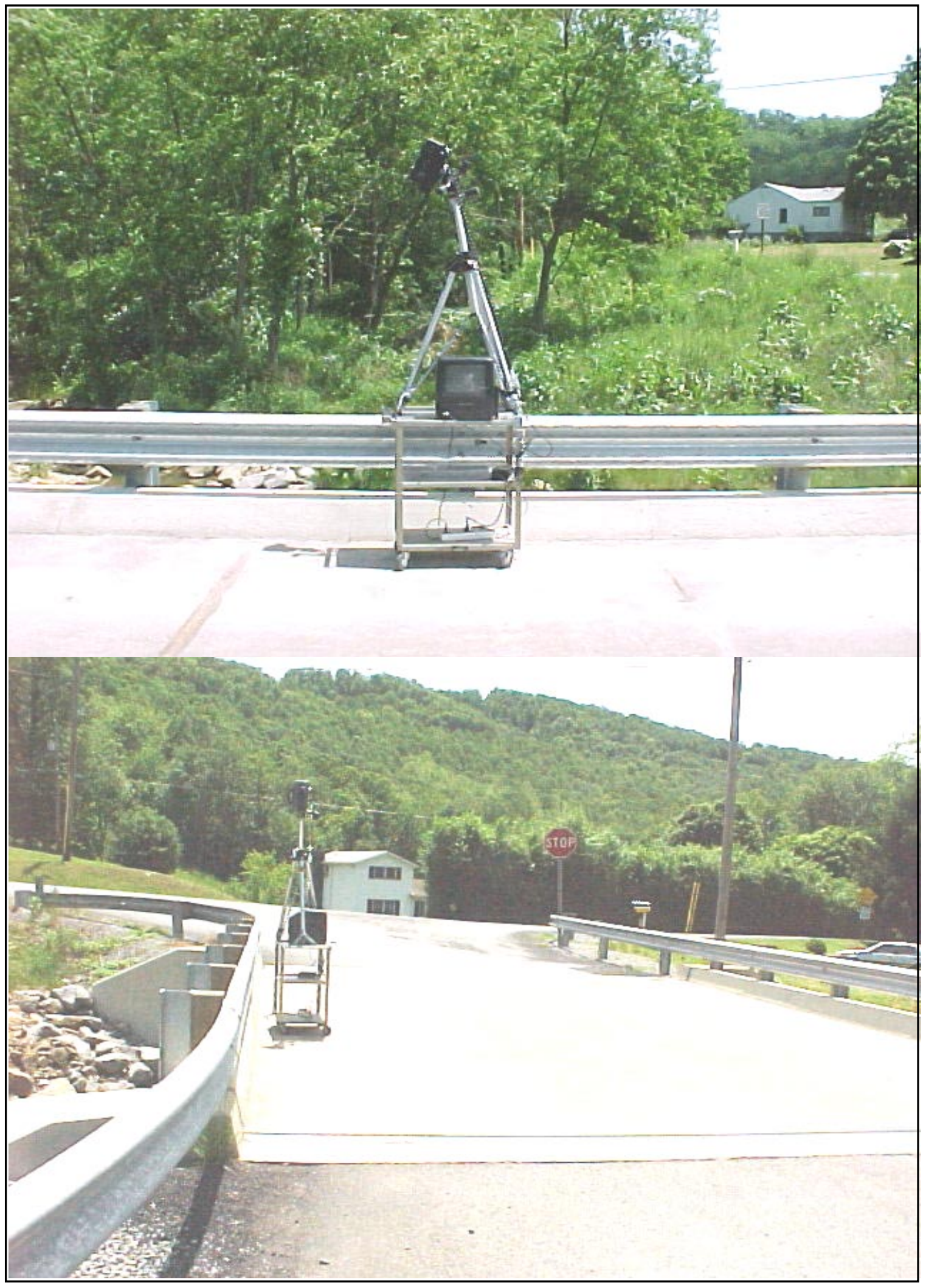

Figure 5.6: Photographs for Wickwire Run Bridge with the field test equipment set-up 


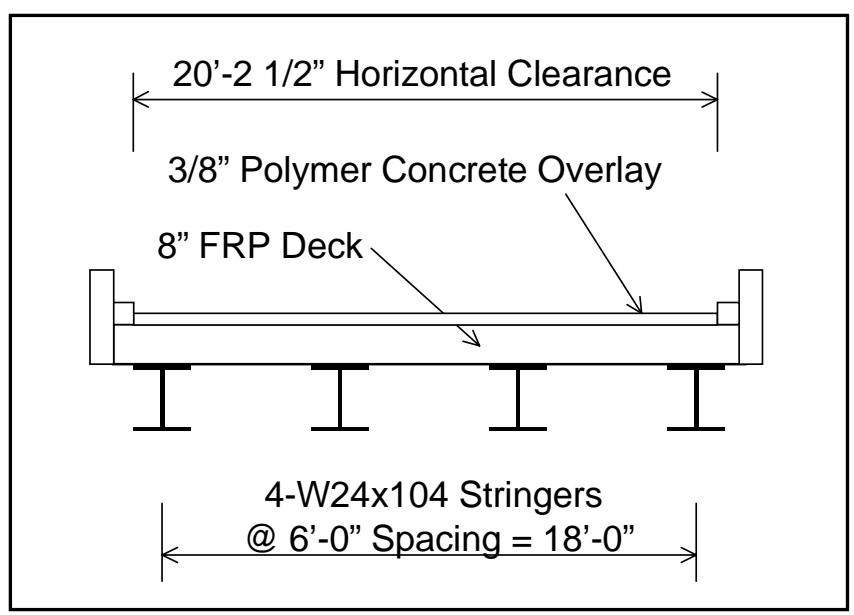

Figure 5.7: Wickwire Run Bridge: Deck Cross-Section

\subsubsection{Pond Creek Bridge}

A steel reinforced concrete column was wrapped with adhesively-bonded fiberglass shells for structural reinforcement as a part of column confinement. The columns were of circular cross section with a diameter of approximately 4 feet. Testing the composite reinforced column was more challenging than testing the composite bridge decks. Since the bridge deck prevents the solar rays from reaching the columns, the columns are relatively cold, which makes it difficult to have significant surface temperature differences between the solid area and the delaminated area of the column. In addition, access to the columns was difficult. The infrared testing was performed while standing on an inclined wall, which made it difficult to carry the equipment on a cart. 


\subsection{Field Results}

\subsubsection{Equipment Set-up}

The field equipment are the same as the laboratory equipment except for the heat source and the angle of imaging. The heat source for the bridge deck is the solar radiation. For field testing, the infrared camera should be pointed at an angle which is away from the path of solar reflection from the bridge deck. A previous study (Kadir 1991) has shown that $35^{\circ}-45^{\circ}$ angle between the infrared camera and the bridge deck is the best since it minimizes the effect of the heat reflection from the surrounding environment. Also, reflections from shiny metallic guardrails should be avoided when testing the edges of the bridge deck.

For field testing, the bridge deck was divided into many 2 feet wide lanes. The equipment was mounted on a cart (see Figure 5.7) and was pulled along the bridge deck by the operator. A microphone was used to record notes while acquiring thermal images, which made it possible to determine the exact location of the delaminated area in the bridge deck. For example, the reference number that relates the infrared image of a certain portion of the bridge deck, which has delamination, to the photograph of the same portion of the bridge deck that was taken by the digital camera, was recorded.

\subsubsection{Laurel Lick Bridge Deck}

The Insight 80 Series infrared camera was used to detect the delaminations in this bridge deck. The field test was conducted on a sunny day with average ambient 
temperature of $75^{\circ} \mathrm{F}$. The bridge deck was cleaned from dust using regular broom and divided into several 2 feet wide lanes for infrared testing.

The thermal images from this bridge deck did not show delamination in any part of the bridge deck. However, some infrared images showed temperature differences on certain portions of the bridge deck. Figure 5.8 shows an infrared image with temperature differences along the edge of the deck that is attached to the guardrail (note that the Insight 80 Series infrared camera has a circular view). Figure 5.9 shows a photograph of the same edge of the deck with the guardrail. The guardrail worked as a mirror that reflected the solar rays, which made the deck edge hotter than the inside portion. On the other side of the deck, the guardrail cast a shadow on the edge of the deck as shown in Figure 5.10. The thermal image of the shaded area (see Figure 5.11) shows cooler temperatures (dark color). Also, irregularity in the surface of the bridge deck (caused by poor finishing during construction) resulted in temperature differences in the thermal image (see Figure 5.12) that can be erroneously interpreted as delamination. Therefore, the operator must be careful while interpreting the thermal images.

Additional testing was conducted on this bridge deck using the Prism Single Point infrared camera. However, the images from this camera did not show significant surface temperature differentials. This is because this camera has a spectral range of $3-5 \mu \mathrm{m}$, which is very close to the visible spectrum, and thus the surrounding environment has a more prominent effect on the infrared measurements. 


\subsubsection{Wickwire Run Bridge Deck}

The Prism Single Point infrared camera was used to detect the delaminations in this bridge deck. The field test was conducted on a sunny day with average ambient temperature of $76^{\circ} \mathrm{F}$. The bridge deck was divided into several 1 foot wide lanes for field testing.

The thermal images did not show delamination in any part of the bridge deck. However, some images showed temperature differences on certain portions of the bridge deck which had surface cracks. Figures 5.13 to 5.15 show these thermal images and the corresponding photographs for these cracks. These figures show the importance of carefully observing unusual surface features and accounting for them during interpretation of infrared field data.

\subsubsection{Pond Creek Bridge Columns}

The field test for these columns was conducted using Insight 80 Series infrared camera to detect any delamination or debonding between the FRP wraps and the concrete columns. The solar rays were able to reach only two of the six columns, hence only these two columns were tested.

Figures 5.16 to 5.18 show thermal images of the delaminated areas (note that the Insight 80 Series infrared camera has a circular view). The white color indicates a hot area (delaminated area) and the darker colors indicate colder areas (sound areas). It should be noted that these surface temperature differentials could also be a result of defects in the FRP wrap. Although, the infrared technique may not be able to conclusively infer whether there is a defect in the wrap or delamination/debonding between the wrap 
and the column, such distinction is not critical for field evaluation since both categories of defects result in loss of confinement in the column. What is more critical is the size of the defect as identified by an infrared image, since larger size means more confinement loss.

\subsection{Conclusions}

From the infrared field tests conducted on Laurel Lick and Wickwire Run bridges, it was found that these bridge decks do not have subsurface delamination. However, there were many surface cracks in the Wickwire Run bridge deck. Infrared testing of the Pond Creek bridge columns showed many subsurface delaminations/debonding with different sizes and shapes. Some of these thermal anomalies could also be a result of defects in the FRP wrap rather than the delamination/debonding between the wrap and the concrete column. Of course, from the point of view of field evaluation, it is not important to distinguish between the two categories of defects since both result in loss of confinement in the column.

The use of the two infrared cameras with different spectral ranges on one of the bridge decks (Laurel Lick) showed that the infrared camera with the higher spectral range in terms of wavelength (i.e., away from the visible spectrum) was more efficient for field testing since it was less sensitive to the surrounding environment. 


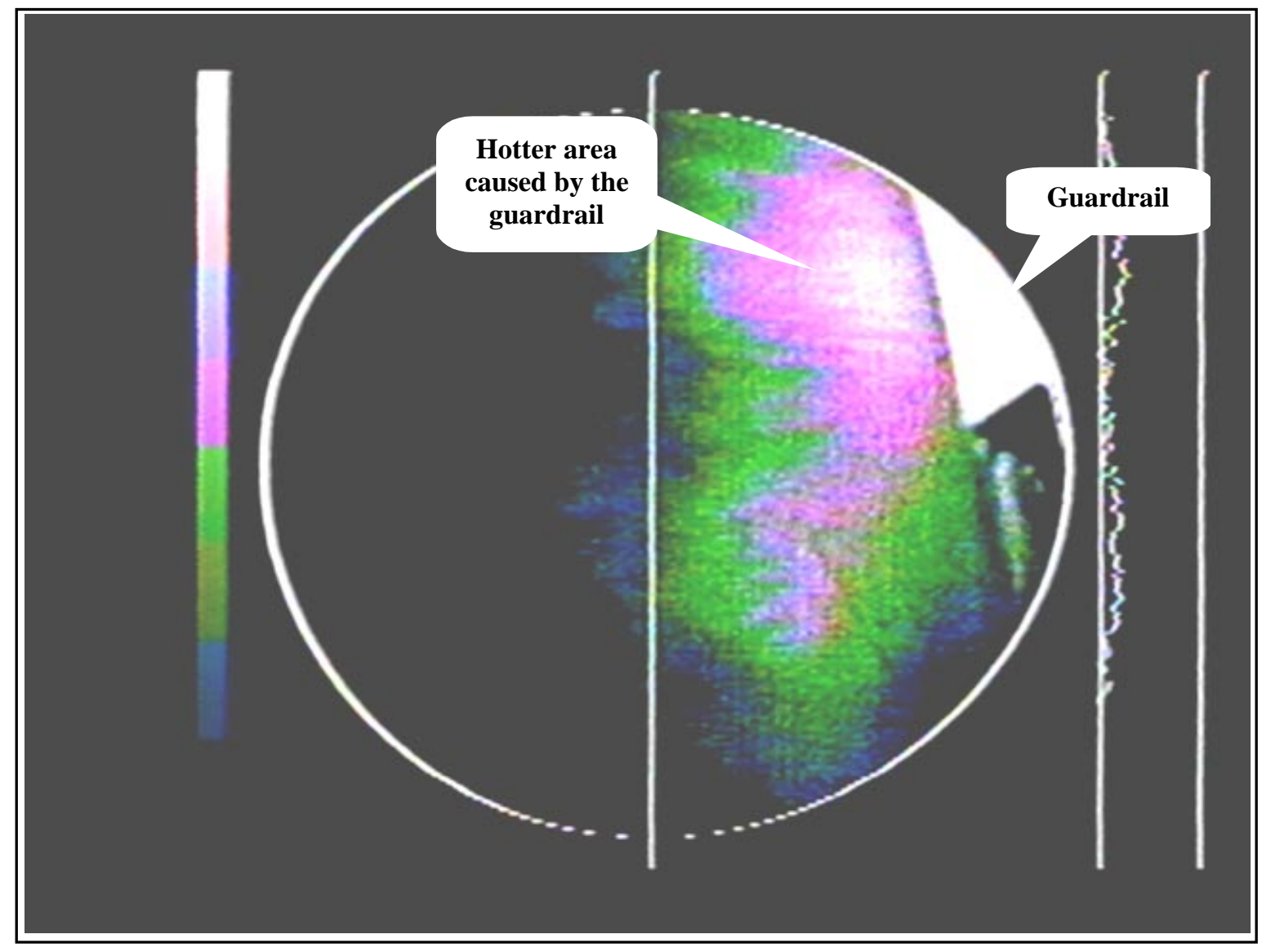

Figure 5.8: Thermal image for Laurel Lick bridge deck. 


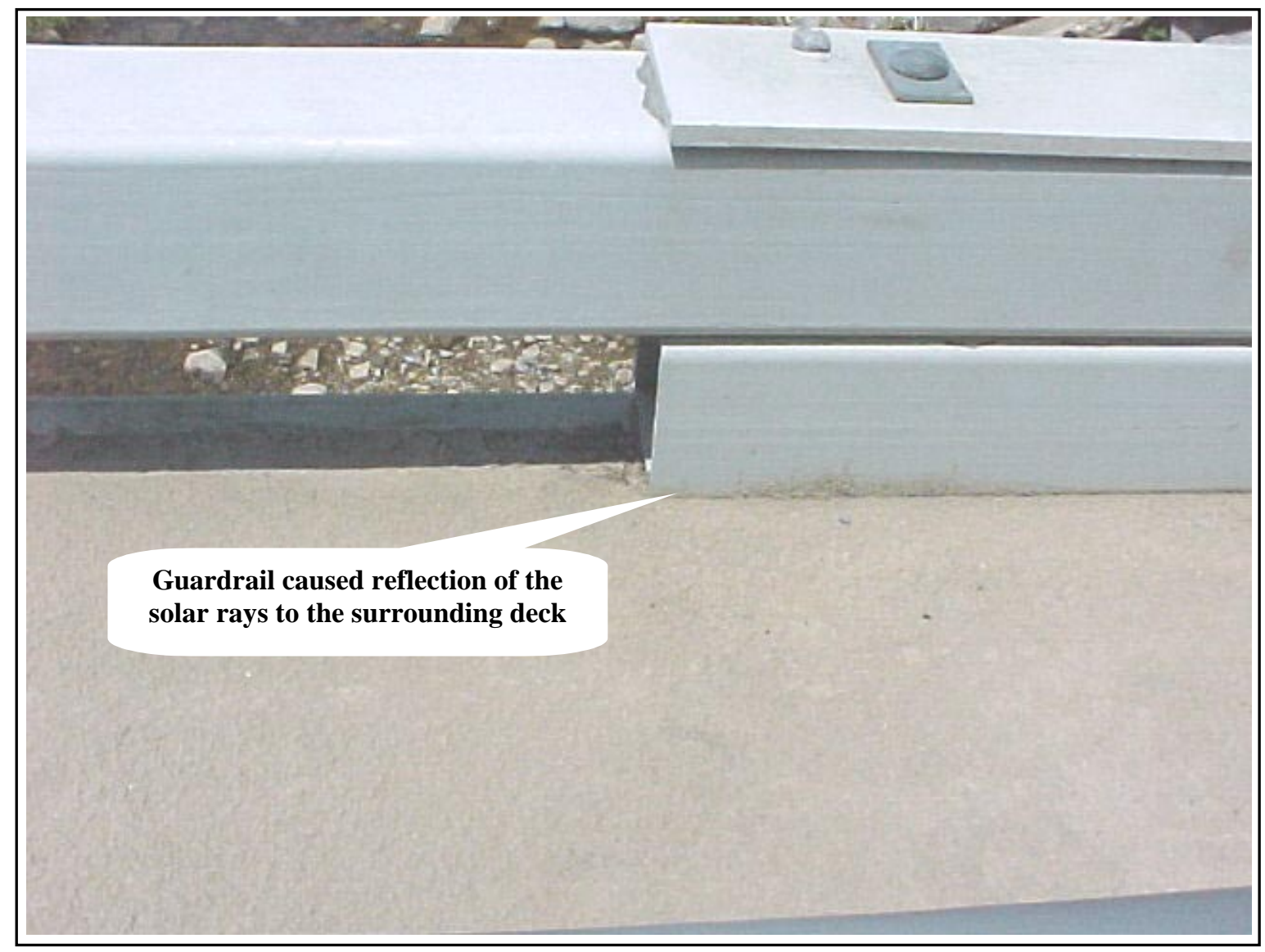

Figure 5.9: Photograph for Laurel Lick bridge guardrail 


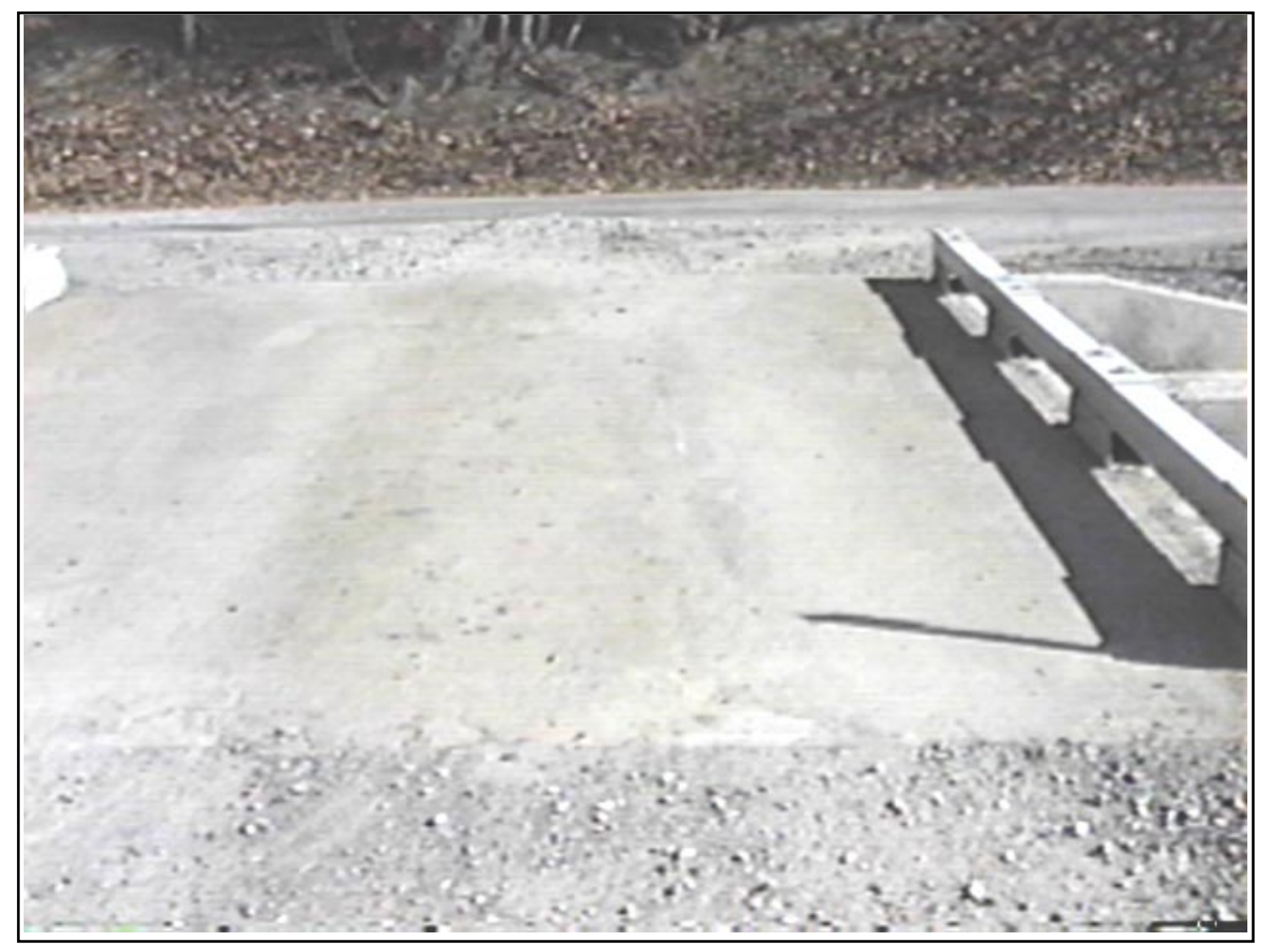

Figure 5.10: Photograph for Laurel Lick bridge guardrail with the shaded area of the bridge deck 


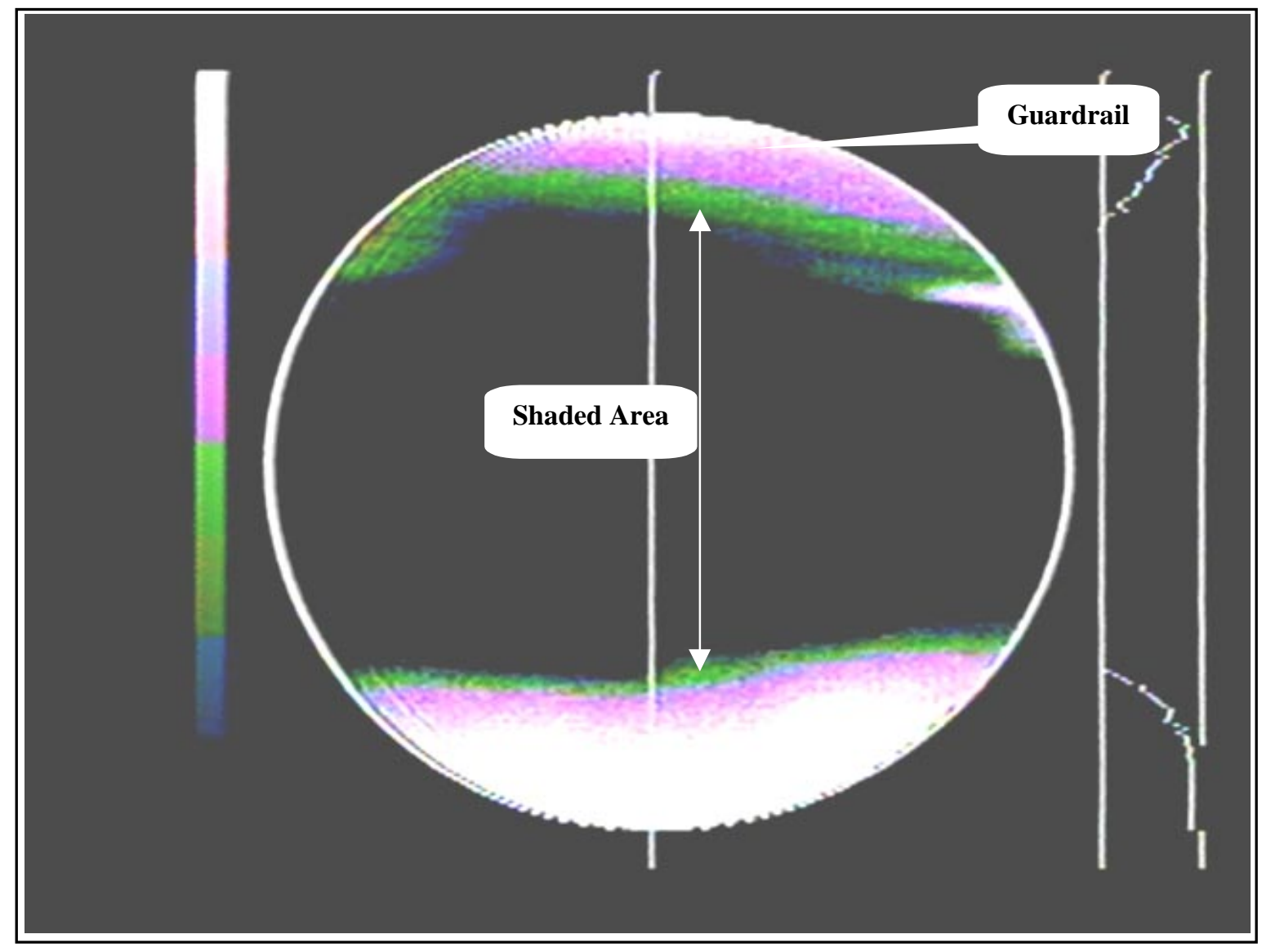

Figure 5.11: Thermal image for the shaded area of Laurel Lick bridge deck 


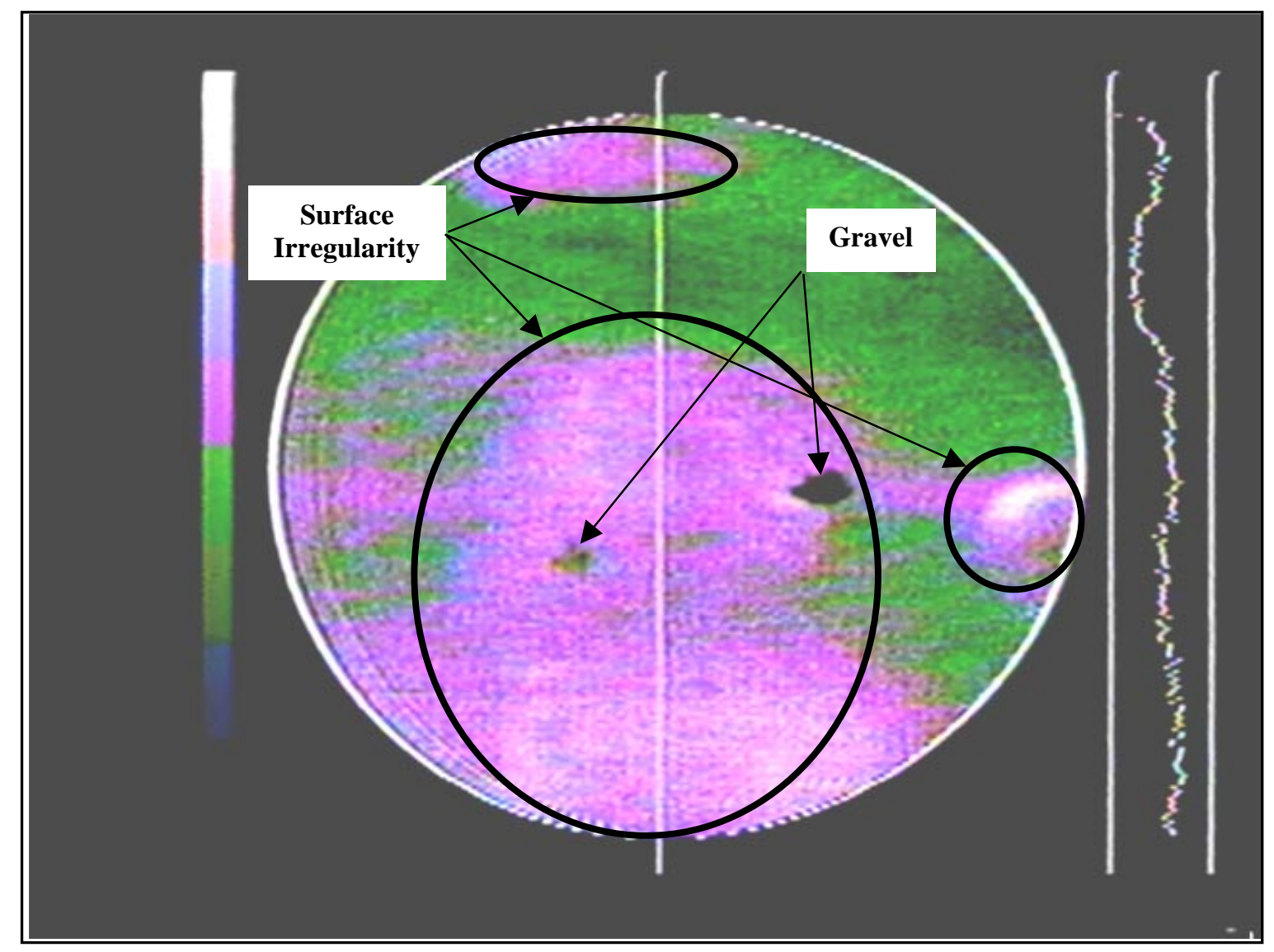

Figure 5.12: Thermal image for Laurel Lick bridge deck with surface irregularity 


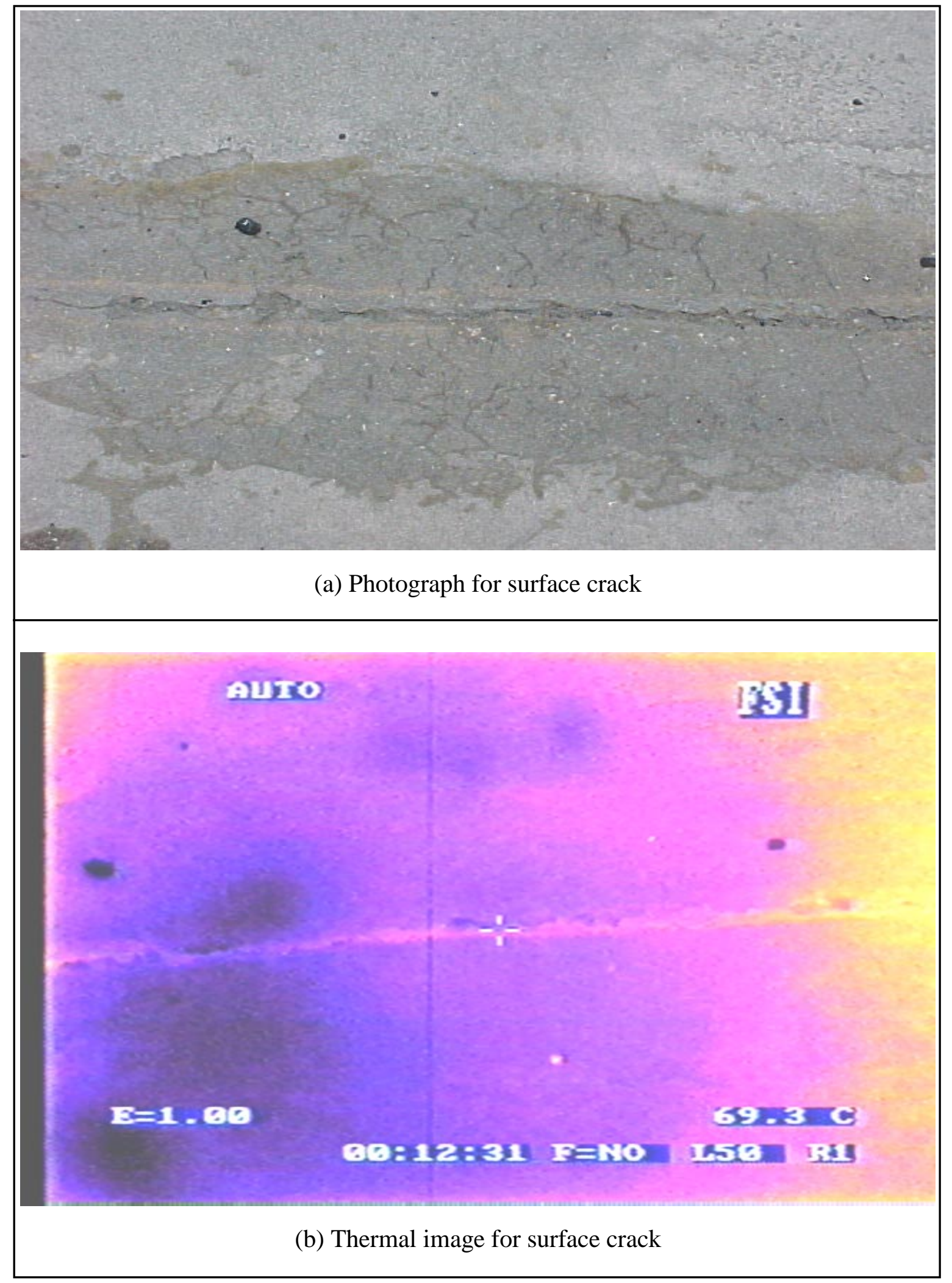

Figure 5.13: Photograph and thermal image for Wickwire Run bridge deck - Surface Crack 1 


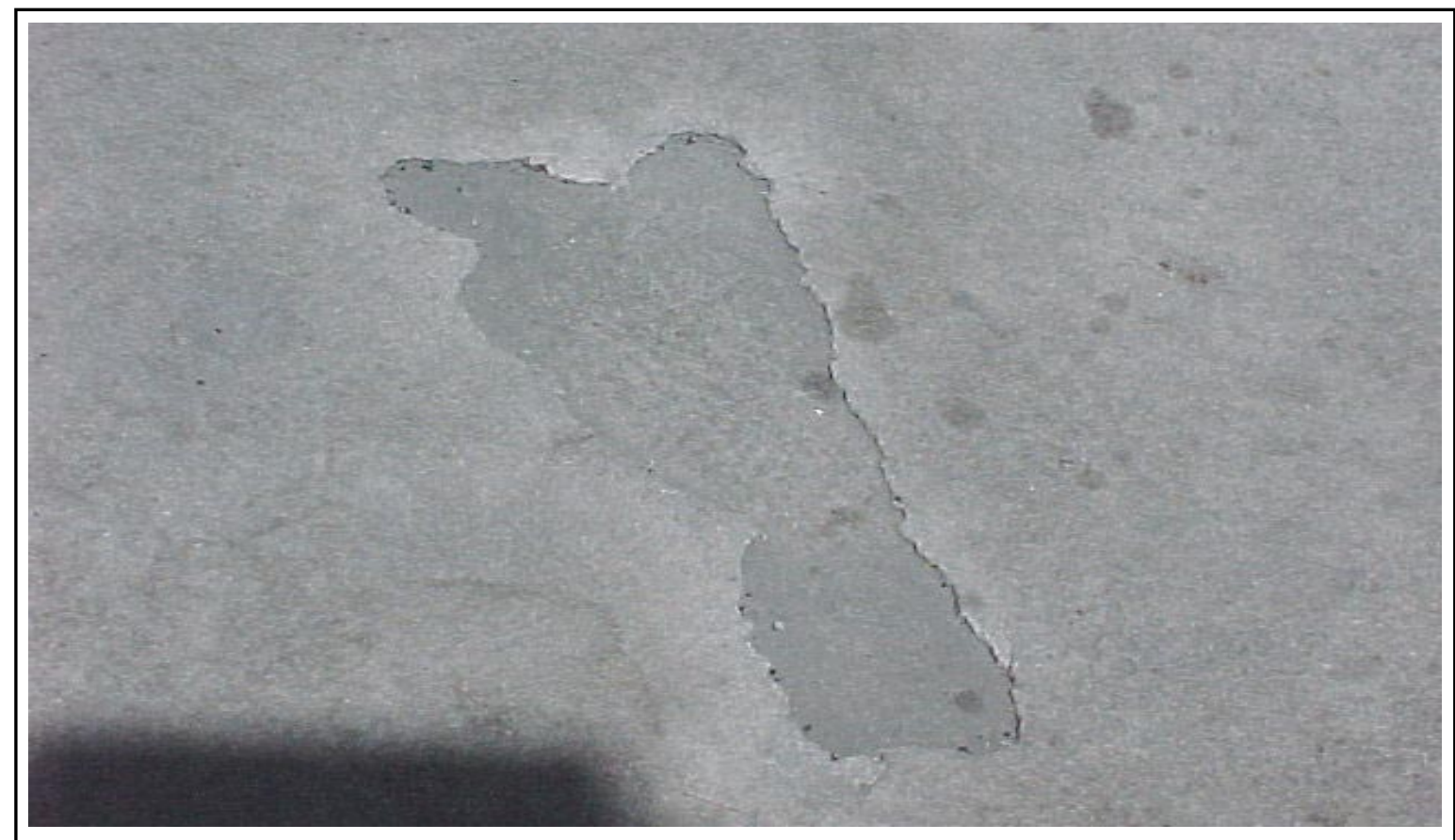

(a) Photograph for surface crack

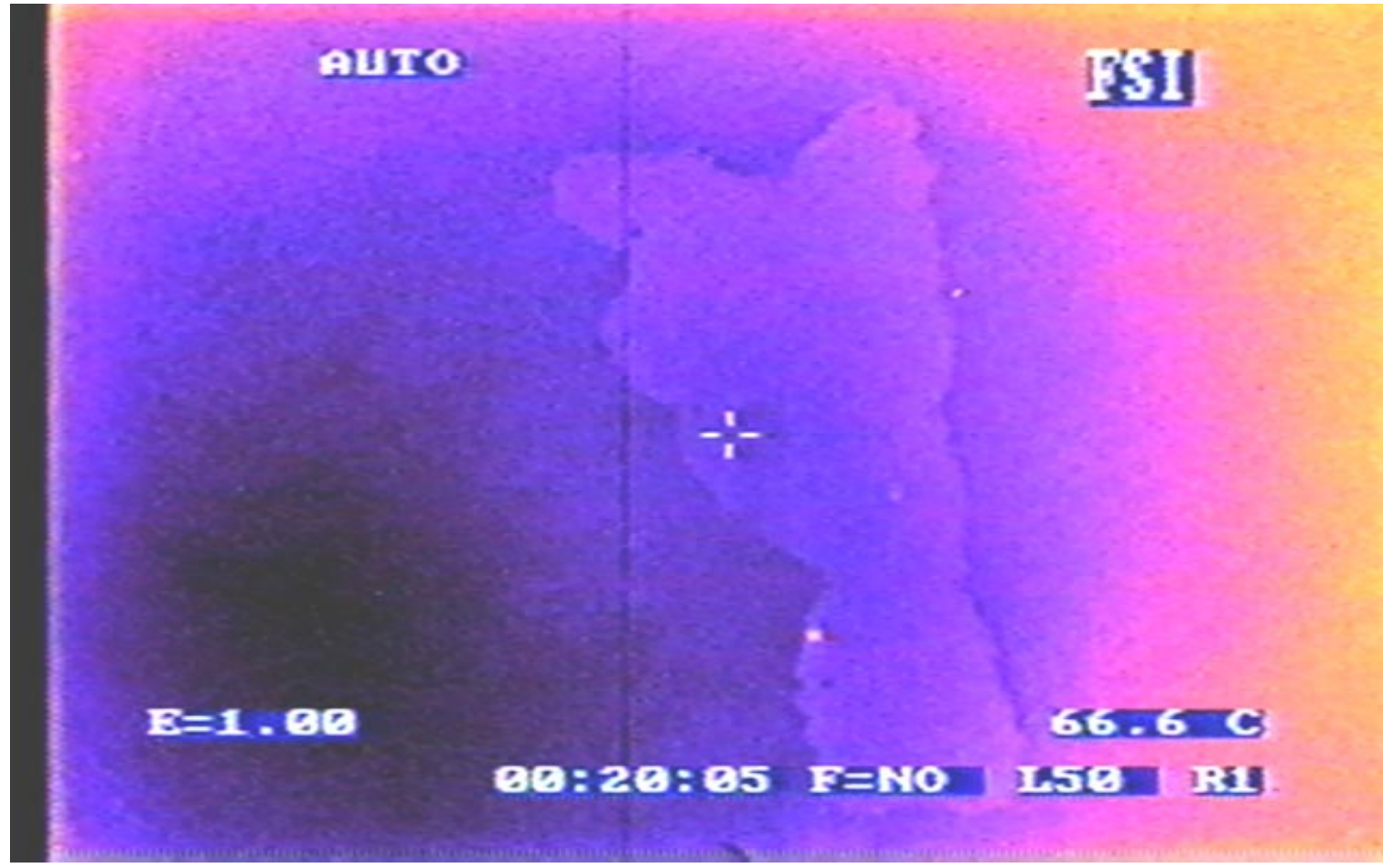

(b) Thermal image for surface crack

Figure 5.14: Photograph and thermal image for Wickwire Run bridge deck - Surface Crack 2 


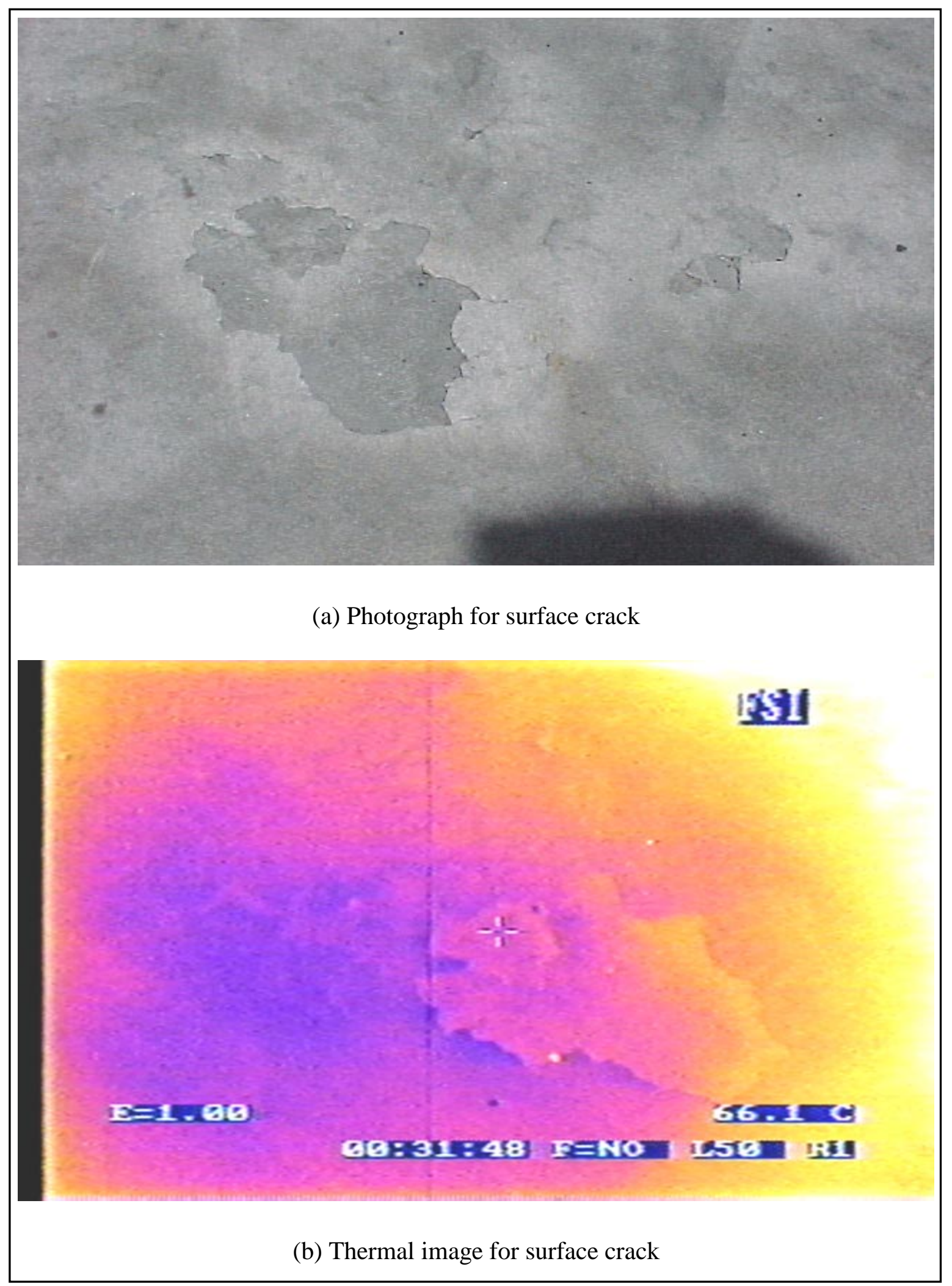

Figure 5.15: Photograph and thermal image for Wickwire Run bridge deck - Surface Crack 3 


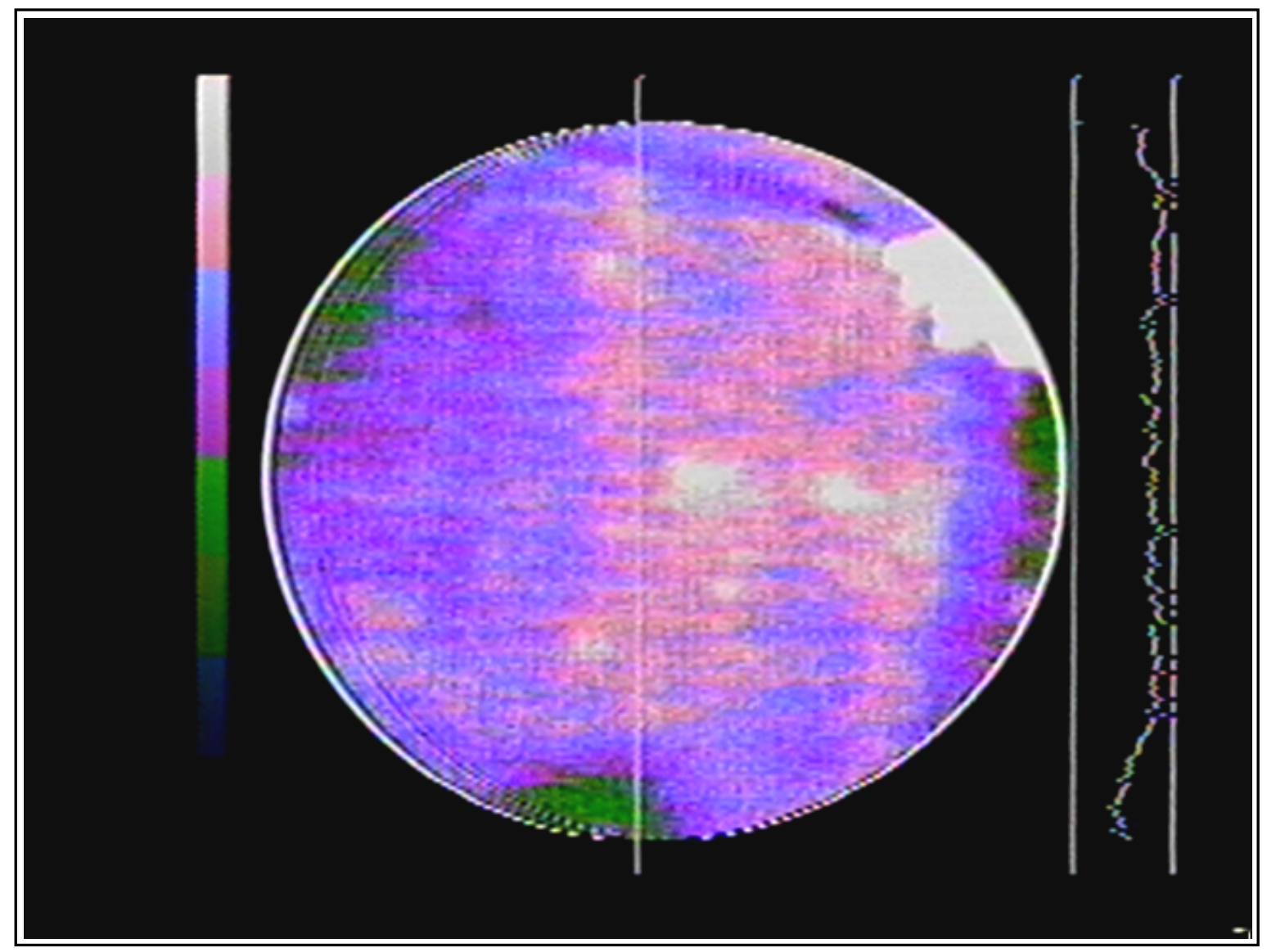

Figure 5.16: Thermal image for Pond Creek bridge column - Location 1 


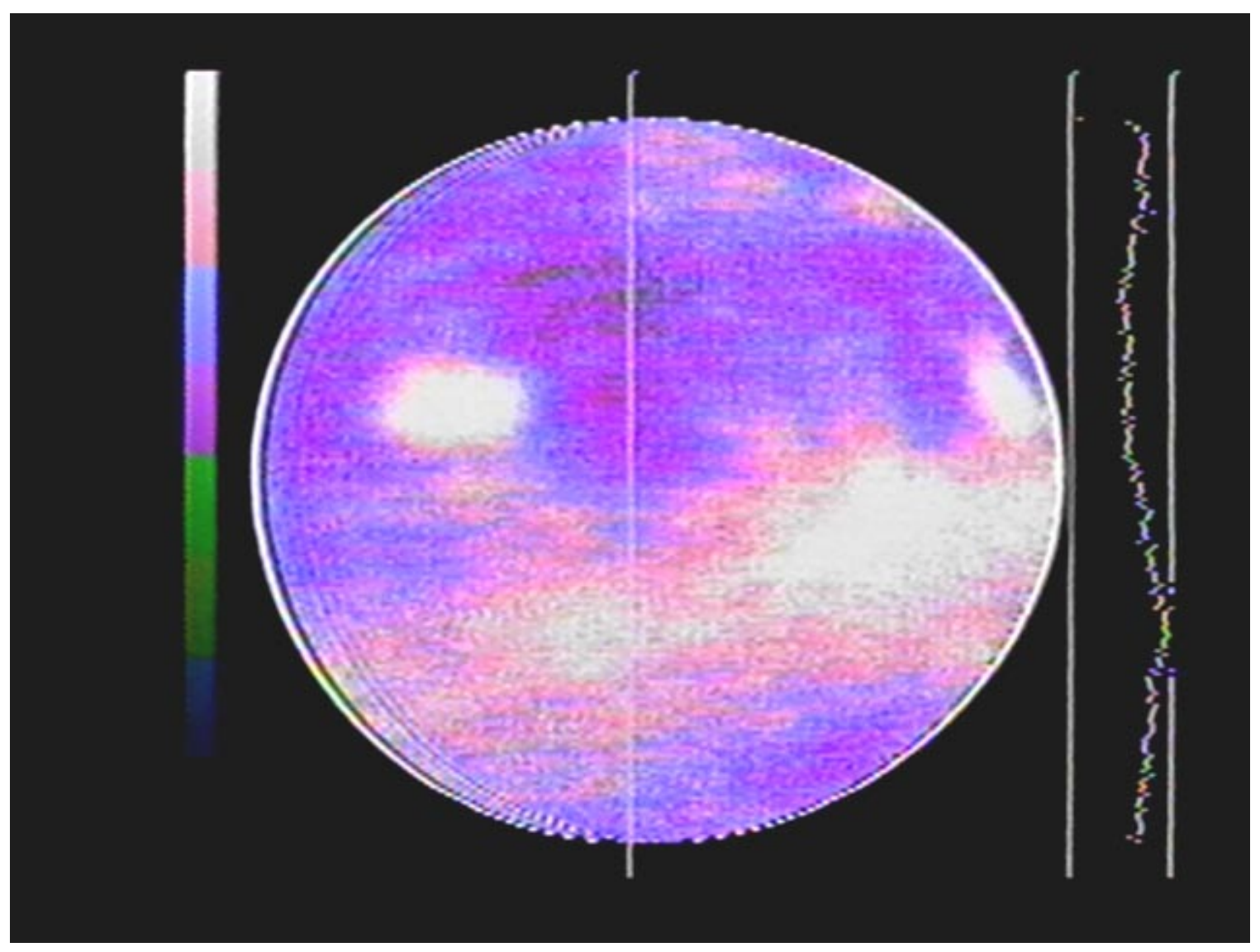

Figure 5.17: Thermal image for Pond Creek bridge column - Location 2 


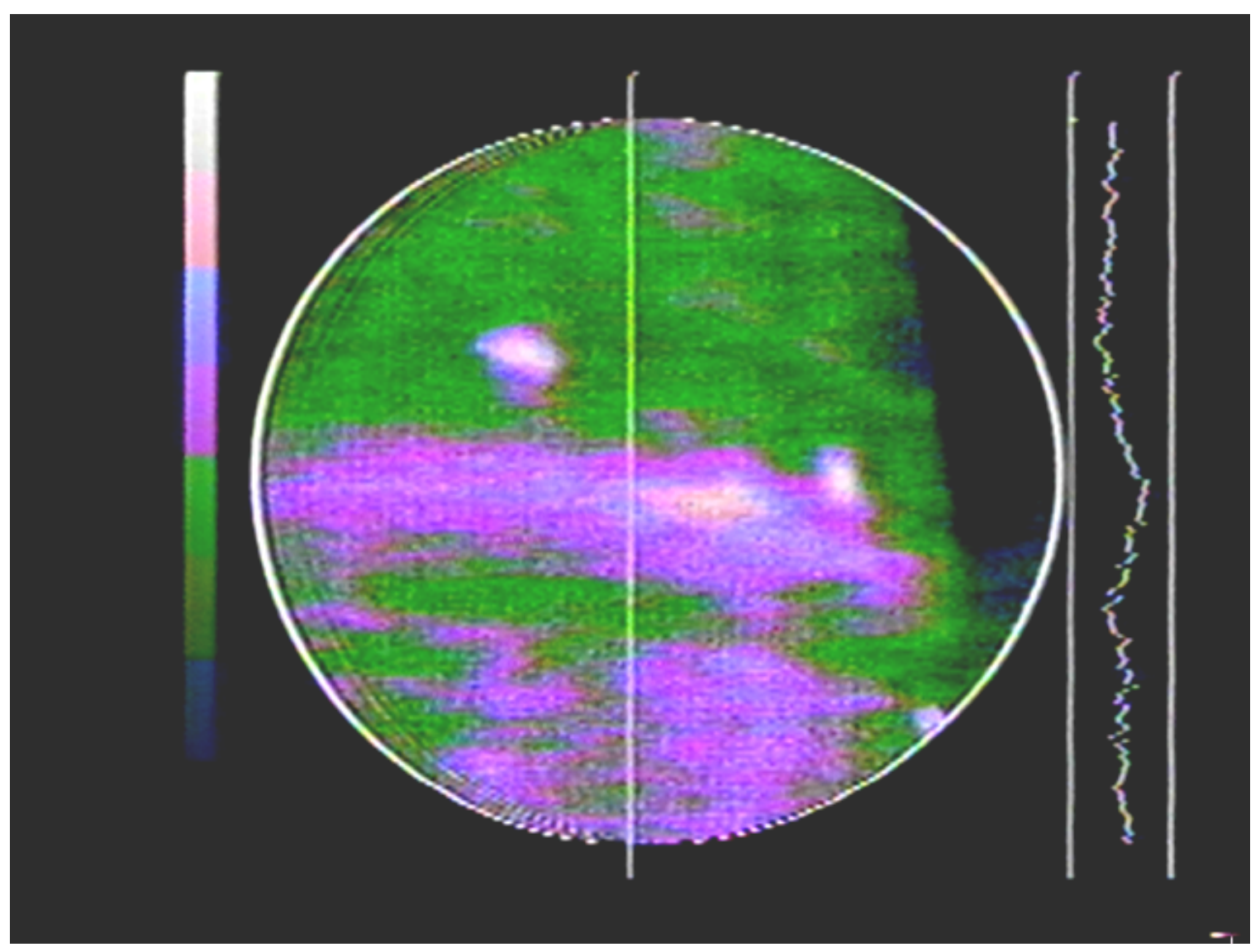

Figure 5.18: Thermal image for Pond Creek bridge column - Location 3 


\section{CHAPTER 6}

\section{CONCLUSIONS AND RECOMMENDATIONS}

\subsection{Conclusions}

From the literature review on the application of infrared thermography for evaluation of composite structures, the following can be concluded:

1. Infrared thermography has a good potential for application to field monitoring of highway bridges.

2. Infrared thermography has distinct advantages over other techniques for the following reasons:

- The technique enables rapid survey of delamination between the wearing surface and the FRP bridge deck.

- The infrared images can be interpreted with relative ease

- The infrared technique does not require the use of external wires or sensors and enables remote surface temperature measurements.

3. Various researchers using infrared thermography technique have successfully located voids and delaminations in composite structures. However, detection is difficult when the delamination is more than $1 / 2$ inch deep and smaller than 1 square inch.

Infrared technique does have certain disadvantages in terms of its application to the field environment. The major disadvantages are: 
1. The infrared technique works well only in the presence of a strong heating or cooling source (e.g., hot sun, artificial heating or cooling). During hot sunny days, the infrared images will show delaminations only during certain times of the day (10 A.M. to 2 P.M. or around midnight) when a significant thermal gradient exists across the thickness of the bridge deck.

2. Field variables such as presence of shadows, edges or boundaries, oil spills or surface cracks can contaminate the infrared data, and care should be taken to account for these factors during data interpretation.

3. Presence of moisture can adversely affect the infrared data. Since water-filled delaminations conduct heat much more efficiently compared to air-filled ones, the delaminations are difficult to detect under moist field conditions.

4. The angle of inclination of the infrared camera has a significant influence on the infrared images. Care should be taken to avoid angles which places the camera lens in the path of reflection of solar rays from the bridge deck. Solar reflection from other objects in the field (e.g., shiny metallic guardrails) should also be avoided in order to acquire quality data.

From the controlled laboratory tests conducted on four composite bridge deck specimens, the following can be concluded:

1. As the area and the thickness of the subsurface delamination increases, the surface temperature differential increases, which makes it easier to detect the delamination by the infrared camera. 
2. Subsurface debonding under $3 / 8$ " wearing surface did not result in temperature differences on the surface and therefore, could not be detected.

3. Subsurface delamination under $3 / 8$ " wearing surface with thickness of 0.05 " resulted in surface temperature differentials that could be detected with an infrared camera.

From the field tests conducted on two composite bridge decks and bridge columns wrapped with fiber reinforced polymer (FRP) jacket, the following can be concluded:

1. While field testing showed measurable surface temperature differentials, many of the differences were a result of shadows and not necessarily subsurface delaminations. Also, presence of cracks/irregularities on the top of the wearing surface led to surface temperature differentials. Therefore, the operator must be aware of the surface conditions (e.g., shaded areas, oil spills) when interpreting the infrared images. Also, the moisture content of the bridge deck may adversely affect the measured surface temperature differential, so infrared measurements should be conducted on dry and hot sunny days.

2. The surface temperature differentials may be a result of subsurface delaminations as well as irregularities and inhomogenieties in the wearing surface. While the infrared technique does not distinguish between the two cases, either of these defects may require remedial action once the detected anomaly exceeds a certain size in plan. Thus, infrared thermography can be used as a useful tool for maintenance of composite decks. 
3. The infrared camera's angle should be carefully chosen to avoid reflection of the sun from the bridge deck and shiny guardrails.

4. The spectral range of the infrared camera can affect the output image. The output image will be more sensitive to the surrounding environment when the spectral range of the infrared camera is closer to the visible spectrum. Therefore, for field testing, the preferred spectral range for the infrared camera is $8-12 \mu \mathrm{m}$.

\subsection{Recommendations}

There are several recommendations that can be made to improve the evaluation of composite bridge decks using infrared thermography. These recommendations are:

1. The use of dual-band infrared camera (which acquires infrared images in two different spectra) is highly recommended to minimize the environmental effect.

2. Applying negative heat (cooling) using the proper cooling blanket and/or cooling liquid such as liquid nitrogen over a sustained duration (more than 10 minutes) will enhance the surface temperature differentials. This will make it possible to detect smaller and/or deeper subsurface defects (delaminations or debonding).

3. Combining two NDT techniques (infrared thermography and ground penetrating radar) would be very useful, since it will utilize the rapid scanning ability of the infrared technique as well as the ability of radar to detect deeper defects. Also, the infrared technique is more sensitive to air-filled delaminations, while radar is more sensitive to water-filled delaminations, so the two techniques complement each other very well. In addition, infrared thermography may have difficulties in 
detecting a deeper delamination located just under a shallower delamination, while GPR data may be able to identify both delaminations.

4. Development of a finite element (FE) model using heat transfer equations and simulated delaminations/debonding between the wearing surface and the FRP bridge deck will be a useful analytical tool to establish the magnitude and severity of a given defect.

5. Use of Fourier domain image processing and enhancement algorithms should be explored to increase the sensitivity of the infrared technique to small size defects and debonding. 


\section{References}

Burleigh, D., Bohner, R. and Young, W. P., “Thermal nondestructive testing (TNDT) of adhesively bonded composite reinforcements applied to concrete civil structures," Nondestructive Evaluation of Bridges And Highways III, Vol. 3587, Newport Beach, CA, 3-5 March,1999, pp.105-115.

Del Grande, N. K. and Durbin, P. F., "Delamination Detection in Reinforced Concrete Using Thermal Inertia," Nondestructive Evaluation of Bridge And Highways III, Vol. 3587, Newport Beach, CA, 3-5 March,1999, pp.186-199.

Dunker, K. F. and Rabbat, B. G., "Highway Bridge Type and Performance Patterns," Journal of Performance of Constructed Facilities, ASCE, Vol. 4, No. 3, August, 1990, pp. 161-173.

Garber, N. J. and Hoel, L. A., Traffic and Highway Engineering II, PWS, Boston, MA, 1997, pp.13.

Halabe, U. B., Nondestructive Material and Structural Evaluations, CE 364 Course Package, Department of Civil and Environmental Engineering, West Virginia University, Morgantown, WV, 1999, pp.161-176.

Jackson, D. R., Islam, M., and Alampalli, S., "Feasibility of evaluating the performance of fiber reinforced plastic (FRP) wrapped reinforced concrete columns using ground penetrating radar (GPR), and infrared (IR) thermography techniques," Proceedings of 
Structural Materials Technology IV - An NDT Conference, Atlantic City, NJ, Feb. 28 March 3, 2000.

Kadir, R., Detection of Highway Pavement Cracks through Infrared Thermography and Digital Image Processing, Master's thesis, Department of Civil and Environmental Engineering, West Virginia University, Morgantown, WV, August, 1991, pp. 81.

Kazzi, S. F., "Development of infrared thermography for bridge deck condition assessment," Master's thesis, Department of Civil and Environmental Engineering, MIT, Cambridge, MA, 1988.

Maldague, X. P. V., Nondestructive Evaluation of Materials by Infrared Thermography, Spinger-Verlag, London, U.K.; NY, 1993, pp. xii.

Manning D. G. and Holt F. B., "Detecting delaminations in concrete bridge decks," Concrete International, 1980, pp. 34-41.

Manning D. G. and Holt F. B., "Detecting deterioration in asphalt covered bridge decks," Transportation Research Record, Vol. 899, 1983, pp. 10-20.

Maser, K. R. and Roddis, W. M. K., "Principles of thermography and radar for bridge deck assessment," Journal of Transportation Engineering, ASCE, Vol. 116, No. 5, Sep.Oct., 1990, pp. 583-601.

Morten, F. D., "Infrared detectors and their applications," Applications of Infrared Detectors, Sowan, F. A., ed., Mullard Ltd., London, U.K., 1971, Chapter 1, pp. 1-25. 
Neville, A. M., Properties of Concrete, John Wiley \& Sons, Inc., New York, 1973.

Weil, G. J., "Detecting the defects," Civil Engineering, ASCE, Sept. 1989, pp. 74 - 77.

Winfree, W. P., "Enhanced thermographic detection of delaminations with computational pulse shaping," Review of Progress in Quantitative Nondestructive Evaluation, Vol.17A, NY, 1998, pp.441-447. 